\title{
The Fight against the Influenza A Virus H1N1: Synthesis, Molecular Modeling, and Biological Evaluation of Benzofurazan Derivatives as Viral RNA Polymerase Inhibitors
}

\author{
Mafalda Pagano, ${ }^{[\mathrm{a}]}$ Daniele Castagnolo, ${ }^{[\mathrm{a}]}$ Martina Bernardini, ${ }^{[\mathrm{a}]}$ Anna Lucia Fallacara, ${ }^{[\mathrm{a}, \mathrm{b}]}$ \\ Ilaria Laurenzana, ${ }^{[\mathrm{c}]}$ Davide Deodato, ${ }^{[\mathrm{a}]}$ Ulrich Kessler, ${ }^{[\mathrm{d}]}$ Beatrice Pilger, ${ }^{[\mathrm{d}]}$ Lilli Stergiou, ${ }^{[\mathrm{d}]}$ \\ Stephan Strunze, ${ }^{[\mathrm{d}]}$ Cristina Tintori ${ }^{[\mathrm{a}]}$ and Maurizio Botta ${ }^{*[\mathrm{a}, \mathrm{e}]}$
}

The influenza RNA polymerase complex, which consists of the three subunits PA, PB1, and PB2, is a promising target for the development of new antiviral drugs. A large library of benzofurazan compounds was synthesized and assayed against influenza virus A/WSN/33 (H1N1). Most of the new derivatives were found to act by inhibiting the viral RNA polymerase complex through disruption of the complex formed between subunits
PA and PB1. Docking studies were also performed to elucidate the binding mode of benzofurazans within the PB1 binding site in PA and to identify amino acids involved in their mechanism of action. The predicted binding pose is fully consistent with the biological data and lays the foundation for the rational development of more effective PA-PB1 inhibitors.

\section{Introduction}

Influenza is an infectious disease of birds and mammals caused by ribonucleic acid (RNA) viruses of the family Orthomyxoviridae. It is a contagious disease that occurs seasonally in epidemic and sometimes pandemic proportions. On the basis of serological subtyping, three distinct types of influenza-A, $B$, and $C$-are present, of which types $A$ and $B$ are of great concern as human pathogens. ${ }^{[1,2]}$ The virus has two major antigenic glycoproteins: hemagglutinin (HA) and neuraminidase (NA). Three HA subtypes $(\mathrm{H} 1, \mathrm{H} 2$, and $\mathrm{H} 3$ ) and two NA subtypes (N1 and N2) have frequently been found in human influenza virus, ${ }^{[1,2]}$ resulting in the possibility for distinct viral strains such as H1N1, H1N2, H2N1, H2N2, etc. Influenza epidemics and pandemics in the past century have had a serious impact on global morbidity, mortality, and economy. ${ }^{[3-5]}$ Recent outbreaks

[a] Dr. M. Pagano, Dr. D. Castagnolo, Dr. M. Bernardini, A. L. Fallacara D. Deodato, Dr. C. Tintori, Prof. M. Botta

Dipartimento Biotecnologie, Chimica e Farmacia

Università degli Studi di Siena, Via A. De Gasperi 2, 53100 Siena (Italy)

[b] A. L. Fallacara

Dipartimento di Chimica e Tecnologie del Farmaco

Università La Sapienza, Piazzale Aldo Moro 5, 00185 Roma (Italy)

[c] I. Laurenzana

IRCCS-Centro di Riferimento Oncologico Basilicata (CROB)

Laboratory of Preclinical and Translational Research Via Padre Pio 1, Rionero in Vulture, 85028 Potenza (Italy)

[d] Dr. U. Kessler, Dr. B. Pilger, Dr. L. Stergiou, Dr. S. Strunze PiKe Pharma GmbH, Institute of Pharmaceutical Sciences Swiss Federal Institute for Technology, 8093 Zürich (Switzerland)

[e] Prof. M. Botta

Biotechnology College of Science and Technology

Temple University, Biolife Science Building, Suite 333

1900 North 12th Street, Philadelphia, PA 19122 (USA)

E-mail:botta.maurizio@gmail.com of swine influenza (H1N1) in Mexico and other parts of the world have led to issuances of pandemic alerts by the World Health Organization (WHO). ${ }^{[6]}$ Influenza virus continuously evolves to avoid host detection systems by changing its antigenicity through mutation of its surface glycoprotein (NA, HA) genes; in this way it maintains the capacity to reinfect the same individual in subsequent flu seasons. Another major factor for the emergence of extremely aggressive influenza viruses is the reassortment of genetic materials between different strains of the virus circulating in humans and avians. ${ }^{[7]}$ Given this elevated rate of mutation, every season WHO experts identify the proper combination of antigenic strains for which vaccines are developed. However, the 9-12-month time gap between WHO recommendation and actual application of vaccine could result in a mismatch between the virus and vaccine, decreasing its effectiveness against the strains in circulation. ${ }^{[8]}$ The development of an effective flu vaccine is hampered by these and other complicating factors. Therefore, additional weapons in the form of efficacious anti-influenza agents are a must in the fight against future seasonal or pandemic influenza outbreaks. ${ }^{[9,10]}$

A few antiviral drugs are effective in defending the body against infection, particularly in patients for whom it is not possible to administer an influenza vaccine or when a new type of virus enters circulation (i.e., swine H1N1 virus, 2009). ${ }^{[1]}$ NA inhibitors, such as oseltamivir ${ }^{[12]}$ and zanamivir, which inhibit virus budding, ${ }^{[13]}$ are available for clinical use. Furthermore, M2 protein inhibitors, amantadine and rimantadine, historically the first drugs available for the treatment of influenza, have been used for over 50 years. Although both drugs can be effective against influenza virus A infection, they have been re- 
a)

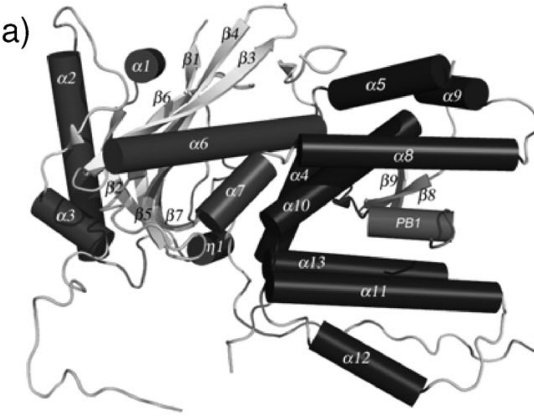

b)
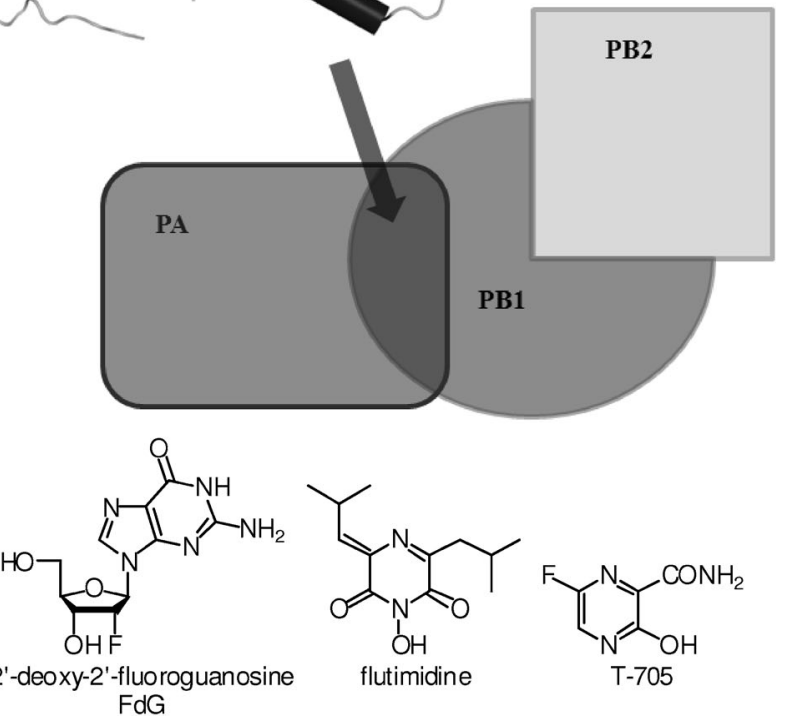

roguanosine $(\mathrm{FdG})^{[21,22]}$ and T-705 ${ }^{[23-25]}$ (Figure $\left.1 \mathrm{~b}\right)$. In addition, flutimide, a 2,6-diketopiperazine identified in extracts of the fungus Delitschia confertaspora, has been shown to specifically inhibit the cap-dependent endonuclease activity associated with influenza viral RNA polymerase and to inhibit the replication of influenza $A$ and $B$ virus in cell culture. ${ }^{[26]}$ The discovery of molecules able to interact with the PA subunit is an extremely important goal in the synthesis of broad-spectrum antiviral drugs. In fact, because the $\mathrm{N}$-terminal PA interaction domain of PB1 is highly conserved, a compound that can block the interaction between these two proteins can be expected to inhibit most, if not all, influenza strains. We recently reported the discovery of a novel class of influenza A (H1N1) inhibitors by taking advantage of a biochemical ELISA-based screening approach specifically designed to identify compounds that efficiently block the PA-PB1 interaction. ${ }^{[27,28]}$ However, because only a limited amount of structure-activity relationship (SAR) information arose from our previous work, we decided to synthesize a larger library of benzofurazan derivatives to explore the chemical space around the heterocyclic nucleus. Both cell-based and enzyme bioassays were planned in order to test the antiviral activity and the ability of the benzofurazan compounds to interact with and inhibit the viral RNA polymerase complex. Furthermore, docking studies were performed to explore the structural features responsible for the biological activity of benzofurazan derivatives.

Figure 1. a) Structure of influenza RNA polymerase; b) influenza A RNA polymerase inhibitors.

ported to cause CNS side effects and have given rise to the rapid emergence of drug-resistant viral strains. ${ }^{[14-19]}$

In the last few years, influenza RNA polymerase has been identified as a new target for inhibition of the virus. This enzyme consists of a complex of three virus-encoded polypeptides (PB1, PB2, and PA; Figure $1 \mathrm{a}$ ). In addition to RNA replicative activity, this polymerase also contains an endonuclease activity to ensure "cap snatching" to initiate the transcription and subsequent translation process. The polymerase complex genes contribute to the high virulence of the human $\mathrm{H} 5 \mathrm{~N} 1$ influenza virus isolate A/Vietnam/ $1203 / 04$. This observation highlights the importance of novel antivirals that target the polymerase for further development of therapy and prophylaxis of human and avian influenza virus infections. ${ }^{[20]}$ Few compounds have been reported to operate at the RNA polymerase. Like the inhibitors that have been found to act against reverse transcriptase (RNA-dependent DNA polymerase) of HIV or RNA replicase (RNA-dependent RNA polymerase) of HCV, influenza RNA polymerase inhibitors can be divided into two classes: nucleosides and non-nucleosides. Examples of the nucleoside-type inhibitors are 2'-deoxy-2'-fluo-

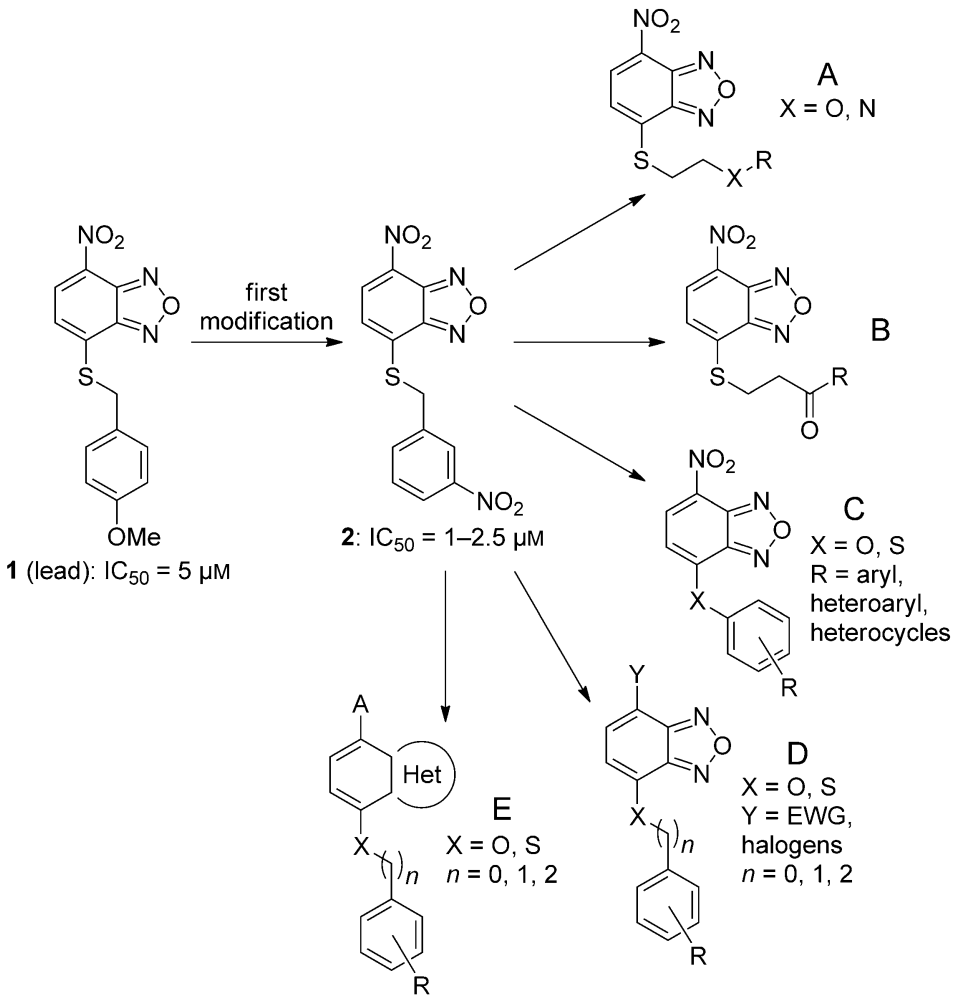

Figure 2. Second-generation benzofurazan derivatives. 


\section{Results and Discussion}

\section{Chemistry}

To identify novel benzofurazans as RNA polymerase inhibitors and to study the SARs, five series of analogues (A-E, Figure 2) of previously discovered compounds 1 and $2^{[27]}$ were designed and synthesized. Both series A and $\mathbf{B}$ bear an alkylthio substituent at $\mathrm{C} 4$ of the benzofurazan ring. In the first series of compounds with general structure $\mathbf{A}$ we planned to introduce a $>1$-carbon alkyl spacer between the sulfur and the aromatic ring. Moreover, enhancing the solubility of the compounds by replacing the aromatic moiety with hydrophilic groups was also investigated. Similarly, the second series of derivatives B was planned with the aim to introduce a hydrophilic/hydrogen-donor moiety at $\mathrm{C} 4$ and to evaluate their importance for activity. The $\mathbf{C}$ series is composed of benzofurazans bearing an S- or O-aryl moiety at C4. In particular, the introduction of heteroaryl moieties bound to the phenyl ring at $\mathrm{C} 4$ was planned in order to improve the solubility of the new compounds and thus to improve their activity in cellular assays. To determine the importance of the nitro group, the fourth series of compounds $D$, bearing various groups at C7 was also planned. Finally, the synthesis of compounds $\mathbf{E}$ with a non-benzofurazan core was accomplished. The benzofurazan core was replaced by (bio)isosteric (hetero)aromatic cores in order to investigate the importance of the oxadiazole ring for activity against influenza viruses.

\section{Synthesis of derivatives with general structures $A$ and $B$}

The synthesis of the first series of benzofurazan derivatives containing a cysteamine or thioethyl chain at C4 was carried out according to Scheme 1. Commercially available benzofurazan 3 was first treated with protected thioethanol to afford 4, which, after deprotection with TBAF, led to intermediate $\mathbf{5}$. Acylation of the latter afforded derivatives 6 a-c in excellent yields. Reaction of benzofurazan $\mathbf{3}$ with cysteamine gave intermediate 7. Acylation of 7 with various acyl chlorides in the presence of pyridine as base selectively afforded compounds $\mathbf{8} \mathbf{a}-\mathbf{c}$. If the same reaction was carried out in the pres- ence of triethylamine, compounds $9 \mathrm{a}$ and $\mathbf{9 b}$ were also isolated. The formation of these latter compounds was due to an intramolecular Smiles rearrangement of the cysteamine chain catalyzed by triethylamine, as previously reported by our group. ${ }^{[29]}$ Finally, reaction of 3 with 12 and 13, in turn obtained through guanylation and amidation with cysteamine, and acidmediated removal of the Boc protecting group led to the formation of derivatives $\mathbf{1 0} \mathbf{a}, \mathbf{b}$. Compounds belonging to the $\mathbf{B}$ series of derivatives, bearing a thiopropionic acid side chain at C4, were then synthesized according to Scheme 2. Benzofurazan 3 was first allowed to react with amides $18 a, b$, in turn obtained through the reaction of thiopropionic acid 14 with morpholine and thiomorpholine. Reaction of 3 with ethyl 3-thiopropionate or with $\mathrm{N}$-Boc-cysteine ethyl ester led to derivatives $15 \mathrm{a}, \mathrm{b}$. Finally, the allyl derivative 16 was obtained under the same reaction conditions.

\section{Synthesis of derivatives with general structure C}

A new series of benzofurazans bearing a thioaryl moiety at C4 was synthesized according to Scheme 3 . The starting material 


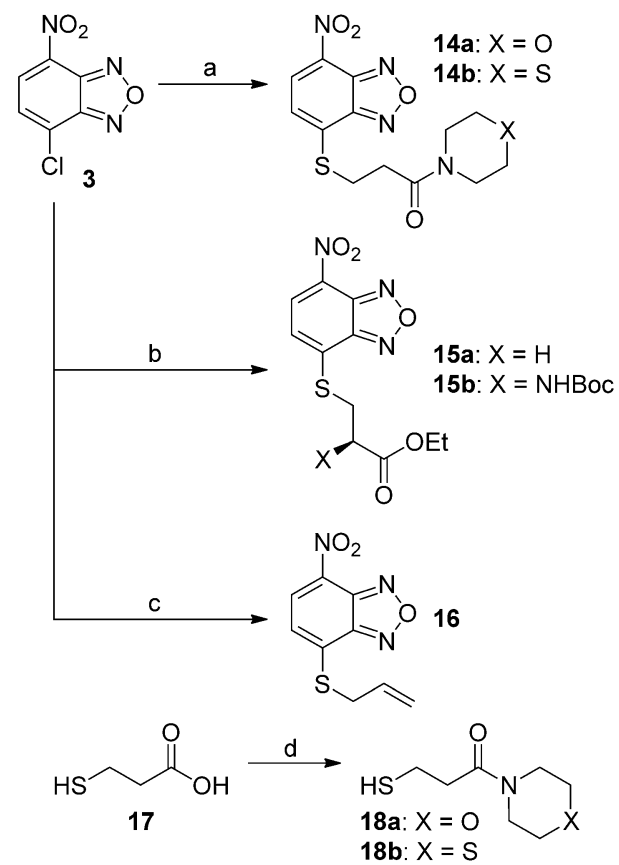

Scheme 2. Reagents and conditions: a) $\mathbf{1 8 a}$ or $\mathbf{1 8} \mathrm{b}$, pyridine, $\mathrm{KOAc}, \mathrm{EtOH}$, reflux, $1 \mathrm{~h}$; b) ethyl 3-thiopropionate or $\mathrm{N}$-Boc-cysteine ethyl ester, pyridine, $\mathrm{KOAc}, \mathrm{EtOH}$, reflux, $1 \mathrm{~h}$; c) allylthiol, pyridine, $\mathrm{KOAc}$, EtOH, reflux, $1 \mathrm{~h}$; d) morpholine or thiomorpholine, EDC, HOBt, DIPEA, DMF, RT, $10 \mathrm{~h}$.

19 , obtained from compound 3 by reaction with $m$-aminothiophenol in ethanol at reflux, ${ }^{[29]}$ was then derivatized at the amino function. Imidazole derivative $\mathbf{2 0}$ was obtained through a microwave-accelerated one-pot reaction previously reported by our group ${ }^{[30]}$ leading to the formation of the heterocyclic ring in $10 \mathrm{~min}$. Reaction of 19 with $p$-toluenesulfonyl isocyanate and cyanuric chloride led to derivatives $\mathbf{2 1}$ and 22. This latter compound was also converted into its hydrochloride salt 23 in order to improve aqueous solubility. Finally, reductive amination of 19 with various aldehydes led to compounds 24 a-d. A second series of derivatives bearing an $O$-aryl moiety at C4 was then synthesized. With the purpose to avoid potential oxidation at the sulfur atom, which could reduce antiviral activity, several derivatives containing an ether moiety were synthesized. Moreover, the oxy-derivatives 27 a-d and 29 (Scheme 4) were synthesized with the aim to introduce an alkyl spacer between the two aromatic moieties and to obtain further SARs. Alkynes 26a-d were obtained through Sonogashira coupling from 4-iodophenol 25 and then reacted with compound 3 . Hydrogenation of $26 \mathrm{c}$ led to saturated phenol $\mathbf{2 8}$, which was in turn converted into derivative 29 . Finally, derivative $\mathbf{3 3}$ was easily synthesized by starting from commercially available aldehyde 30, which was converted into diene 31 in three steps. Ring-closing metathesis and deprotection led to phenol 32, which, after reaction with 4-chloro-7-nitrobenzofurazan 3, led to the desired compound 33. We then turned our attention to the introduction of a heteroaliphatic group in order to improve the solubility of target compounds. Therefore, the synthesis of a series of phenol derivatives bearing a pi- perazine at the para position of the phenyl ring was planned (Scheme 5). Compound $\mathbf{3 4}$ was alkylated, acylated, and guanylated to give compounds 35-37, which were in turn coupled with 4-chloro-7-nitrobenzofurazan 3 to give the desired products $38 \mathbf{a}-\mathbf{c}$. Hydrochloride salts $\mathbf{3 9} \mathbf{a}, \mathbf{b}$ were also synthesized, and Boc deprotection of compound $38 \mathrm{c}$ led to compound $40 \mathrm{c}$.

Finally, we planned to introduce a heteroaromatic moiety into the C4 chain. In particular, we focused our attention to the triazole ring, which is known to be a bioisostere of the amide bond. Azides $\mathbf{4 2} \mathbf{a}, \mathbf{b}$ were allowed to react with various alkynes through Huisgen-1,3-dipolar cycloaddition to afford triazoles $44 a-f, 45 a, b$, and, after deprotection of $44 d$, compound 46 . These were coupled with compound 3 to furnish the desired compounds 47-48 a-h (Scheme 6, Table 1). Both

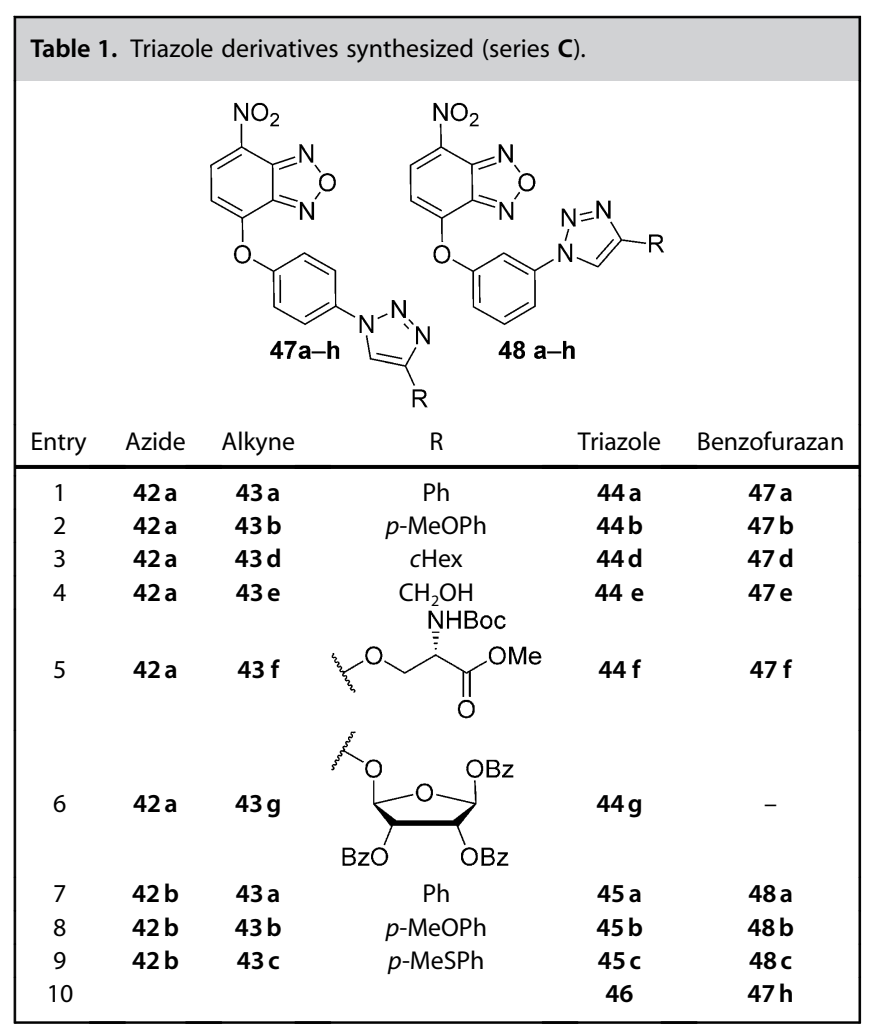

meta- and para-substituted phenols were synthesized. The syntheses of benzofurazans $\mathbf{4 7} f$ and $\mathbf{4 7} \mathrm{h}$, respectively bearing an amino acid and a carbohydrate group, were planned in order to enhance the aqueous solubility of these derivatives.

\section{Synthesis of derivatives with general structure $D$}

A further series of compounds with general structure D was then planned with the aim of investigating the role of the substituents at $\mathrm{C7}$. Compounds in which the nitro group was replaced by a halogen or an amino moiety were then designed and synthesized. Compounds $1,14 \mathrm{a}$, and 49, which in our previous studies ${ }^{[27]}$ showed high antiviral activity in cellular assays, 


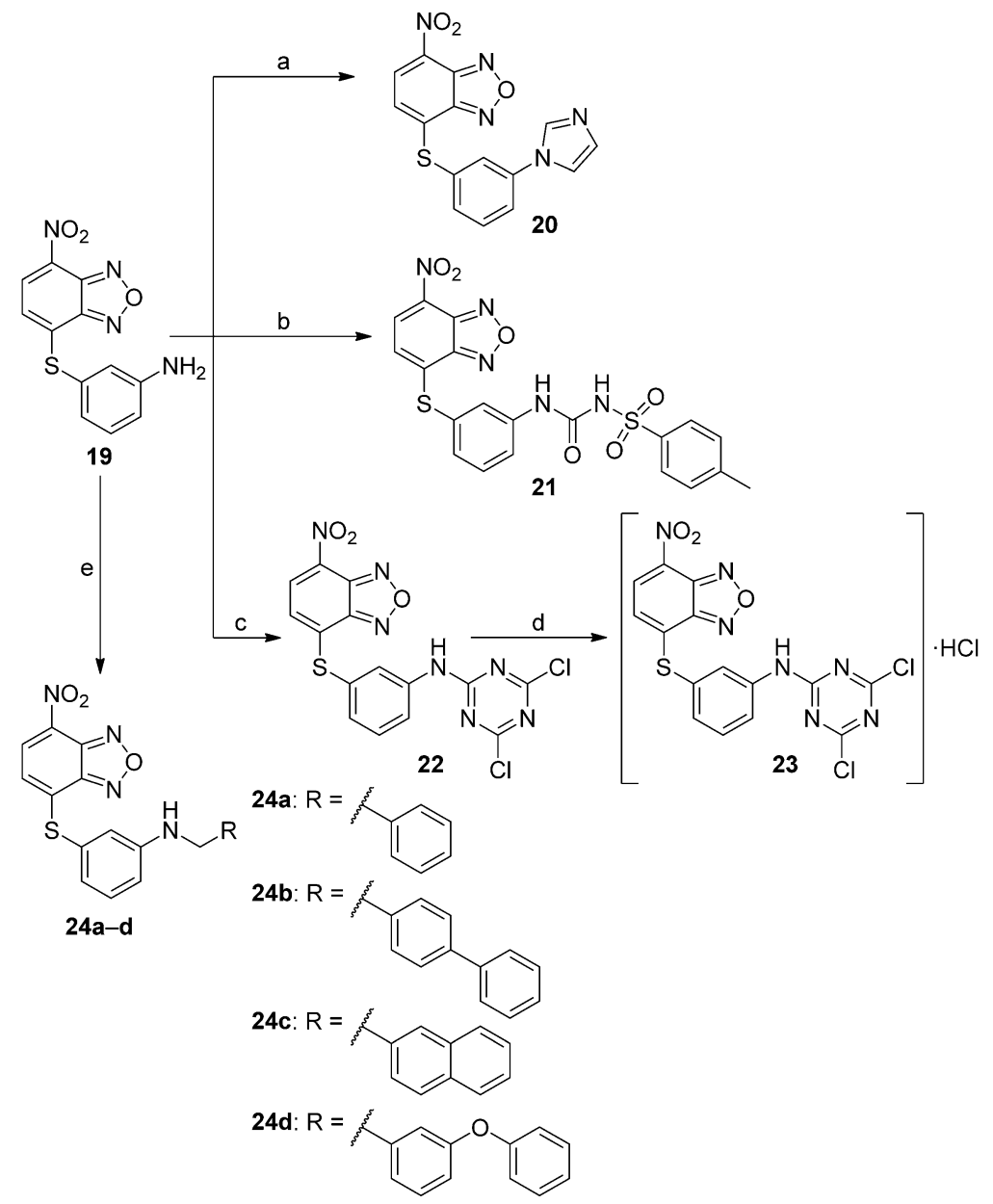

Scheme 3. Reagents and conditions: a) $\mathrm{H}_{3} \mathrm{PO}_{4}$, paraformaldehyde, glyoxal, $\mathrm{NH}_{4} \mathrm{Cl}, \mathrm{H}_{2} \mathrm{O}$ /dioxane, $\mathrm{MW}\left(120^{\circ} \mathrm{C}\right)$, $10 \mathrm{~min}$; b) $p$-toluenesulfonyl isocyanate, $\mathrm{CH}_{2} \mathrm{Cl}_{2}, \mathrm{RT}, 24 \mathrm{~h}$; c) cyanuric chloride, $\mathrm{DME},-30^{\circ} \mathrm{C}, 1 \mathrm{~h}$; d) acetyl chloride, $\mathrm{MeOH}, \mathrm{CH}_{2} \mathrm{Cl}_{2}, \mathrm{RT}, 2$ min; e) $\mathrm{RCHO}, \mathrm{NaBH}_{4}-\mathrm{PTSA}, \mathrm{DCE}, \mathrm{RT}, 16 \mathrm{~h}$.

were chosen as substrates. Reduction of the nitro group was carried out with $\mathrm{Fe}^{0}$ in acidic medium, to afford amines $50 \mathrm{a}-\mathrm{c}$. Chlorination and iodination were performed with $\mathrm{CuCl}_{2}$-tertbutylnitrile and $\mathrm{NaNO}_{2}-\mathrm{Kl}$, respectively, to allow formation of $51 \mathrm{~b}$ and $52 \mathrm{c}$. Amines $53 \mathrm{a}$ and $54 \mathrm{c}$ were also synthesized by hydrochlorination and acylation reactions. Finally, sulfonamides $\mathbf{5 8}$ a-d were synthesized from amide 56, in turn obtained from sulfonyl chloride $\mathbf{5 5}$ (Scheme 7).

\section{Synthesis of the series of derivatives with general structure E: modifications of the heterocyclic core}

The synthesis of a series of non-benzofurazan derivatives related to previous compounds was then planned in order to investigate the role and importance of the benzooxadiazole nucleus to anti-influenza activity. A series of tricyclic compounds strictly related to benzofurazans was obtained by Diels-Alder reaction of $49 a-f$ with the Danishefsky diene, leading to the formation of diastereomers $59 \mathrm{a}-\mathrm{f}$ and $60 \mathrm{a}-\mathrm{f}$ (Scheme 8). The benzo2,1,3-thiadiazoles $63 \mathrm{a}, \mathrm{b}$ were then synthesized from commercially available $\mathbf{6 1}$, which was converted into the bromo derivative $\mathbf{6 2}$ by holding it at reflux in concentrated nitric acid. Reac- tion of $\mathbf{6 2}$ with the appropriate nucleophile led to the desired products $63 \mathrm{a}, \mathbf{b}$. The oxadiazole ring of the bezofurazans was then replaced with a pyridine ring. Hence, a series of quinoline and isoquinoline derivatives was synthesized. Skraup reaction between aniline 64 and acrolein 65 led to quinoline nucleus $\mathbf{6 6}$, which, after coupling with the appropriate thiol or phenol, led to desired compounds $67 \mathrm{a}-\mathbf{d}$. The synthesis of isoquinoline derivatives was accomplished by starting from 68 , which was converted into derivative 69 by bromination with $\mathrm{N}$-bromosuccinimide (NBS) and nitration with potassium nitrate. Coupling with the appropriate thiol led to isoquinolines 70 a,b (Scheme 9). Finally, the oxadiazole ring was replaced with a 2-methylthiazole ring. Aniline 71 was acylated into 72 and cyclized into benzothiazole $\mathbf{7 3}$ by reaction with Lawesson's reagent. Nitration of 73 led to 74, which was converted into desired compounds $75 \mathrm{a}-\mathbf{d}$ after reaction with the appropriate thiol/phenol. Finally, derivative $\mathbf{7 8}$ was obtained in a two-step sequence starting from aniline $\mathbf{7 6}$ in order to investigate the importance of the heterocyclic core for antiviral activity (Scheme 10).

\section{Biological assays}

The synthesized compounds were assayed for their inhibitory activity toward influenza virus strain A/WSN/33 (H1N1), and the results are listed in Table 2 . With regard to derivatives with general structure $A$, compound $6 a$, containing a thioethanol chain, showed good activity, with an $\mathrm{IC}_{50}$ value of $2.5 \mu \mathrm{M}$. However, 6 a proved to be slightly cytotoxic. On the other hand, related compounds $\mathbf{6} b, c$ were found to be inactive. The best activity data were obtained with cysteamine derivative 8 . The unsubstituted derivative 7 showed a good biological profile, with an $\mathrm{IC}_{50}$ value of $10 \mu \mathrm{M}$ and low cytotoxicity. Acylated derivatives $8 \mathrm{a}-\mathrm{c}$ showed excellent antiviral activity $(1-2.5 \mu \mathrm{M})$, but also proved to be highly cytotoxic. It seems clear that the presence of an aromatic moiety is fundamental for improvement of activity, yet it is also detrimental in terms of cytotoxicity. Compound $\mathbf{8 c}$ proved to be a perfect compromise, bearing an aromatic moiety endowed with partial hydrophilic character, namely a pyridine. Compound $\mathbf{8} \mathbf{d}$ was found to be active 

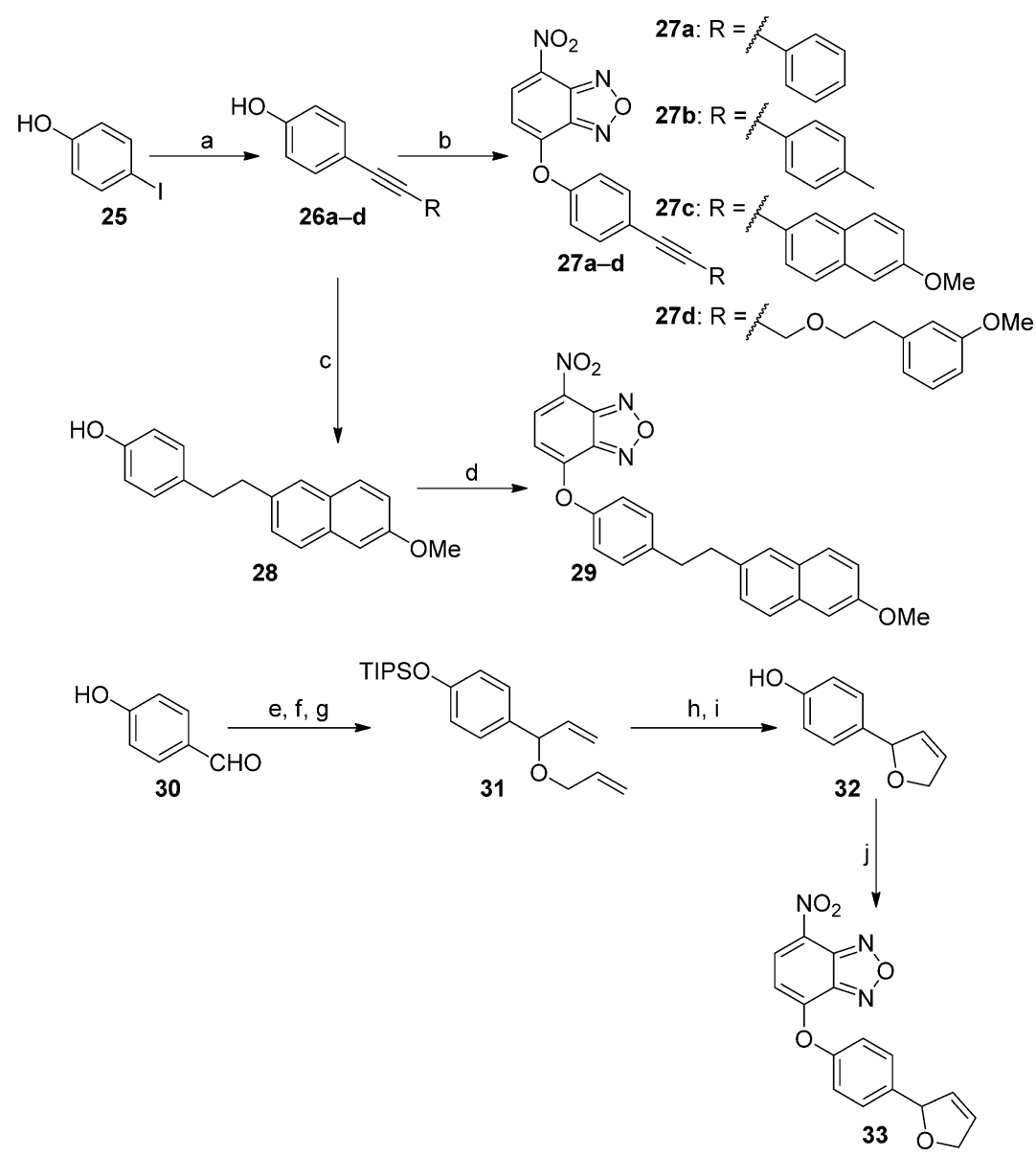

Scheme 4. Reagents and conditions: a) alkyne, $\left(\mathrm{PPh}_{3}\right)_{2} \mathrm{PdCl}_{2}, \mathrm{Cul}, \mathrm{DMF} / \mathrm{Et}{ }_{3} \mathrm{~N}, \mathrm{MW}\left(120^{\circ} \mathrm{C}\right), 5 \mathrm{~min}$; b) 3, cat. pyridine and $\mathrm{KOAc}$, EtOH, reflux, $20 \mathrm{~min}$; c) $\mathrm{H}_{2}, \mathrm{Pd} / \mathrm{C}$, EtOAc, RT, $8 \mathrm{~h}$; d) 3, cat. pyridine and $\mathrm{KOAc}$, EtOH, reflux, 20 min; e) TIPSCl, imidazole, DMF, $60^{\circ} \mathrm{C}, 1 \mathrm{~h}$; f) vinylmagnesium bromide, THF, RT, $1 \mathrm{~h}$; g) allyl bromide, NaH, THF, RT, $5 \mathrm{~h}$; h) 2nd-gen. Grubbs catalyst, $\mathrm{CH}_{2} \mathrm{Cl}_{2}, \mathrm{RT}, 1 \mathrm{~h}$; i) TBAF, THF, RT, $1 \mathrm{~h}$; j) 3, cat. pyridine and $\mathrm{KOAc}$, EtOH, reflux, $2 \mathrm{~h}$.

against influenza virus $\mathrm{H} 1 \mathrm{~N} 1$ and showed low cytotoxicity. Compounds with general structure B (namely 14, 15, and 16) were all inactive against influenza $\mathrm{H} 1 \mathrm{~N} 1$ virus in cellular assays, with compound 16 as the only exception: $I_{50} 10 \mu \mathrm{M}$. In contrast, good results were obtained from compounds with general structure C (compounds 20-48); all were active against influenza $\mathrm{H} 1 \mathrm{~N} 1$ virus, with $\mathrm{IC}_{50}$ values ranging from 1 to $60 \mu \mathrm{M}$. Overall, the introduction of aryl/benzyl ethers or thioethers or longer aliphatic/aromatic chains at $\mathrm{C} 4$ is favorable for activity against influenza H1N1. Notably, compound 47 e proved to be active against $\mathrm{H} 1 \mathrm{~N} 1$ virus, with an $\mathrm{IC}_{50}$ value of $1 \mu \mathrm{M}$ and low cytotoxicity, thus proving to be the best benzofurazan derivative identified in this series.

Focusing on compounds of series C and D (compounds 4978), the biological data indicate that replacement of the nitro group or change of the benzofurazan core cause a loss of activity (data not shown). Similarly, the introduction of substituents at C6 is detrimental for antiviral activity. On the other hand, to study the mechanism of action of the new antiviral benzofurazan compounds, active derivatives were also tested in the novel biochemical ELISA previously described for influenza peptides and specifically designed to identify compounds that efficiently block the PA-PB1 interaction. Most of the new antiviral benzofurazan compounds (8c, 20, 23, 39b, 40, 47a, 47e, $48 \mathrm{~b}, 48 \mathrm{c}$ ) acted by disrupting the interaction between the PA and PB1 subunits of the viral RNA polymerase at the micromolar level, thus blocking an essential protein in the replication process of the virus. Notably, all the compounds observed to be active in the ELISA bear a heterocyclic or heteroaromatic ring in the benzofurazan chain. Imidazole derivative $\mathbf{2 0}$ showed a close correlation between the results of cell-based assays and ELISAs, confirming that its biological activity is due to interaction with the RNA polymerase complex. Close correlations between cellular and ELISAs were also observed for piperazine derivatives $39 \mathrm{~b}$ and $\mathbf{4 0}$, and for triazoles $47 \mathrm{a}, \mathrm{e}$ and $48 \mathrm{~b}, \mathrm{c}$. On the other hand, the high ELISA IC $C_{50}$ values determined for some compounds $(16,21,24 a$, and 33), which were found active in cells at low micromolar levels, suggest that their mechanism of action could be different. Further studies are in progress to better elucidate this aspect.

\section{Molecular modeling}

Docking studies were performed on the novel benzofurazans to explore the structural features responsible for their inhibitory activity toward influenza H1N1 virus. Because most of the derivatives were shown to act as PA-PB1 inhibitors, they were subjected to focused docking experiments within the PB1 binding site of PA.

Computational analysis was performed by using a protein assembly built with the aid of two recently deposited crystallographic structures of the PA-PB1 complex (PDB IDs 3CM8 and $2 Z \mathrm{ZNL}$ ). The complete library of benzofurazans was docked by using both Glide and Gold programs. Docking results on derivatives reported herein did not converge to a single solution, but several binding modes were identified. The inability to recognize a unique pose was likely due to the large size of the pocket, adapted to the co-crystallized PB1 peptide. However, the most reliable binding mode identified for active inhibitors shows the benzofurazan scaffold involved in a $\pi$-stacking interaction with Trp706. Furthermore, a hydrogen bond between the oxygen atom of the furazan group and Gln408 and an 

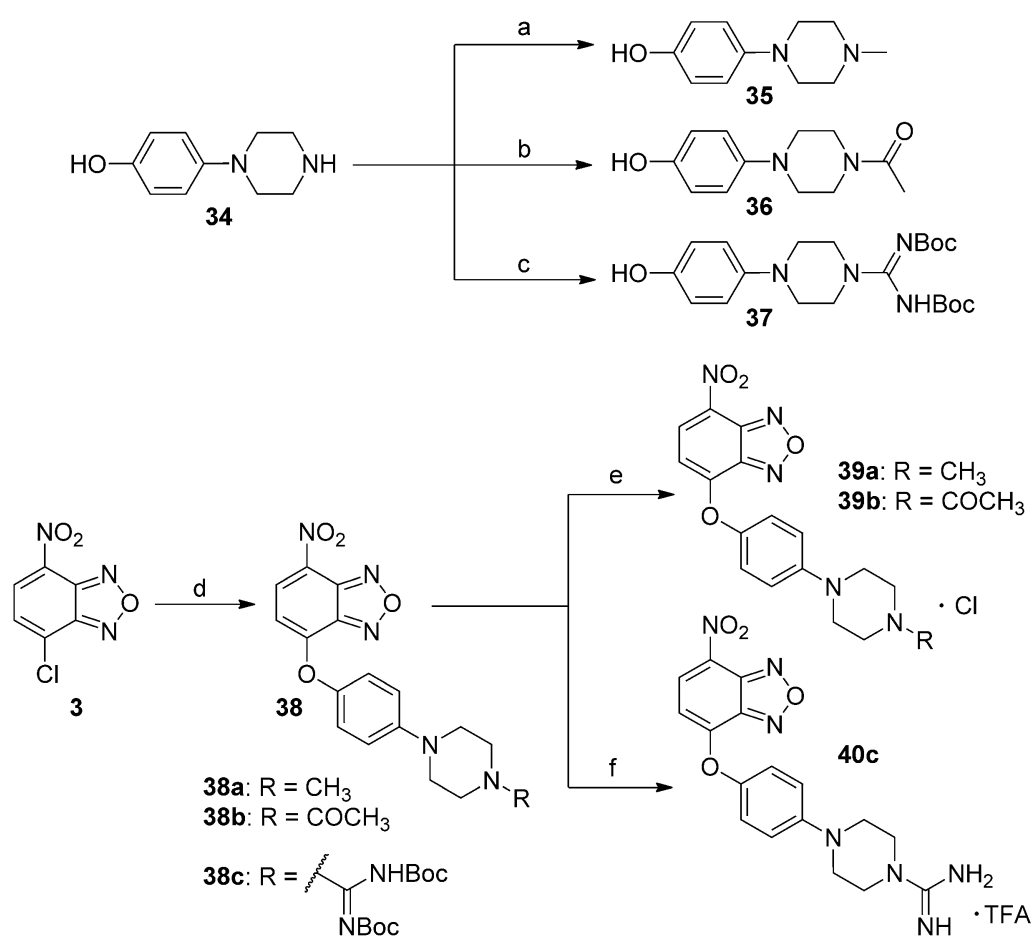

Scheme 5. Reagents and conditions: a) $\mathrm{CH}_{2} \mathrm{O}$, formic acid, $\mathrm{MeOH}$, reflux, $12 \mathrm{~h}$; b) $\mathrm{Ac}_{2} \mathrm{O}$, pyridine, RT, $1 \mathrm{~h}$; c) $\mathrm{N}, \mathrm{N}^{\prime}-\mathrm{di}-$ Boc- $N$ "'-trifluoromethanesulfonylguanidine, DIPEA, DMF, RT, $16 \mathrm{~h}$; d) 35, 36, or 37, cat. pyridine and/or KOAc, EtOH, reflux, 20 min; e) 38 a or $\mathbf{3 8}$ b, acetyl chloride, $\mathrm{MeOH}, \mathrm{CH}_{2} \mathrm{Cl}_{2}, \mathrm{RT}, 2 \mathrm{~min}$; f) $38 \mathrm{c}, \mathrm{TFA}, \mathrm{CH}_{2} \mathrm{Cl}_{2}, \mathrm{RT}, 24 \mathrm{~h}$.

electrostatic interaction recurrent between the $\mathrm{NH}_{3}{ }^{+}$of Lys643 and the nitro group were found. As an example, the binding mode of compound $39 \mathrm{~b}$ is shown in Figure 3. Similar interactions were previously described for other recently identified PA-PB1 inhibitors. ${ }^{[31,32]}$ Accordingly, the lack of activity of compounds in which the nitro group is replaced by another group may depend on the loss of the electrostatic interaction with Lys643. Additionally, replacement of the benzofurazan core is detrimental to activity, probably from the loss of interactions with Trp706 and Gln408.

The ligand efficiency (LE) ${ }^{[33]}$ of benzofurazan derivatives was calculated as the free energy of binding divided by the number of heavy atoms (non-hydrogen atoms, NHA) of the molecule (Table 2). Values of LE span from 0.16 to $0.34 \mathrm{kcal}(\mathrm{mol} \cdot \mathrm{NHA})^{-1}$, putting compounds 7,16 , and 20 in a promising range for further optimization, as an LE value

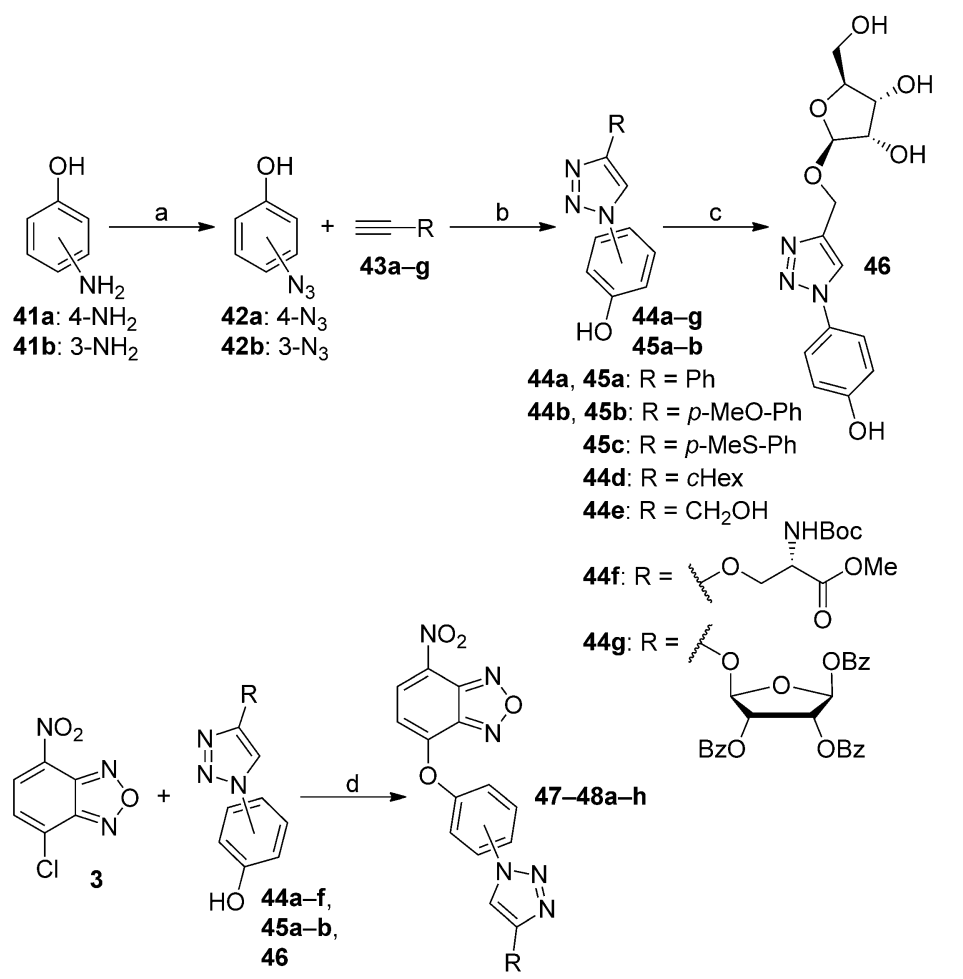

Scheme 6. Reagents and conditions: a) $\mathrm{NaNO}_{2}, \mathrm{NaN}_{3}, \mathrm{AcOH} / \mathrm{H}_{2} \mathrm{O}, 15 \mathrm{~min}$; b) appropriate alkyne, sodium ascorbate/ $\left.\mathrm{Cu}(\mathrm{SO})_{4}, \mathrm{H}_{2} \mathrm{O} / \mathrm{tBuOH}, \mathrm{MW}\left(125^{\circ} \mathrm{C}\right), 10 \mathrm{~min} ; \mathrm{c}\right) \mathbf{4 4} \mathbf{~ g}, \mathrm{MeOH} /$ $\mathrm{NH}_{4} \mathrm{OH}(4: 1), \mathrm{RT}, 18 \mathrm{~h}$; d) $\mathbf{4 4 - 4 5} \mathrm{a}-\mathrm{f}$ or $\mathbf{4 6}$, cat. pyridine and/or $\mathrm{KOAc}, \mathrm{EtOH}$, reflux, $3 \mathrm{~h}$. of $0.24 \mathrm{kcal}(\mathrm{mol} \cdot \mathrm{NHA})^{-1}$ has been described as a limit over which small molecules are able to disrupt protein-protein interfaces. ${ }^{[34]}$

\section{Conclusions}

In summary, the present study demonstrates the potential of benzofurazan compounds as a new family of influenza virus inhibitors that act by targeting the interaction between the PA and PB1 subunits of the viral RNA polymerase. A large library of compounds was synthesized and biologically evaluated, leading to the identification of lead compounds $(8 \mathrm{c}$ and $47 \mathrm{e})$ with high anti-H1N1 activity $\left(\mathrm{IC}_{50}=1 \mu \mathrm{M}\right)$. ELISA results confirmed the mechanism of action of benzofurazan derivatives being through inhibition of the viral RNA polymerase. These compounds are a starting point in the identification and development of novel therapeutic antiviral agents. Results of docking studies suggest that the residues Trp706, Gln408, and Lys643 are crucial for the binding of the benzofurazan derivatives to the PB1 binding pocket on PA, and therefore could be targeted for the design of novel PA-PB1 interaction inhibitors. 


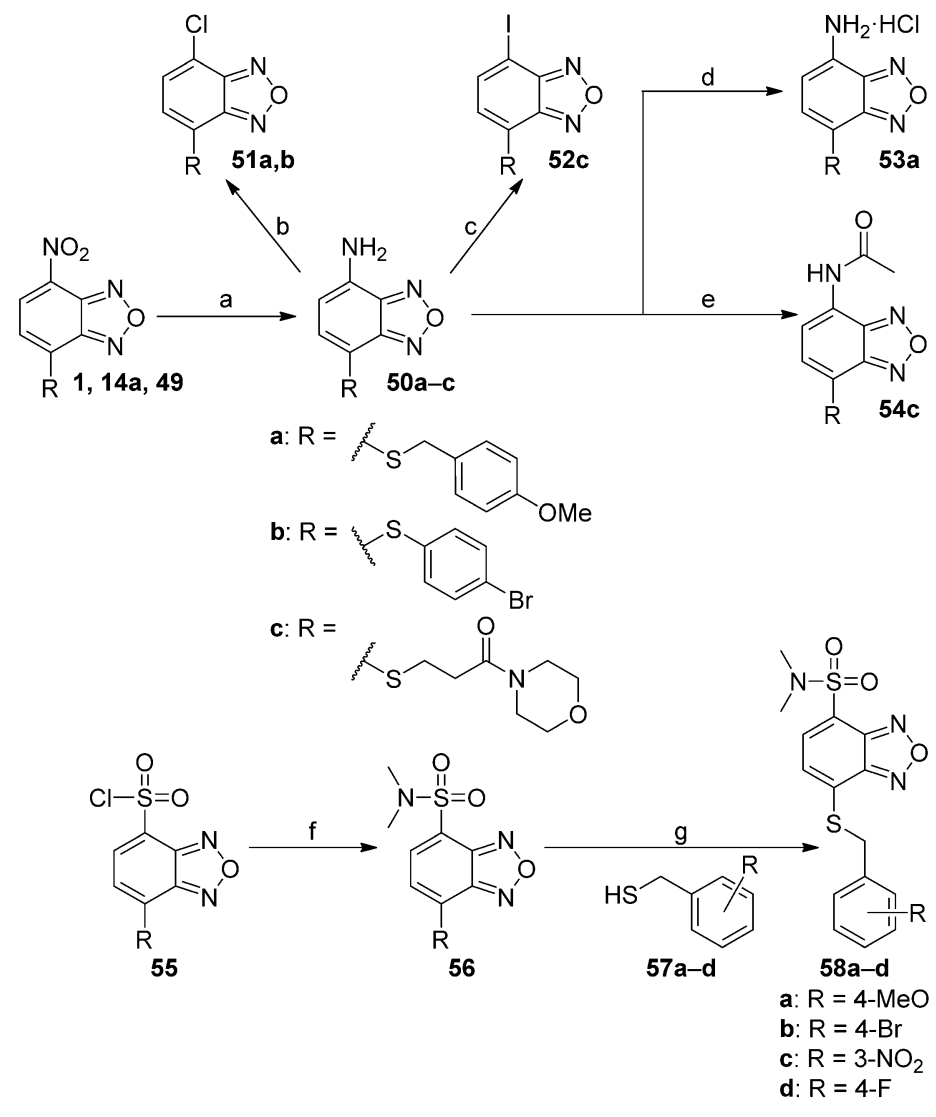

Scheme 7. Reagents and conditions: a) $\mathrm{Fe}^{0}, \mathrm{HCl}, \mathrm{CH}_{2} \mathrm{Cl}_{2} / \mathrm{MeOH}, \mathrm{RT}, 25 \mathrm{~min}$; b) $\mathrm{CuCl}_{2}$, tertbutyl nitrite, $\mathrm{CH}_{3} \mathrm{CN}, 65^{\circ} \mathrm{C}, 3 \mathrm{~h}$; c) 1. $\mathrm{NaNO}_{2}, \mathrm{H}_{2} \mathrm{O}, \mathrm{HCl} / \mathrm{H}_{2} \mathrm{SO}_{4}, 0^{\circ} \mathrm{C}, 40 \mathrm{~min}, 2 . \mathrm{KI}, \mathrm{H}_{2} \mathrm{O}, \mathrm{RT}$, $2 \mathrm{~h}$; d) acetyl chloride, $\mathrm{MeOH}, \mathrm{CH}_{2} \mathrm{Cl}_{2}, \mathrm{RT}, 2$ min; e) $\mathrm{Ac}_{2} \mathrm{O}$, pyridine, cat. DMAP, $\mathrm{RT}, 4 \mathrm{~h}$; f) $\mathrm{Me}_{2} \mathrm{NH}$, cat. $\mathrm{Et}_{3} \mathrm{~N}, \mathrm{CH}_{3} \mathrm{CN}, \mathrm{RT}, 3 \mathrm{~h}$; g) appropriate nucleophile, cat. pyridine and/or KOAc, $\mathrm{EtOH}$, reflux, $2 \mathrm{~h}$.

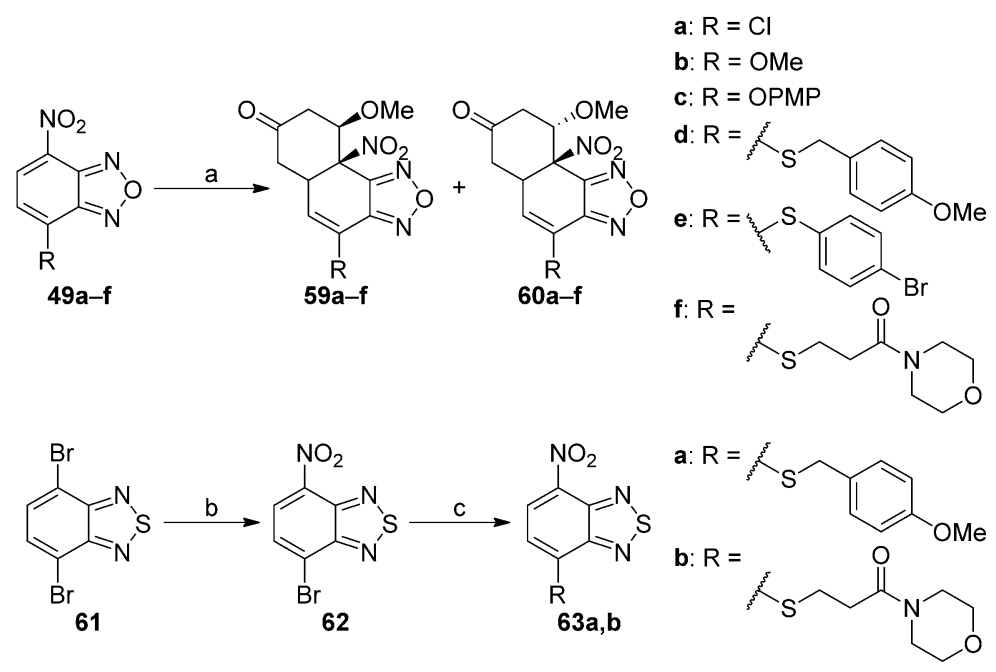

Scheme 8. Reagents and conditions: a) Danishefsky diene, $\mathrm{CH}_{2} \mathrm{Cl}_{2}, \mathrm{RT}, 6 \mathrm{~h}$; b) conc $\mathrm{HNO}_{3}$, reflux, $1 \mathrm{~h}$; c) appropriate nucleophile, cat. pyridine and/or $\mathrm{KOAC}, \mathrm{EtOH}$, reflux, $3 \mathrm{~h}$.

\section{Experimental Section}

\section{Chemistry}

Reagents were obtained from commercial suppliers and were used without further purification. ${ }^{1} \mathrm{H}$ and ${ }^{13} \mathrm{C}$ NMR spectra were mea- sured on a Bruker Avance DPX400. Chemical shifts are reported relative to $\mathrm{CDCl}_{3}$ at $\delta=7.24 \mathrm{ppm}$ and tetramethylsilane at $\delta=0.00 \mathrm{ppm}$. Mass spectrometry (MS) data were obtained on an Agilent 1100 LC/MSD VL system (G1946C) at a flow rate of $0.4 \mathrm{~mL} \mathrm{~min}^{-1}$ using a binary solvent system of 95:5 $\mathrm{MeOH} / \mathrm{H}_{2} \mathrm{O}$. UV detection was monitored at $\lambda 254 \mathrm{~nm}$. MS data were acquired in both positive and negative modes, scanning over the mass range of 50-1500. The following ion source parameters

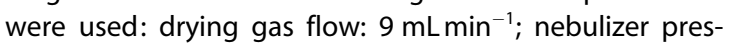
sure: 40 psig; drying gas temperature: $350^{\circ} \mathrm{C}$.

\section{4-(2-(tert-Butyldiphenylsilyloxy)ethylthio)-7-}

nitrobenzo[c][1,2,5]oxadiazole (4): To a solution of 4chloro-7-nitrobenzofurazan $3(1 \mathrm{mmol})$ in $5 \mathrm{~mL} \mathrm{CH}_{2} \mathrm{Cl}_{2}$, $\mathrm{K}_{2} \mathrm{CO}_{3}(1 \mathrm{mmol})$ and OTBDPS-thioethanol $(1.1 \mathrm{mmol})$ were added and the reaction mixture was heated at reflux for $4 \mathrm{~h} . \mathrm{H}_{2} \mathrm{O}$ was added, and the organic layer was washed with brine, dried over $\mathrm{Na}_{2} \mathrm{SO}_{4}$, filtered off and the solvent was removed. The crude mixture was purified by flash chromatography (Hex/EtOAc 9:1) to give compound 5 as a yellow solid $(0.71 \mathrm{mmol}, 71 \%)$. ${ }^{1} \mathrm{H}$ NMR (400 MHz, CD $\mathrm{OD}): \delta=8.13-8.11(\mathrm{~d}, J=8,1 \mathrm{H}), 7.58-7.56$ $(m, 4 H), 7.35-7.32(m, 2 H), 7.30-7.26(m, 4 H), 6.89-6.87$ $(\mathrm{d}, J=8,1 \mathrm{H}), 4.00-3.96(\mathrm{~d}, J=8,2 \mathrm{H}), 3.40-3.36(\mathrm{~d}, J=8$, $2 \mathrm{H}), 0.97 \mathrm{ppm}(\mathrm{s}, 9 \mathrm{H}) ;{ }^{13} \mathrm{CNMR}\left(100 \mathrm{MHz}, \mathrm{CDCl}_{3}\right): \delta=$ $143.78,143.42,135.66,134.05,130.07,129.56,126.23$, $124.48,119.08,67.26,43.39,31.75,26.88$ ppm; MS (ESI) $\mathrm{m} / \mathrm{z}: 502[\mathrm{M}+\mathrm{Na}]^{+}$.

2-(7-Nitrobenzo[c][1,2,5]oxadiazol-4-ylthio)ethanol (5): To a solution of $4(134 \mathrm{mg}, 0.28 \mathrm{mmol})$, in dry THF $(5 \mathrm{~mL})$ previously cooled to $0{ }^{\circ} \mathrm{C}$, a $1 \mathrm{M}$ TBAF solution in THF $(280 \mu \mathrm{L}, 0.28 \mathrm{mmol}$ ) was slowly added. The mixture was stirred at room temperature for $1 \mathrm{~h}$, then the solvent was evaporated. The residue was purified by flash chromatography (EtOAc/Hex 4:1) giving the desired compound 5 as a colorless oil ( $0.28 \mathrm{mmol}$, quant). ${ }^{1} \mathrm{H}$ NMR $\left(400 \mathrm{MHz}, \mathrm{CDCl}_{3}\right): \delta=8.38-8.36(\mathrm{~d}, J=8,1 \mathrm{H}), 7.37-7.35$ $(\mathrm{d}, J=8,1 \mathrm{H}), 3.88-3.85(\mathrm{t}, J=4,2 \mathrm{H}), 3.42-3.38 \mathrm{ppm}(\mathrm{t}$, $J=4,2 \mathrm{H}) ;{ }^{13} \mathrm{C}$ NMR $\left(100 \mathrm{MHz}, \mathrm{CDCl}_{3}\right): \delta=148.98,140.38$, $135.78,127.22,124.53,119.42,57.13,38.46$ ppm; MS (ESI) $\mathrm{m} / \mathrm{z}: 264[\mathrm{M}+\mathrm{Na}]^{+}$.

\section{General procedure for esters $6 a-c$}

To a suspension of 5 ( $35 \mathrm{mg}, 0.14 \mathrm{mmol}$ ) in dry $\mathrm{CH}_{2} \mathrm{Cl}_{2}$ $(5 \mathrm{~mL})$, the appropriate acyl chloride $(0.43 \mathrm{mmol})$, pyridine $(50 \mu \mathrm{L}, 0.58 \mathrm{mmol})$, and a catalytic amount of DMAP were added. The reaction mixture was stirred at room temperature for $6 \mathrm{~h}$, after which time it was washed with $\mathrm{NaHCO}_{3}$ and then with $1 \mathrm{~N} \mathrm{HCl}$. The combined organic layers were dried over $\mathrm{Na}_{2} \mathrm{SO}_{4}$, filtered off and the solvent removed under reduced pressure. The crude was purified by flash chromatography.

2-(7-Nitrobenzo[c][1,2,5]oxadiazol-4-ylthio)ethyl 4-bromobenzoate (6a): Yellow solid $(0.13 \mathrm{mmol}, 94 \%)$. ${ }^{1} \mathrm{H}$ NMR $\left(400 \mathrm{MHz}, \mathrm{CDCl}_{3}\right): \delta=8.35-8.33(\mathrm{~d}, J=7.8,1 \mathrm{H})$, 7.77-7.75 (d, $J=8.3,2 \mathrm{H}), 7.52-7.50(\mathrm{~d}, J=8.3,2 \mathrm{H}), 7.40-$ $7.38(\mathrm{~d}, J=7.8,1 \mathrm{H}), 4.62-4.59(\mathrm{t}, J=6.7,2 \mathrm{H}), 3.65-3.62 \mathrm{ppm}(\mathrm{t}, J=$ $6.7,2 \mathrm{H}) ;{ }^{13} \mathrm{CNMR}\left(100 \mathrm{MHz}, \mathrm{CDCl}_{3}\right): \delta=165.46,149.22,142.44$, $139.31,133.31,131.87,131.04,130.40,128.78,127.96,121.92$, 62.00, $30.25 \mathrm{ppm}$; MS (ESI) m/z: $447[\mathrm{M}+\mathrm{Na}]^{+}$. 
<smiles>Nc1cc([N+](=O)[O-])ccc1Cl</smiles><smiles>CC(C)Oc1ccc(N2CCN(C)CC2)cc1</smiles>

b: $R=$<smiles>CC(=O)N1CCN(c2ccc(OC(C)C)cc2)CC1</smiles>

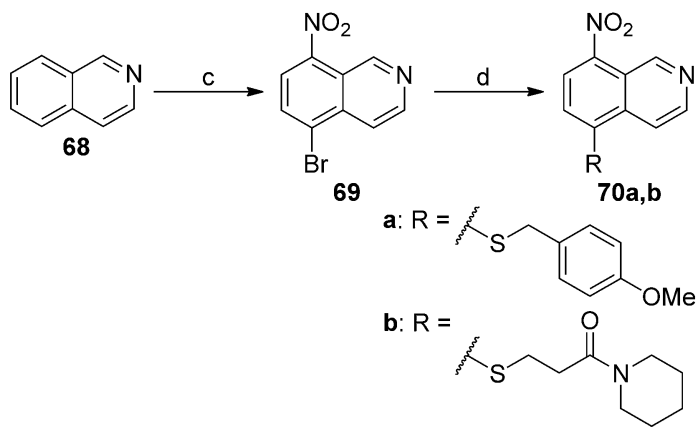

Scheme 9. Reagents and conditions: a) toluene, $100^{\circ} \mathrm{C}, 2 \mathrm{~h}$; b) appropriate nucleophile, $\mathrm{K}_{2} \mathrm{CO}_{3}, \mathrm{DMF}, \mathrm{MW}\left(130^{\circ} \mathrm{C}\right), 10 \mathrm{~min}$; c) 1. NBS, conc $\mathrm{H}_{2} \mathrm{SO}_{4}$ $-25^{\circ} \mathrm{C} /-18^{\circ} \mathrm{C}, 3 \mathrm{~h}$, 2. conc $\mathrm{H}_{2} \mathrm{SO}_{4}, \mathrm{KNO}_{3},-10^{\circ} \mathrm{C}, 1 \mathrm{~h}$; d) appropriate nucleophile, $\mathrm{K}_{2} \mathrm{CO}_{3}, \mathrm{DMF}, \mathrm{MW}\left(130^{\circ} \mathrm{C}\right), 10 \mathrm{~min}$.<smiles>CCCCCCCc1ccc(NC(C)=O)c(F)c1Cl</smiles>

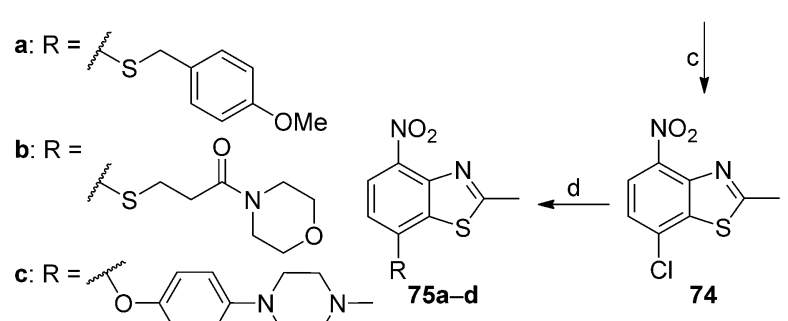<smiles>[10B]CC(C)Oc1ccc(N2CCN(C(C)=O)CC2)cc1</smiles>

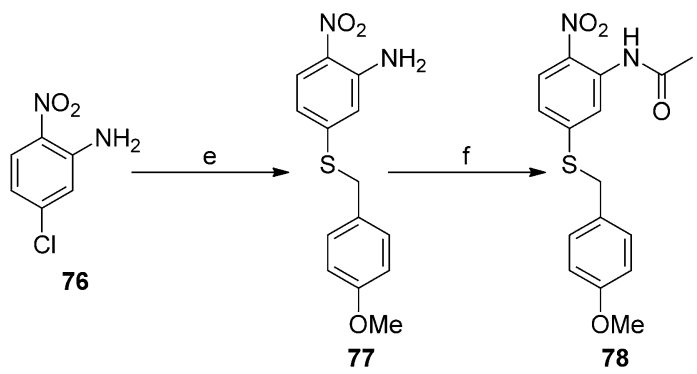

Scheme 10. Reagents and conditions: a) $\mathrm{Ac}_{2} \mathrm{O}$, reflux, $2 \mathrm{~h}$; b) 1. Lawesson's reagent, xylene, $110^{\circ} \mathrm{C}, 2 \mathrm{~h}$. 2. $\mathrm{Cs}_{2} \mathrm{CO}_{3}$, reflux, $16 \mathrm{~h}$; c) conc $\mathrm{H}_{2} \mathrm{SO}_{4}, \mathrm{KNO}_{3}, 1 \mathrm{~h}$, $-10^{\circ} \mathrm{C}$, then $\mathrm{RT}, 2 \mathrm{~h}$; d) appropriate nucleophile, cat. pyridine and/or KOAc, $\mathrm{EtOH}$, reflux, $3 \mathrm{~h}$; e) 4-OMePhSH, $\mathrm{K}_{2} \mathrm{CO}_{3}$, EtOH, reflux, $3 \mathrm{~h}$; f) $\mathrm{Ac}_{2} \mathrm{O}$, reflux, $2 \mathrm{~h}$.
Table 2. In vitro inhibition of the PA-PB1 interaction (ELISA) and ligand efficiency (LE), along with activity (Act) and cytotoxicity (Cytox) of compounds 6-48 toward influenza virus strain A/WSN/33 (H1N1).

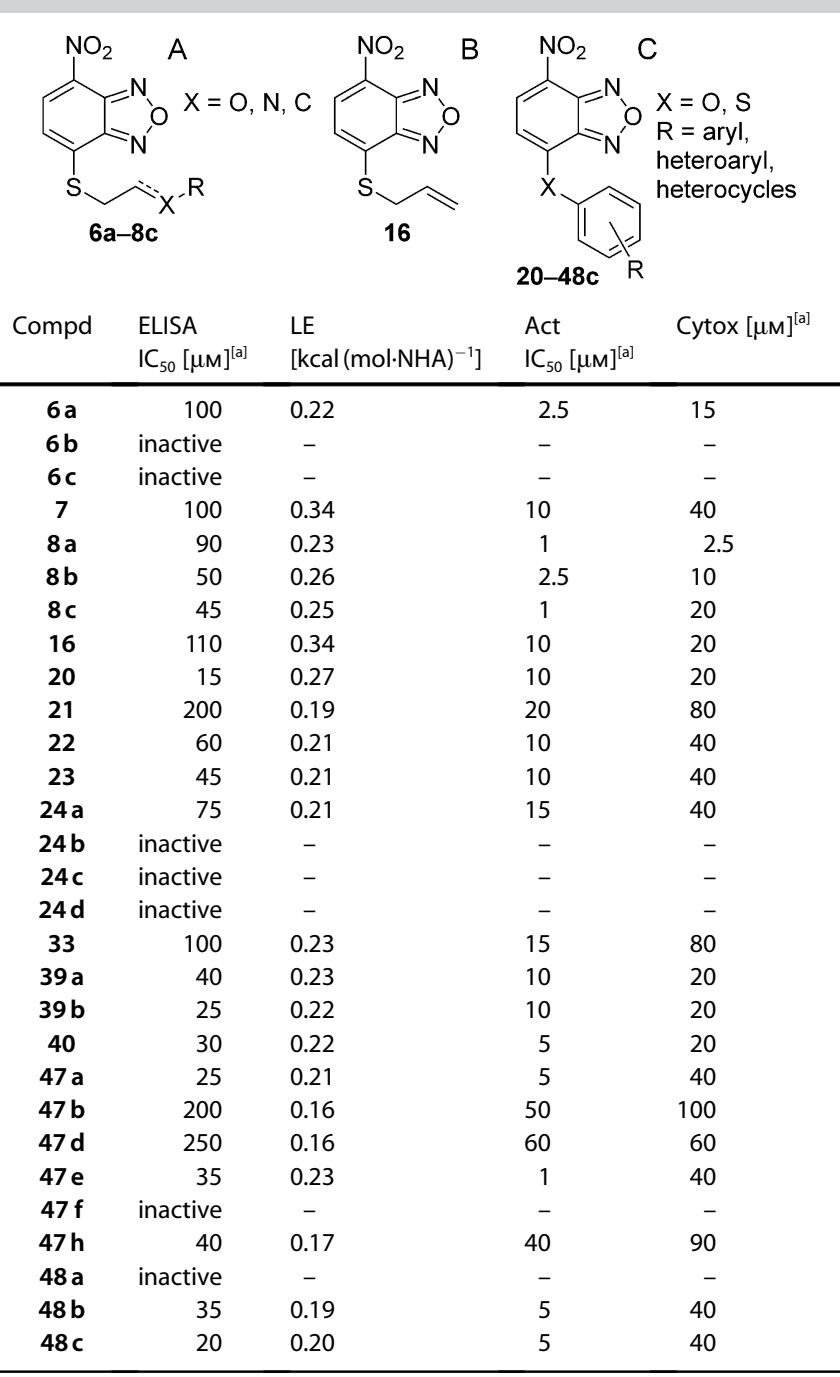

[a] All compounds were tested twice; values are the average of two experiments.

2-(7-Nitrobenzo[c][1,2,5]oxadiazol-4-ylthio)ethyl cinnamate (6 b): Yellow solid (0.12 mmol, 87\%). ${ }^{1} \mathrm{H}$ NMR $\left(400 \mathrm{MHz}, \mathrm{CDCl}_{3}\right): \delta=8.45-$ $8.43(\mathrm{~d}, J=7.8,1 \mathrm{H}), 7.71-7.65(\mathrm{~d}, J=16,1 \mathrm{H}), 7.52-7.39(\mathrm{~m}, 6 \mathrm{H})$, 6.41-6.36 (d, J=16, 1 H), 4.58-4.54 (t, J=7.2, 2H), 3.66-3.62 ppm (t, $J=7.2,2 \mathrm{H}) ;{ }^{13} \mathrm{C} \mathrm{NMR}\left(100 \mathrm{MHz}, \mathrm{CDCl}_{3}\right): \delta=166.83,149.52,146.46$, $142.75,139.97,134.13,131.03,130.88,129.25,128.42,121.92$, 116.97, 61.64, 30.44 ppm; MS (ESI) m/z: $394[M+N a]^{+}$.

2-(7-Nitrobenzo[c][1,2,5]oxadiazol-4-ylthio)ethyl thiophene-2carboxylate (6c): Yellow solid $(0.116 \mathrm{mmol}, 83 \%)$. ${ }^{1} \mathrm{H}$ NMR $\left(400 \mathrm{MHz}, \mathrm{CDCl}_{3}\right): \delta=8.34-8.32(\mathrm{~d}, J=8,1 \mathrm{H}), 7.69-7.68(\mathrm{~m}, 1 \mathrm{H})$, 7.52-7.51 (m, $1 \mathrm{H}), 7.43-7.41(\mathrm{~d}, J=8,1 \mathrm{H}), 7.04-7.02(\mathrm{~m}, 1 \mathrm{H}), 4.60-$ $4.58(\mathrm{t}, J=7.8,2 \mathrm{H}), \quad 3.65-3.62 \mathrm{ppm} \quad(\mathrm{t}, J=7.8,2 \mathrm{H}) ;{ }^{13} \mathrm{C} \mathrm{NMR}$ $\left(100 \mathrm{MHz}, \mathrm{CDCl}_{3}\right): \delta=162.95,143.86,143.48,136.72,134.66,133.82$, $128.98,126.78,124.52,119.13,57.33,36.67$ ppm; MS (ESI) m/z: 260 $[\mathrm{M}+\mathrm{Na}]^{+}$. 


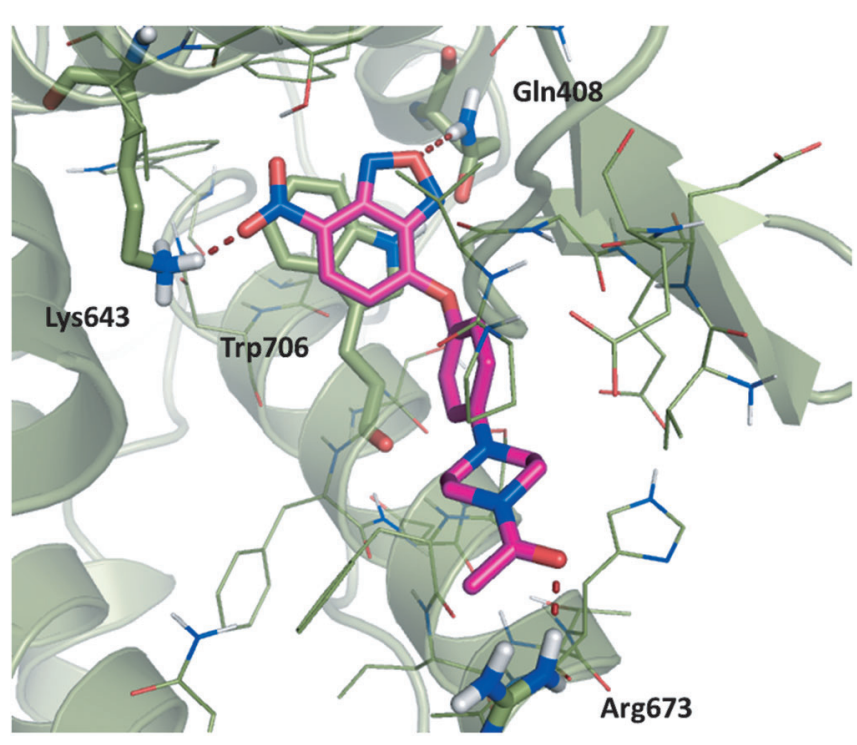

Figure 3. Binding mode of the benzofurazan derivative $39 \mathrm{~b}$.

\section{General procedure (A) for aromatic nucleophilic substitution}

To a solution of 4-chloro-7-nitrobenzofuzan $(50 \mathrm{mg}, 0.25 \mathrm{mmol}$ ) in $5 \mathrm{~mL} \mathrm{EtOH}$, the appropriate nucleophile was added $(0.27 \mathrm{mmol})$. The reaction mixture was heated at reflux for $5 \mathrm{~min}$ and, if the color had not changed, a catalytic amount of pyridine $(0.05 \mathrm{~mL})$ or of KOAC $(0.01 \mathrm{mmol})$ was added, and reflux was continued for a further $20 \mathrm{~min}$. If a strong red coloration did develop within $5 \mathrm{~min}$, no catalyst was added, and reflux was continued for a further $15 \mathrm{~min}$. The mixture was cooled to room temperature, and the precipitate formed was filtered off to give the desired product pure.

7-(2-Aminoethylthio)-4-nitrobenzofurazan (7): Compound 7 was synthesized according the general procedure for aromatic nucleophilic substitution. Yellow solid $(0.217 \mathrm{mmol}, 87 \%)$. ${ }^{1} \mathrm{H}$ NMR (400 MHz, CD 3 OD): $\delta=8.48-8.46(\mathrm{~d}, J=7.9,1 \mathrm{H}), 7.55-7.53(\mathrm{~d}, J=$ $7.9,1 \mathrm{H}), 3.65-3.62,(\mathrm{~m}, 2 \mathrm{H}), 3.35-3.31 \mathrm{ppm}(\mathrm{m}, 2 \mathrm{H}) ;{ }^{13} \mathrm{C}$ NMR $\left(100 \mathrm{MHz}, \mathrm{CDCl}_{3}\right): \delta=149.43,142.68,137.06,133.52,130.99,122.86$, 37.57, 27.78 ppm; MS (ESI) m/z: $241[\mathrm{M}+\mathrm{H}]^{+}$.

\section{General procedure (B) for compounds $8 a-c$ and $9 a-c$}

To a solution of $7(30 \mathrm{mg}, 0.125 \mathrm{mmol})$ in dry $\mathrm{CH}_{2} \mathrm{Cl}_{2}(2 \mathrm{~mL})$, pyridine $(0.15 \mathrm{mmol})$, catalytic amount of DMAP $(0.1)$ and the appropriate acyl chloride $(0.15 \mathrm{mmol})$ were added. The reaction was stirred at room temperature for $6 \mathrm{~h}$ and then was quenched with $\mathrm{NaHCO}_{3}$. The mixture was extracted with EtOAc and washed with $1 \mathrm{~N} \mathrm{HCl}$ and brine. The organic layer was dried over $\mathrm{Na}_{2} \mathrm{SO}_{4}$, filtered off and the solvent was removed. The crude residue was purified by flash chromatography (Hex/EtOAc 1:1).

$N$-(2-(7-Nitrobenzo[c][1,2,5]oxadiazol-4-ylthio)ethyl)benzamide (8a): Yellow solid (0.09 mmol, $62 \%)$. ${ }^{1} \mathrm{H} N M R \quad(400 \mathrm{MHz}$, $\left[\mathrm{D}_{6}\right.$ ] ]acetone): $\delta=8.50-8.48(\mathrm{~d}, J=8,1 \mathrm{H}), 8.19(\mathrm{brs}, 1 \mathrm{H}), 7.83-7.78$ $(\mathrm{m}, 3 \mathrm{H}), 7.48-7.44,(\mathrm{~m}, 1 \mathrm{H}), 7.40-7.36(\mathrm{~m}, 2 \mathrm{H}), 3.79-3.77(\mathrm{~m}, 2 \mathrm{H})$, $3.62-3.59 \mathrm{ppm} \quad(\mathrm{m}, 2 \mathrm{H}) ;{ }^{13} \mathrm{C} \mathrm{NMR}\left(100 \mathrm{MHz}, \quad\left[\mathrm{D}_{6}\right]\right.$ acetone $): \delta=$ $167.07,153.08,149.97,140.35,134.76,131.62,131.40,128.36$ 127.12, 122.23, 38.24, 30.32 ppm; MS (ESI) $\mathrm{m} / \mathrm{z}: 367[\mathrm{M}+\mathrm{Na}]^{+}$.

$N$-(2-(7-Nitrobenzo[c][1,2,5]oxadiazol-4-ylthio)ethyl)thiophene-2carboxamide (8b): Yellow solid $(0.072 \mathrm{mmol}, 58 \%)$. ${ }^{1} \mathrm{H}$ NMR $\left(400 \mathrm{MHz}, \mathrm{CDCl}_{3}\right): \delta=8.51-8.49(\mathrm{~d}, J=8,1 \mathrm{H}), 7.77-7.75(\mathrm{~d}, J=8$,
$1 \mathrm{H}), 7.62-7.59(\mathrm{~m}, 2 \mathrm{H}), 7.05-7.03(\mathrm{~m}, 1 \mathrm{H}), 3.76-3.73(\mathrm{~m}, 2 \mathrm{H}), 3.61-$ $3.57 \mathrm{ppm}(\mathrm{m}, 2 \mathrm{H}) ;{ }^{13} \mathrm{C}$ NMR $\left(100 \mathrm{MHz}, \mathrm{CDCl}_{3}\right): \delta=162.47,143.78$, $141.07,136.53,134.59,133.44,132.71,131.71,130.49,128.17$, 99.53, 44.62, $27.78 \mathrm{ppm}$; MS (ESI) $\mathrm{m} / \mathrm{z}: 373[\mathrm{M}+\mathrm{Na}]^{+}$.

$\mathrm{N}$-(2-(7-Nitrobenzo[c][1,2,5]oxadiazol-4-ylthio)ethyl)nicotinamide (8c): Yellow solid $(0.072 \mathrm{mmol}, 58 \%)$. ${ }^{1} \mathrm{H}$ NMR $\left(400 \mathrm{MHz}, \mathrm{CDCl}_{3}\right): \delta=$ $9.18(\mathrm{~s}, 1 \mathrm{H}), 8.76(\mathrm{brs}, 1 \mathrm{H}), 8.75(\mathrm{brs}, 1 \mathrm{H}), 8.57(\mathrm{brs}, 1 \mathrm{H}), 8.51(\mathrm{~d}$, $1 \mathrm{H}, J=8 \mathrm{~Hz}), 7.78(\mathrm{~d}, 1 \mathrm{H}, J=8 \mathrm{~Hz}), 3.90-3.85(\mathrm{~m}, 2 \mathrm{H}), 3.68-$ $3.64 \mathrm{ppm}(\mathrm{m}, 2 \mathrm{H}) ;{ }^{13} \mathrm{C}$ NMR $\left(100 \mathrm{MHz}, \mathrm{CDCl}_{3}\right): \delta=165.92,147.64$, $146.73,143.74,143.05,135.52,131.46,126.29,122.27,37.43$, 30.17 ppm; MS: (ESI): $\mathrm{m} / \mathrm{z} 345[\mathrm{M}-\mathrm{H}]^{-}, 381[\mathrm{M}+\mathrm{Cl}]^{-}$

\section{S-2-(7-Nitrobenzo[c][1,2,5]oxadiazol-4-ylamino)ethylbenzo-} thioate (9a): Red solid $(0.018 \mathrm{mmol}, 15 \%)$. ${ }^{1} \mathrm{H} \mathrm{NMR}(400 \mathrm{MHz}$, [D $\mathrm{D}_{6}$ ]DMSO): $\delta=8.46(\mathrm{~d}, 1 \mathrm{H}, J=8.3 \mathrm{~Hz}), 7.84(\mathrm{~d}, 2 \mathrm{H}, J=8.5 \mathrm{~Hz}), 7.62$ $(\mathrm{t}, 1 \mathrm{H}, J=8.5 \mathrm{~Hz}), 7.48(\mathrm{t}, 2 \mathrm{H}, J=8.5 \mathrm{~Hz}), 6.50(\mathrm{~d}, 1 \mathrm{H}, J=8.3 \mathrm{~Hz})$, 3.68 (brs, $1 \mathrm{H}), 3.35(\mathrm{t}, 2 \mathrm{H}, J=6.1 \mathrm{~Hz}), 3.23 \mathrm{ppm}(\mathrm{t}, 2 \mathrm{H}, J=6.1 \mathrm{~Hz})$; ${ }^{13} \mathrm{C}$ NMR $\left(100 \mathrm{MHz},\left[\mathrm{D}_{6}\right] \mathrm{DMSO}\right): \delta=199.4,149,143.4,141.4,137.9$, $134.5,132.6,129.7,127,123.8,95.1,68.5,33.3$ ppm.

S-2-(7-Nitrobenzo[c][1,2,5]oxadiazol-4-ylamino)ethylthiophene2-carbothioate (9 b): Red solid $(0.027 \mathrm{mmol}, 22 \%)$. ${ }^{1} \mathrm{H}$ NMR $\left(400 \mathrm{MHz}, \mathrm{CDCl}_{3}\right): \delta=8.47-8.45(\mathrm{~d}, J=8,1 \mathrm{H}), 7.79-7.77(\mathrm{~m}, 1 \mathrm{H})$, 7.65-7.63 (m, $1 \mathrm{H}), 7.10-7.08(\mathrm{~m}, 1 \mathrm{H}), 6.34-6.32(\mathrm{~d}, J=8,1 \mathrm{H}), 3.77-$ $3.75(\mathrm{~m}, 2 \mathrm{H}), 3.39-3.36 \mathrm{ppm}(\mathrm{m}, 2 \mathrm{H}) ;{ }^{13} \mathrm{C} \mathrm{NMR}\left(100 \mathrm{MHz}, \mathrm{CDCl}_{3}\right): \delta=$ $192.33,143.40,140.87,136.17,133.95,133.27,132.11,131.69$, $129.99,128.17,99.02,44.13,27.49$ ppm; MS (ESI) m/z: $373[M+$ $\mathrm{Na}]^{+}$.

\section{General procedure for compounds $10 a, b$}

Benzofurazans $10 \mathrm{a}, \mathbf{b}$ were prepared through the reaction of 3 with 12 or 13 according to general procedure (B).

$N$-Boc-(N-(2-(7-nitrobenzo[c][1,2,5]oxadiazol-4-ylthio)ethyl)guanidine (10a): Yellow solid $(0.088 \mathrm{mmol}, 71 \%)$. ${ }^{1} \mathrm{H} \mathrm{NMR}(400 \mathrm{MHz}$, $\left.\mathrm{CDCl}_{3}\right): \delta=8.60-8.58(\mathrm{~d}, J=8,1 \mathrm{H}), 7.24-7.22(\mathrm{~d}, J=8,1 \mathrm{H}), 3.84-$ $3.82(\mathrm{~m}, 2 \mathrm{H}), 3.73-3.70(\mathrm{~m}, 2 \mathrm{H}), 1.35 \mathrm{ppm}(\mathrm{s}, 9 \mathrm{H}) ;{ }^{13} \mathrm{C} \mathrm{NMR}$ $\left(100 \mathrm{MHz}, \mathrm{CDCl}_{3}\right): \delta=163.12,156.30,153.17,144.23,143.73,136.19$, 124.12, 83.53, 79.47, 39.22, 36.69, 28.13 ppm; MS (ESI) m/z: 483 $[\mathrm{M}+\mathrm{H}]^{+}$.

(S)-2-Amino-3-hydroxy-N-(2-(7-nitrobenzo[c][1,2,5]oxadiazol-4ylthio)ethyl)propanamide hydrochloride $(10 \mathrm{~b})$ : Yellow solid (0.125 mmol, quant). $[\alpha]_{D}:-2.92^{\circ} \quad(c=5.7, \quad \mathrm{MeOH}) ;{ }^{1} \mathrm{H}$ NMR (400 MHz, $\left.\mathrm{CDCl}_{3}\right): \delta=8.45(\mathrm{~d}, 1 \mathrm{H}, J=8 \mathrm{~Hz}$, benzofurazan), $7.55(\mathrm{~d}$, $1 \mathrm{H}, J=8 \mathrm{~Hz}), 3.88-3.85(\mathrm{~m}, 2 \mathrm{H}), 3.78-3.73(\mathrm{~m}, 1 \mathrm{H}), 3.64-3.59(\mathrm{~m}$, $4 \mathrm{H}), 3.47-3.44 \mathrm{ppm}(\mathrm{m}, 2 \mathrm{H}) ;{ }^{13} \mathrm{C} \mathrm{NMR}\left(100 \mathrm{MHz}, \mathrm{CDCl}_{3}\right): \delta=167.20$, $149.38,143.53,142.60,139.23,130.99,121,81,60.14,54.79,37.40$, 29.90 ppm; MS (ESI) m/z: $483[\mathrm{M}+\mathrm{H}]^{+}$.

tert-Butyl-(tert-butoxycarbonylamino) (2- thioethylamino)methylenecarbamate (12): Cysteamine was reacted with protected guanidine according to the general procedure (B). The residue was purified by flash chromatography (Hex/EtOAc 4:1). White solid (0.098 mmol, 79\%). ${ }^{1} \mathrm{H}$ NMR $\left(400 \mathrm{MHz}, \mathrm{CDCl}_{3}\right): \delta=8.53$ (brs, $\left.1 \mathrm{H}\right)$, $3.67-3.69(\mathrm{~m}, 2 \mathrm{H}), 2.80-2.77(\mathrm{~m}, 2 \mathrm{H}), 1.40 \mathrm{ppm}(\mathrm{s}, 18 \mathrm{H}) ;{ }^{13} \mathrm{C} \mathrm{NMR}$ $\left(100 \mathrm{MHz}, \mathrm{CDCl}_{3}\right): \delta=158.78,157.83,161.03,84.92,80.05,40.23$, $27.87 \mathrm{ppm} ; \mathrm{MS}$ (ESI) $\mathrm{m} / \mathrm{z}: 320[\mathrm{M}+\mathrm{H}]^{+}$.

(S)-tert-Butyl-3-hydroxy-1-(2-thioethylamino)-1-oxo-propan-2-ylcarbamate (13): Compound 13 was obtained using the same procedure as for 12, but with cysteamine and Boc-serine as the starting materials $(0.052 \mathrm{mmol}, 42 \%) .[\alpha]_{\mathrm{D}}:-1.76^{\circ}(c=10, \mathrm{MeOH})$; ${ }^{1} \mathrm{H}$ NMR (400 MHz, [D $]$ ]acetone): $\delta=87.47$ (brs, $1 \mathrm{H}$ ), 5.96 (br s, $1 \mathrm{H}$ ), 
4.11-4.08 (m, 1 H), $4.03(\mathrm{brs}, 1 \mathrm{H}), 3.76-3.72(\mathrm{~m}, 1 \mathrm{H}), 3.68-3.63(\mathrm{~m}$, $1 \mathrm{H}), 3.36-3.29(\mathrm{~m}, 2 \mathrm{H}), 2.59-2.53(\mathrm{~m}, 2 \mathrm{H}), 1.78(\mathrm{t}, J=8 \mathrm{~Hz}, 1 \mathrm{H})$, $1.34 \mathrm{ppm}(\mathrm{s}, 9 \mathrm{H}) ;{ }^{13} \mathrm{C}$ NMR $\left(100 \mathrm{MHz}\right.$, [ $\left.\mathrm{D}_{6}\right]$ acetone): $\delta=170.6,155.9$, 78.6, 62.4, 56.3, 42.3, 27.5, 23.6 ppm; MS (ESI) $\mathrm{m} / \mathrm{z}: 287[\mathrm{M}+\mathrm{H}]^{+}$.

1-Morpholino-3-(7-nitrobenzo[c][1,2,5]oxadiazol-4-ylthio)propan1-one (14a): Yellow solid (0.091 mmol, $73 \%)$. 'H NMR $(400 \mathrm{MHz}$, $\left.\mathrm{CDCl}_{3}\right): \delta=8.33-8.31(\mathrm{~d}, J=8,1 \mathrm{H}), 7.21-7.19(\mathrm{~d}, J=8,1 \mathrm{H}), 3.62-$ $3.52(\mathrm{~m}, 8 \mathrm{H}), 3.41-3.38(\mathrm{~m}, 2 \mathrm{H}), 2.81-2.77 \mathrm{ppm}(\mathrm{m}, 2 \mathrm{H}) ;{ }^{13} \mathrm{C}$ NMR $\left(100 \mathrm{MHz}, \mathrm{CDCl}_{3}\right): \delta=168.17,149.06,142.42,141.00,132.64,130.67$, $120.74,66.65,66.33,45.62,42.14,31.56,26.86$ ppm; MS (ESI) $\mathrm{m} / \mathrm{z}$ : $361[\mathrm{M}+\mathrm{Na}]^{+}$.

\section{3-(7-Nitrobenzo[c][1,2,5]oxadiazol-4-ylthio)-1-thiomorpholino-} propan-1-one (14b): Yellow solid $(0.096 \mathrm{mmol}, 77 \%)$. ${ }^{1} \mathrm{H} \mathrm{NMR}$ $\left(400 \mathrm{MHz}, \mathrm{CDCl}_{3}\right): \delta=8.28-8.26(\mathrm{~d}, J=8,1 \mathrm{H}), 7.18-7.16(\mathrm{~d}, J=8$, $1 \mathrm{H}), 3.78-3.64(\mathrm{~m}, 4 \mathrm{H}), 3.49-3.46(\mathrm{~m}, 2 \mathrm{H}), 2.79-2.76(\mathrm{~m}, 2 \mathrm{H}), 2.54-$ $2.51 \mathrm{ppm}(\mathrm{m}, 4 \mathrm{H}) ;{ }^{13} \mathrm{C}$ NMR $\left(100 \mathrm{MHz}, \mathrm{CDCl}_{3}\right): \delta=167.96,149.00$, $142.37,141.17,132.37,130.94,120.71,47.96,44.47,31.76,27.71$, 27.22, $26.92 \mathrm{ppm}$; MS (ESI) $\mathrm{m} / \mathrm{z}: 377[\mathrm{M}+\mathrm{Na}]^{+}$.

Ethyl 3-(7-nitrobenzo[c][1,2,5]oxadiazol-4-ylthio)propanoate (15 a): Yellow solid $(0.095 \mathrm{mmol}, 76 \%)$. ${ }^{1} \mathrm{H}$ NMR $\left(400 \mathrm{MHz}, \mathrm{CDCl}_{3}\right)$ : $\delta=8.34-8.32(\mathrm{~d}, J=8,1 \mathrm{H}), 7.20-7.18(\mathrm{~d}, J=8,1 \mathrm{H}), 4.11-4.06(\mathrm{q}$, $J=8,2 \mathrm{H}), 3.50-3.46(\mathrm{t}, J=8,2 \mathrm{H}), 2.78-2.75(\mathrm{t}, J=8,2 \mathrm{H}), 1.19-$ $1.16 \mathrm{ppm} \quad(\mathrm{t}, J=8,4 \mathrm{H}) ;{ }^{13} \mathrm{C}$ NMR $\left(100 \mathrm{MHz}, \mathrm{CDCl}_{3}\right): \delta=170.56$, $149.08,142.42,140.41,132.64,120.91,61.28,32.88,26.57$, $14.12 \mathrm{ppm} ; \mathrm{MS}(\mathrm{ESI}) \mathrm{m} / \mathrm{z}: 320[\mathrm{M}+\mathrm{Na}]^{+}$.

(R)-Ethyl-2-(tert-butoxycarbonylamino)-3-(7-nitrobenzo[c][1,2,5]oxadiazol-4yl-thio)propanoate (15 b): Yellow solid (0.086 mmol, 69\%). 'H NMR ( $\left.400 \mathrm{MHz}, \mathrm{CD}_{3} \mathrm{OD}\right): \delta=8.53-8.51$ (d, $J=8,1 \mathrm{H}), 7.55-7.53(\mathrm{~d}, J=8,1 \mathrm{H}), 4.55-4.51(\mathrm{~m}, 1 \mathrm{H}), 4.26-4.18(\mathrm{~m}$, $2 \mathrm{H})$, 3.92-3.87 $(\mathrm{m}, 1 \mathrm{H}), 3.64-3.59(\mathrm{~m}, 1 \mathrm{H}), 1.41(\mathrm{~s}, 9 \mathrm{H}), 1.31-$ $1.28 \mathrm{ppm}(\mathrm{m}, 3 \mathrm{H}) ;{ }^{13} \mathrm{C}$ NMR $\left(100 \mathrm{MHz}, \mathrm{CD}_{3} \mathrm{OD}\right): \delta=169.49,155.01$, $149.23,142.38,139.67,133.20,130.55,121.29,80.83,62.52,52.85$, 33.88, 28.1514 .06 ppm; MS (ESI) $\mathrm{m} / \mathrm{z}: 413[\mathrm{M}+\mathrm{H}]^{+}$.

4-(Allylthio)-7-nitrobenzo[c][1,2,5]oxadiazole (16): Yellow solid ( $0.113 \mathrm{mmol}, 91 \%)$. ${ }^{1} \mathrm{H}$ NMR $\left(400 \mathrm{MHz}, \mathrm{CDCl}_{3}\right): \delta=8.33-8.31$ (d, $J=$ 7.9, $1 \mathrm{H}), 7.15-7.13(\mathrm{~d}, J=7.9,2 \mathrm{H}), 5.94-5.84(\mathrm{~m}, 1 \mathrm{H}), 5.40-5.25(\mathrm{~m}$, $2 \mathrm{H}), 3.90-3.88 \mathrm{ppm}(\mathrm{m}, 2 \mathrm{H}) ;{ }^{13} \mathrm{C}$ NMR $\left(100 \mathrm{MHz}, \mathrm{CDCl}_{3}\right): \delta=148.92$, $142.45,137.41,135.82,133.25,131.02,130.76,123.25,122.68$, $119.43,37.66 \mathrm{ppm} ; \mathrm{MS}(\mathrm{ESI}) \mathrm{m} / \mathrm{z}: 260[\mathrm{M}+\mathrm{Na}]^{+}$

3-Thio-1-morpholinopropan-1-one (18a): Morpholine (100 $\mu \mathrm{L}$, $1.147 \mathrm{mmol})$ was dissolved in dry $\mathrm{CH}_{2} \mathrm{Cl}_{2}(10 \mathrm{~mL})$ and cooled to $0{ }^{\circ} \mathrm{C}$. Then 3-thiopropionic acid $(100 \mu \mathrm{L}, 1.147 \mathrm{mmol})$, EDC (200 mg, $1.043 \mathrm{mmol}), \mathrm{HOBt}(141 \mathrm{mg}, 1.043 \mathrm{mmol})$ and DIPEA $(218 \mu \mathrm{L}$, $1.251 \mathrm{mmol}$ ) were added and the mixture was stirred at room temperature for $16 \mathrm{~h}$. The reaction mixture was quenched with saturated aqueous solution of $\mathrm{NaHCO}_{3}(10 \mathrm{~mL})$ and extracted with EtOAc $(3 \times 10 \mathrm{~mL})$. The combined extract was dried over anhydrous $\mathrm{Na}_{2} \mathrm{SO}_{4}$ and evaporated to dryness. The crude product was purified by flash chromatography (EtOAc/Hex 9:1) to provide desired compound $(0.48 \mathrm{mmol}, 42 \%)$. ${ }^{1} \mathrm{H}$ NMR $\left(400 \mathrm{MHz}, \mathrm{CDCl}_{3}\right): \delta=3.45$ (brs, $4 \mathrm{H}), 3.39$ (brs, $2 \mathrm{H}), 3.26(\mathrm{brs}, 2 \mathrm{H}), 2.61-2.56(\mathrm{~m}, 2 \mathrm{H}), 2.44-2.41(\mathrm{~m}$, $2 \mathrm{H}), 1.55 \mathrm{ppm}(\mathrm{t}, J=8 \mathrm{~Hz}, 1 \mathrm{H}) ;{ }^{13} \mathrm{C}$ NMR $\left(100 \mathrm{MHz}, \mathrm{CDCl}_{3}\right): \delta=$ $169.2,66.6,66.3,45.5,41.7,36.7,18.8 \mathrm{ppm}$.

3-Thio-1-thiomorpholinopropan-1-one (18b): To a solution of thiomorpholine $(172 \mu \mathrm{L}, 1.71 \mathrm{mmol})$ in dry DMF $(5 \mathrm{~mL})$ previously cooled to $0^{\circ} \mathrm{C}$, 3-thiopropionic acid $125(164 \mu \mathrm{L}, 1.88 \mathrm{mmol})$, EDC $(328 \mathrm{mg}, 1.71 \mathrm{mmol}), \mathrm{HOBt}(231 \mathrm{mg}, 1.71 \mathrm{mmol})$, and DIPEA (338 mL, $2.05 \mathrm{mmol}$ ) were added. The reaction mixture was allowed to stir at room temperature for $10 \mathrm{~h}$. After that time $\mathrm{NaHCO}_{3}$ was added and the mixture was extracted with EtOAc.
The organic layer was dried over $\mathrm{Na}_{2} \mathrm{SO}_{4}$, filtered off and the solvent removed under reduced pressure. The crude was purified by flash chromatography (Hex/EtOAc 20:80) to give the desired amide as a yellow oil $(1.28 \mathrm{mmol}, 75 \%)$. ${ }^{1} \mathrm{H}$ NMR $\left(400 \mathrm{MHz}, \mathrm{CDCl}_{3}\right): \delta=$ 3.69-3.67 (m, 4H), 3.55-3.53 (m, 4H), 2.64-2.59 (m, 2H), 2.47-2.44 $(\mathrm{m}, 2 \mathrm{H}), 1.60-1.56 \mathrm{ppm}(\mathrm{m}, 1 \mathrm{H}) ;{ }^{13} \mathrm{C}$ NMR $\left(100 \mathrm{MHz}, \mathrm{CDCl}_{3}\right): \delta=$ $169.00,47.91,44.19,37.10,27.68,27.24,19.94$ ppm; MS (ESI) m/z: $214[\mathrm{M}+\mathrm{Na}]^{+}$

\section{4-(3-(1H-Imidazol-1-yl)phenylthio)-7-nitrobenzo[c]-}

[1,2,5]oxadiazole (20): Compound $19(0.38 \mathrm{mmol})$ was dissolved into a solution of $\mathrm{H}_{2} \mathrm{O} /$ dioxane $(3: 1 \mathrm{~mL})$ and $\mathrm{H}_{3} \mathrm{PO}_{4}$ was added until $\mathrm{pH} 2$ was reached. Solid paraformaldehyde $(15 \mathrm{mg})$, glyoxal sol. $40 \%$ in $\mathrm{H}_{2} \mathrm{O}(0.1 \mathrm{~mL})$, and $\mathrm{NH}_{4} \mathrm{Cl}$ saturated solution $(0.5 \mathrm{~mL})$ were then added and the resulting mixture was irradiated by microwave for $10 \mathrm{~min}$ at $120^{\circ} \mathrm{C}$. The mixture was then cooled to $0^{\circ} \mathrm{C}$, and $\mathrm{NaOH}$ was added to $\mathrm{pH} 12$. The alkaline solution was extracted with EtOAc $(2 \times 10 \mathrm{~mL})$. The combined organic layers were washed with brine, dried $\left(\mathrm{Na}_{2} \mathrm{SO}_{4}\right)$, filtered and evaporated to give the crude 11. The crude product was then purified by flash chromatography (EtOAc/MeOH 9:1) $(0.17 \mathrm{mmol}, 45 \%)$. ${ }^{1} \mathrm{H} \mathrm{NMR}(400 \mathrm{MHz}$, $\left.\mathrm{CDCl}_{3}\right): \delta=8.21(\mathrm{~d}, J=8 \mathrm{~Hz}, 1 \mathrm{H}), 7.96,(\mathrm{~s}, 1 \mathrm{H}), 7.70(\mathrm{~s}, 1 \mathrm{H}), 7.67-$ $7.58(\mathrm{~m}, 3 \mathrm{H}), 7.28,(\mathrm{~s}, 1 \mathrm{H}), 7.19(\mathrm{~s}, 1 \mathrm{H}), 6.75 \mathrm{ppm}(\mathrm{d}, J=8 \mathrm{~Hz}, 1 \mathrm{H})$; ${ }^{13} \mathrm{C} \mathrm{NMR} \quad\left(100 \mathrm{MHz}, \quad \mathrm{CDCl}_{3}\right): \delta=149.03,142.89,138.84,136.77$, $136.28,133.97,132.52,131.93,130.03,129.89,125.74,125.25$, 122.51, 121.37, 116.71 ppm; MS (ESI) $\mathrm{m} / \mathrm{z}: 340[\mathrm{M}+\mathrm{H}]^{+}$.

4-Methyl-N-(3-(7-nitrobenzo[c][1,2,5]oxadiazol-4-ylthio)phenylcarbamoyl)benzenesulfonamide (21): To a solution of compound $19(0.2 \mathrm{mmol})$ in dry $\mathrm{CH}_{2} \mathrm{Cl}_{2}(4 \mathrm{~mL})$ was added $p$-toluenesulfonyl isocyanate (1.5 equiv) and the solution was stirred at room temperature for $24 \mathrm{~h}$. The mixture was then concentrated in vacuo, and the crude product was purified by flash chromatography (EtOAc/ $\mathrm{MeOH}$ 9:1) (0.116 mmol, $58 \%)$. ${ }^{1} \mathrm{H}$ NMR $\left(400 \mathrm{MHz},\left[\mathrm{D}_{6}\right] \mathrm{DMSO}\right): \delta=$ 8.75 (brs, $1 \mathrm{H}), 8.41(\mathrm{~d}, J=8 \mathrm{~Hz}, 1 \mathrm{H}), 7.86(\mathrm{brs}, 1 \mathrm{H}) 7.65-7.59(\mathrm{~m}$, $3 \mathrm{H}), 7.47(\mathrm{~d}, J=8 \mathrm{~Hz}, 1 \mathrm{H}), 7.33-7.29(\mathrm{~m}, 1 \mathrm{H}) 7.12(\mathrm{~d}, J=8 \mathrm{~Hz}, 1 \mathrm{H})$, $7.55(\mathrm{~d}, 1 \mathrm{H}, J=8 \mathrm{~Hz}), 6.71(\mathrm{~d}, J=8 \mathrm{~Hz}, 1 \mathrm{H}), 2.23 \mathrm{ppm}(\mathrm{s}, 1 \mathrm{H})$; ${ }^{13} \mathrm{C}$ NMR (100 MHz, [D 6 DMSO): $\delta=157.95,151.23,148.82,144.44$, $143.53,143.19,142.23,141.12,140.07,133.09,130.91,129.19$, 128.60, 126.94, 125.49, 123.64, 120.35 ppm; MS (ESI) m/z: 484 $[\mathrm{M}-\mathrm{H}]^{-}$.

4,6-Dichloro- $N$-(3-(7-nitrobenzo[c][1,2,5]oxadiazol-4-ylthio)phenyl)-1,3,5-triazin-2-amine (22): To a stirred solution of cyanuric chloride $\left(51 \mathrm{mg}, 0.8\right.$ equiv) in DME $(10 \mathrm{~mL})$ at $-30^{\circ} \mathrm{C}$, compound 19 (100 mg, 1 equiv) was added and the resulting mixture was stirred at $-30^{\circ} \mathrm{C}$ for $1 \mathrm{~h}$. The reaction mixture was then warmed to room temperature, diluted with EtOAc, washed with saturated aqueous solution of $\mathrm{NaHCO}_{3}(10 \mathrm{~mL})$, dried and concentrated in vacuo. The crude product was purified by flash chromatography (Hex/EtOAc 3:1) (0.263 mmol, 76\%). ${ }^{1} \mathrm{H}$ NMR $\left(400 \mathrm{MHz}, \mathrm{CDCl}_{3}\right): \delta=$ $8.22(\mathrm{~d}, J=8 \mathrm{~Hz}, 1 \mathrm{H}), 7.91(\mathrm{~s}, 1 \mathrm{H}) 7.75(\mathrm{brs}, 1 \mathrm{H}) 7.67(\mathrm{~d}, J=8 \mathrm{~Hz}$, $1 \mathrm{H}), 7.57-7.53(\mathrm{t}, J=8 \mathrm{~Hz}, 1 \mathrm{H}), 7.46(\mathrm{~d}, J=8 \mathrm{~Hz}, 1 \mathrm{H}), 6.79 \mathrm{ppm}(\mathrm{d}$, $J=8 \mathrm{~Hz}, 1 \mathrm{H}) ;{ }^{13} \mathrm{C}$ NMR $\left(100 \mathrm{MHz}, \mathrm{CDCl}_{3}\right): \delta=178.48,165.48,156.26$, $155.05,150.62,144.85,141.60,141.35,135.07,132.22,128.88$, 125.69, 118.07, $117.65 \mathrm{ppm}$; MS (ESI) m/z: 434-438 [M-H] ${ }^{-}$.

4,6-Dichloro- $N$-(3-(7-nitrobenzo[c][1,2,5]oxadiazol-4-ylthio)phenyl)-1,3,5-triazin-2-aminium chloride (23): To a solution of compound 22 (1 equiv) in $\mathrm{CH}_{2} \mathrm{Cl}_{2}$, a $1 \mathrm{M}$ solution of $\mathrm{HCl}$ in $\mathrm{MeOH}$ ( 2 equiv) was added dropwise. The mixture was stirred at room temperature for $2 \mathrm{~min}$, then the solvent was removed in vacuo to give the desired pure product $(0.31 \mathrm{mmol}$, quant $)$. ${ }^{1} \mathrm{H} \mathrm{NMR}$ (400 MHz, [D $\mathrm{D}_{6}$ ]acetone): $\delta=10.09(\mathrm{~s}, 1 \mathrm{H}), 8.43(\mathrm{~d}, J=8 \mathrm{~Hz}, 1 \mathrm{H}), 8.11$ $(\mathrm{s}, 1 \mathrm{H}) 7.90(\mathrm{~d}, J=8 \mathrm{~Hz}, 1 \mathrm{H}), 7.64-7.60(\mathrm{t}, J=8 \mathrm{~Hz}, 1 \mathrm{H}), 7.52(\mathrm{~d}, J=$ 
$8 \mathrm{~Hz}, 1 \mathrm{H}), 7.03(\mathrm{~d}, J=8 \mathrm{~Hz}, 1 \mathrm{H}), 2.88 \mathrm{ppm}(\mathrm{brs}, 1 \mathrm{H}) ;{ }^{13} \mathrm{C} \mathrm{NMR}$ (100 MHz, [D $\mathrm{D}_{6}$ acetone): $\delta=179.21,165.83,156.31,155.02,150.82$, $145.15,141.77,141.46,135.12,132.32,129.02,126.08,118.23$, $118.12 \mathrm{ppm}$; MS (ESI) m/z: 434-438 [M-H] $]^{-}$.

\section{General procedure (C) for reductive amination}

To a solution of compound 19 (1.0 equiv) in DCE the appropriate aldehyde (1.0 equiv) was added and the mixture was stirred at room temperature for $10 \mathrm{~min}$. Then a 1:1 mixture of $\mathrm{NaBH}_{4} / \mathrm{PTSA}$ ( 1 equiv) was added and the suspension was stirred at room temperature for $16 \mathrm{~h}$. The reaction mixture was quenched with saturated aqueous solution of $\mathrm{NaHCO}_{3}(10 \mathrm{~mL})$ and extracted with $\mathrm{CH}_{2} \mathrm{Cl}_{2}$ $(3 \times 10 \mathrm{~mL})$. The combined extract was dried over anhydrous $\mathrm{Na}_{2} \mathrm{SO}_{4}$, filtered and concentrated. The crude products obtained were further purified by a flash column chromatography on silica gel (Hex/EtOAc 3:1).

$\mathrm{N}$-Benzyl-3-(7-nitrobenzo[c][1,2,5] oxadiazol-4-ylthio)benzenamine (24a): (0.28 mmol, $91 \%)$. ${ }^{1} \mathrm{H}$ NMR $\left(400 \mathrm{MHz}, \mathrm{CDCl}_{3}\right): \delta=8.10$ $(\mathrm{d}, J=8 \mathrm{~Hz}, 1 \mathrm{H}), 7.28-7.23(\mathrm{~m}, 5 \mathrm{H}), 6.91(\mathrm{~d}, J=8 \mathrm{~Hz}, 1 \mathrm{H}), 6.78(\mathrm{~s}$, $1 \mathrm{H}), 6.59(\mathrm{~d}, J=8 \mathrm{~Hz}, 1 \mathrm{H}), 4.30 \mathrm{ppm}(\mathrm{s}, 2 \mathrm{H}) ;{ }^{13} \mathrm{C} \mathrm{NMR}(100 \mathrm{MHz}$, $\left.\mathrm{CDCl}_{3}\right): \delta=152.82,146.40,141.57,141.44,135.74,134.64,134.31$, 134.14, 132.0, 130.79, 130.62, 130.03, 127.06, 124.46, 121.71, 119.07, $51.11 \mathrm{ppm} ; \mathrm{MS}(\mathrm{ESI}) \mathrm{m} / \mathrm{z}: 377[\mathrm{M}-\mathrm{H}]^{-}, 413\left[\mathrm{M}+\mathrm{Cl}^{-}\right.$.

$\mathrm{N}$-(Biphenyl-4-ylmethyl)-3-(7-nitrobenzo[c][1,2,5]oxa-diazol-4ylthio)benzenamine (24b): (0.27 mmol, $87 \%)$. ' $\mathrm{H} \mathrm{NMR}(400 \mathrm{MHz}$, $\left.\mathrm{CDCl}_{3}\right): \delta=8.09(\mathrm{~d}, J=8 \mathrm{~Hz}, 1 \mathrm{H}), 7.52-7.48(\mathrm{~m}, 4 \mathrm{H}), 7.39-7.34(\mathrm{~m}$, $4 \mathrm{H}), 7.31-7.26(\mathrm{~m}, 2 \mathrm{H}), 6.91(\mathrm{~d}, J=8 \mathrm{~Hz}, 1 \mathrm{H}), 6.81(\mathrm{~s}, 1 \mathrm{H}), 6.61(\mathrm{~d}$, $J=8 \mathrm{~Hz}, 1 \mathrm{H}), 4.35 \mathrm{ppm}(\mathrm{s}, 2 \mathrm{H}) ;{ }^{13} \mathrm{C} \mathrm{NMR}\left(100 \mathrm{MHz}, \mathrm{CDCl}_{3}\right): \delta=$ $152.62,151.45,146.17,145.50,143.58,143.41,140.19,134.31$, $133.79,132.40,132.27,132.19,131.87,130.83,130.47,129.93$, 126.88, 124.18, 121.50, 118.82, 50.66 ppm; MS (ESI) m/z: 453 $[\mathrm{M}-\mathrm{H}]^{-}$.

$N$-(Naphthalen-2-ylmethyl)-3-(7-nitrobenzo[c][1,2,5]oxadiazol-4ylthio)benzenamine (24c): (0.26 mmol, $85 \%)$. ${ }^{1} \mathrm{H} \mathrm{NMR}(400 \mathrm{MHz}$, $\left.\mathrm{CDCl}_{3}\right): \delta=7.74(\mathrm{~d}, J=8 \mathrm{~Hz}, 1 \mathrm{H}), 7.69-7.64(\mathrm{~m}, 4 \mathrm{H}), 7.43-7.36(\mathrm{~m}$, $3 \mathrm{H}), 7.28-7.24(\mathrm{~m}, 1 \mathrm{H}), 6.88(\mathrm{~d}, J=8 \mathrm{~Hz}, 1 \mathrm{H}), 6.82(\mathrm{~d}, J=8 \mathrm{~Hz}, 1 \mathrm{H})$, $6.75(\mathrm{~s}, 1 \mathrm{H}), 6.35(\mathrm{~d}, J=8 \mathrm{~Hz}, 1 \mathrm{H}), 4.48 \mathrm{ppm}(\mathrm{s}, 2 \mathrm{H}) ;{ }^{13} \mathrm{C} \mathrm{NMR}$ $\left(100 \mathrm{MHz}, \mathrm{CDCl}_{3}\right): \delta=144.30,143.92,134.97,134.81,134.28,133.89$, $132.86,132.16,130.65,130.17,129.24,129.01,128.16,127.72$, $127.44,126.81,125.22,122.53,119.93,117.82,49.49$ ppm; MS (ESI) $\mathrm{m} / \mathrm{z}: 427[\mathrm{M}-\mathrm{H}]^{-}, 463[\mathrm{M}+\mathrm{Cl}]^{-}$.

3-(7-Nitrobenzo[c][1,2,5]oxadiazol-4-ylthio)- $N$-(3-phenoxybenzyl)benzenamine (24d): (0.266 mmol, $86 \%)$. ${ }^{1} \mathrm{H}$ NMR $(400 \mathrm{MHz}$, $\left.\mathrm{CDCl}_{3}\right): \delta=8.12(\mathrm{~d}, J=8 \mathrm{~Hz}, 1 \mathrm{H}), 7.28-7.21(\mathrm{~m}, 4 \mathrm{H}), 7.05-7.00(\mathrm{~m}$, $2 \mathrm{H}), 6.94-6.88(\mathrm{~m}, 4 \mathrm{H}), 6.84(\mathrm{~d}, J=8 \mathrm{~Hz}, 1 \mathrm{H}), 6.75(\mathrm{~s}, 1 \mathrm{H}), 6.59(\mathrm{~d}$, $J=8 \mathrm{~Hz}, 1 \mathrm{H}), 4.29 \mathrm{ppm}(\mathrm{s}, 2 \mathrm{H}) ;{ }^{13} \mathrm{C}$ NMR $\left(100 \mathrm{MHz}, \mathrm{CDCl}_{3}\right): \delta=$ $158.69,158.61,152.30,150.49,144.77,143.97,142.67,134.53$, $133.03,131.97,127.88,125.33,124.90,124.29,123.69,123.29$, $121.27,120.64,120.40,119.64,119.43,118.95,118.81,117.09$, $47.90 \mathrm{ppm} ; \mathrm{MS}(\mathrm{ESI}) \mathrm{m} / \mathrm{z}: 469[\mathrm{M}-\mathrm{H}]^{-}$.

\section{General procedure for Sonogashira reaction}

An oven-dried screw-cap tube was charged with 4-iodophenol $(100 \mathrm{mg}, 0.45 \mathrm{mmol})$, the appropriate alkyne $(0.49 \mathrm{mmol}), \mathrm{Cul}$ $(0.005 \mathrm{mmol})$, and $\mathrm{PdCl}_{2}\left(\mathrm{PPh}_{3}\right)_{2}(0.005 \mathrm{mmol})$. The reaction mixture was suspended in a DMF/Et ${ }_{3} \mathrm{~N}$ mixture $(0.5: 1 \mathrm{~mL})$ and heated under microwave for $5 \mathrm{~min}$ at $120^{\circ} \mathrm{C}$. After that time the mixture was poured into $0.1 \mathrm{~N} \mathrm{HCl}$ and extracted with $\mathrm{Et}_{2} \mathrm{O}$. The combined organic layers were washed with $\mathrm{NaHCO}_{3}$, dried over $\mathrm{Na}_{2} \mathrm{SO}_{4}$ fil- tered off and the solvent was removed. The crude residue was purified by flash chromatography (Hex/EtOAc 4:1) to give the desired product.

4-(p-Phenylethynyl)phenol $\quad(26 \mathrm{a}): \quad(0.35 \mathrm{mmol}, \quad 79 \%) . \quad{ }^{1} \mathrm{H} \mathrm{NMR}$ (400 MHz, CD $\mathrm{OD}): \delta=7.61-7.59(\mathrm{~m}, 2 \mathrm{H}), 7.48-7.36(\mathrm{~m}, 5 \mathrm{H}), 6.91-$ $6.89(\mathrm{~m}, 2 \mathrm{H}), 5.78 \mathrm{ppm}(\mathrm{brs}, 1 \mathrm{H}) ;{ }^{13} \mathrm{C} \mathrm{NMR}\left(100 \mathrm{MHz}, \mathrm{CDCl}_{3}\right): \delta=$ $157.35,133.82,132.65,128.47,128.43,128.37,127.32,115.78$, 115.46, $89.88 \mathrm{ppm}$; MS (ESI) $\mathrm{m} / \mathrm{z}: 195[\mathrm{M}+\mathrm{H}]^{+}$.

4-(p-Tolylethynyl)phenol (26 b): $\quad(0.33 \mathrm{mmol}, \quad 75 \%) . \quad{ }^{1} \mathrm{H}$ NMR (400 MHz, CD $\mathrm{OD}): \delta=7.38-7.36(\mathrm{~d}, J=8,4 \mathrm{H}), 7.10-7.08(\mathrm{~d}, J=8$, $2 \mathrm{H}), 6.75-6.73(\mathrm{~d}, J=8,2 \mathrm{H}), 2.31 \mathrm{ppm}(\mathrm{s}, 3 \mathrm{H}) ;{ }^{13} \mathrm{C}$ NMR $(100 \mathrm{MHz}$, $\left.\mathrm{CDCl}_{3}\right): \delta=157.98,137.96,133.56,132.15,130.89,128.32,119.83$, 116.01, 115.65, 89.65, 22.87 ppm; MS (ESI) m/z: $209[M+H]^{+}$.

4-((6-Methoxynaphthalen)ethynyl)phenol $\quad$ (26c): $\quad(0.34 \mathrm{mmol}$, $78 \%)$. ${ }^{1} \mathrm{H}$ NMR $\left(400 \mathrm{MHz}, \mathrm{CD}_{3} \mathrm{OD}\right): \delta=7.88(\mathrm{~s}, 1 \mathrm{H}), 7.69-7.61(\mathrm{~m}$, $2 \mathrm{H}), 7.47-7.45(\mathrm{~m}, 1 \mathrm{H}), 7.10-7.08(\mathrm{~m}, 1 \mathrm{H}), 7.05(\mathrm{~s}, 1 \mathrm{H}), 6.77-$ $6.75 \mathrm{ppm}(\mathrm{m}, 2 \mathrm{H}) ;{ }^{13} \mathrm{C}$ NMR $\left(100 \mathrm{MHz}, \mathrm{CDCl}_{3}\right): \delta=158.72,157.33$, $135.02,134.25,133.78,132.32,129.97,129.78,128.92,127.34$, $119.01,117.98,115.67,115.89,94.75,89.82,55.98$ ppm; MS (ESI) m/ $z: 275[M+\mathrm{H}]+$.

4-(3-(4-Methoxybenzyloxy)prop-1-ynyl)phenol (26 d): $(0.27 \mathrm{mmol}$, $61 \%)$. 'H NMR (400 MHz, CD $\mathrm{OD}$ ): $\delta=7.27-7.25(\mathrm{~d}, J=8,4 \mathrm{H}), 6.84-$ $6.82(\mathrm{~d}, J=8,2 \mathrm{H}), 6.69-6.67(\mathrm{~d}, J=8,2 \mathrm{H}), 4.55(\mathrm{~s}, 2 \mathrm{H}), 4.29(\mathrm{~s}, 2 \mathrm{H})$, $3.74 \mathrm{ppm}(\mathrm{s}, 3 \mathrm{H}) ;{ }^{13} \mathrm{C} \mathrm{NMR}\left(100 \mathrm{MHz}, \mathrm{CDCl}_{3}\right): \delta=158.35,157.98$, $134.22,130.01,129.42,127.89,116.02,115.56,114.77,97.01,87.02$, 57.53, 54.98 ppm; MS (ESI) m/z: $269\left[M+\mathrm{H}^{+}\right.$.

4-Nitro-7-(4-(phenylethynyl)phenoxy)benzo[c][1,2,5]oxadiazole (27a): According to general procedure (A) for aromatic nucleophilic substitution. Compound was obtained as a yellow solid $(0.21 \mathrm{mmol}, 65 \%){ }^{1} \mathrm{H}$ NMR $\left(400 \mathrm{MHz}, \mathrm{CDCl}_{3}\right): \delta=8.37-8.35$ (d, $J=$ $7.8,1 \mathrm{H}), 7.57-7.55(\mathrm{~d}, J=8,2 \mathrm{H}), 7.26-7.24(\mathrm{~d}, J=8,2 \mathrm{H}), 7.15-7.13$ $(\mathrm{d}, J=8,2 \mathrm{H}), 6.97-6.95(\mathrm{~d}, J=8,2 \mathrm{H}), 6.51-6.49 \mathrm{ppm}(\mathrm{d}, J=7.8$, $1 \mathrm{H}) ;{ }^{13} \mathrm{C}$ NMR $\left(100 \mathrm{MHz}, \mathrm{CDCl}_{3}\right): \delta=159.67,148.77,144.86,141.03$, $137.89,135.84,133.31,133.07,131.48,120.53,118.91,118.73$, 117.85, 117.58, 90.43, 90.41 ppm; MS (ESI) m/z: $380[\mathrm{M}+\mathrm{Na}]^{+}$.

4-Nitro-7-(4-( $p$-tolylethynyl)phenoxy)benzo[c][1,2,5]oxadiazole (27 b): According to general procedure (A) for aromatic nucleophilic substitution. Compound was obtained as a yellow solid (0.2 mmol, 66\%). ' $\mathrm{H}$ NMR (400 MHz, CD $\mathrm{OD}): \delta=8.36-8.34$ (d, $J=$ $7.8,1 \mathrm{H}), 7.55-7.53(\mathrm{~d}, J=8,2 \mathrm{H}), 7.27-7.25(\mathrm{~d}, J=8,2 \mathrm{H}), 7.16-7.14$ $(\mathrm{d}, J=8,2 \mathrm{H}), 6.94-6.92(\mathrm{~d}, J=8,2 \mathrm{H}), 6.52-6.50 \mathrm{ppm}(\mathrm{d}, J=7.8$, $1 \mathrm{H}) ;{ }^{13} \mathrm{C}$ NMR $\left(100 \mathrm{MHz}, \mathrm{CDCl}_{3}\right): \delta=158.43,147.61,144.56,140.28$, $137.45,135.21,133.87,133.52,130.07,120.35,118.62,118.03$, $117.51,117.36,90.45,90.41,23.67$ ppm; MS (ESI) m/z: $394[M+$ $\mathrm{Na}]^{+}$.

4-(4-((6-Methoxynaphthalen-2-yl)ethynyl)phenoxy)-7nitrobenzo[c][1,2,5]oxadiazole (27c): According to general procedure (A) for aromatic nucleophilic substitution. Compound was obtained as a yellow solid $(0.21 \mathrm{mmol}, 68 \%)$. ${ }^{1} \mathrm{H} \mathrm{NMR}(400 \mathrm{MHz}$, $\left.\mathrm{CD}_{3} \mathrm{OD}\right): \delta=8.37-8.35(\mathrm{~d}, J=8,1 \mathrm{H}), 7.93(\mathrm{~s}, 1 \mathrm{H}), 7.68-7.64(\mathrm{~m}, 4 \mathrm{H})$, 7.50-7.48 (m, 1H), 7.20-7.18 (m, 2H), 7.13-7.11 (m, 1H), $7.07(\mathrm{~s}$, $1 \mathrm{H}), 6.55-6.53(\mathrm{~d}, J=8,1 \mathrm{H}), 3.88 \mathrm{ppm}(\mathrm{s}, 3 \mathrm{H}) ;{ }^{13} \mathrm{C}$ NMR $(100 \mathrm{MHz}$, $\left.\mathrm{CDCl}_{3}\right): \delta=159.82,158.87,145.02,147.71,136.75,135.66,134.82$, $133.98,132.75,132.24,131.69,130.45,129.99,128.77,121.37$, $119.05,118.27,118.02,117.48,116.73,116.52,108.46,106.81,94.03$, 88.72, $57.42 \mathrm{ppm}$; MS (ESI) $\mathrm{m} / \mathrm{z}: 460[\mathrm{M}+\mathrm{Na}]^{+}$.

4-(4-(3-(3-Methoxyphenethoxy)prop-1-ynyl)phenoxy)-7nitrobenzo[c][1,2,5]oxadiazole (27 d): According to general procedure (A) for aromatic nucleophilic substitution. Compound was ob- 
tained as a yellow solid $(0.15 \mathrm{mmol}, 61 \%)$. ${ }^{1} \mathrm{H} \mathrm{NMR}(400 \mathrm{MHz}$, $\left.\mathrm{CD}_{3} \mathrm{OD}\right): \delta=8.37-8.35(\mathrm{~d}, J=8,1 \mathrm{H}), 7.56-7.54(\mathrm{~d}, J=8,2 \mathrm{H}), 7.27-$ $7.25(\mathrm{~d}, J=8,2 \mathrm{H}), 7.16-7.14(\mathrm{~d}, J=8,2 \mathrm{H}), 6.52-6.50(\mathrm{~d}, J=8,1 \mathrm{H})$, $4.55(\mathrm{~s}, 2 \mathrm{H}), 4.32(\mathrm{~s}, 2 \mathrm{H}), 3.75 \mathrm{ppm}(\mathrm{s}, 3 \mathrm{H}) ;{ }^{13} \mathrm{C}$ NMR $(100 \mathrm{MHz}$, $\left.\mathrm{CDCl}_{3}\right): \delta=159.51,153.75,152.62,145.12,134.33,134.13,133.16$, $129.82,122.05,120.99,113.99,113.86,108.15,107.96,86.76,84.73$, 71.57, 56.94 ppm; MS (ESI) $\mathrm{m} / z: 454[\mathrm{M}+\mathrm{Na}]^{+}$.

4-(2-(6-Methoxynaphthalen-2-yl)ethyl)phenol (28): To a solution of $26 \mathrm{c}(84 \mathrm{mg}, 0.30 \mathrm{mmol})$ in EtOAc $(4 \mathrm{~mL})$ a catalytic amount of $\mathrm{Pd} / \mathrm{C}(5 \%)$ was added. The reaction mixture was stirred under hydrogen atmosphere for $10 \mathrm{~h}$. After that time the mixture was filtered on a Celite pad, the solvent was removed and the crude was purified by flash chromatography (Hex/EtOAc 4:1) to give the desired compound (0.24 mmol, $81 \%)$. ${ }^{1} \mathrm{H}$ NMR $\left(400 \mathrm{MHz}, \mathrm{CD}_{3} \mathrm{OD}\right): \delta=$ 7.64-7.60 (m, 2H), $7.47(\mathrm{~s}, 1 \mathrm{H}), 7.27-7.22(\mathrm{~m}, 3 \mathrm{H}), 7.11-7.07(\mathrm{~m}$, $4 \mathrm{H}), 3.89(\mathrm{~s}, 3 \mathrm{H}), 3.03-2.98 \mathrm{ppm}(\mathrm{m}, 4 \mathrm{H}) ;{ }^{13} \mathrm{C} \mathrm{NMR}(100 \mathrm{MHz}$, $\left.\mathrm{CDCl}_{3}\right): \delta=157.73,156.34,135.83,134.28,133.42,131.72,130.81$, $129.78,129.41,128.64,127.19,119.93,117.17,115.85,106.87,57.26$, 39.41, 38.93 ppm; MS (ESI) m/z: $279[\mathrm{M}+\mathrm{H}]^{+}$.

\section{4-(4-(2-(6-Methoxynaphthalen-2-yl)ethyl)phenoxy)-7-}

nitrobenzo[c][1,2,5]oxadiazole (29): Compound 29 was obtained according to general procedure (B) for aromatic nucleophilic substitution. Compound was obtained as a yellow solid $(0.16 \mathrm{mmol}$, $71 \%$ ). ' $\mathrm{H}$ NMR ( $\left.400 \mathrm{MHz}, \mathrm{CD}_{3} \mathrm{OD}\right): \delta=8.33-8.31$ (d, $\left.J=8,1 \mathrm{H}\right), 7.62-$ $7.58(\mathrm{~m}, 2 \mathrm{H}), 7.44(\mathrm{~s}, 1 \mathrm{H}), 7.25-7.20(\mathrm{~m}, 3 \mathrm{H}), 7.09-7.05(\mathrm{~m}, 4 \mathrm{H})$, $6.40-6.38(\mathrm{~d}, J=8,1 \mathrm{H}), 3.85(\mathrm{~s}, 3 \mathrm{H}), 3.02 \mathrm{ppm}(\mathrm{s}, 4 \mathrm{H}) ;{ }^{13} \mathrm{C}$ NMR $\left(100 \mathrm{MHz}, \mathrm{CDCl}_{3}\right): \delta=157.35,150.92,141.01,136.13,133.38,133.13$, $130.77,128.88,127.68,126.85,126.49,120.67,118.84,107.42$, $105.71,55.33,37.70,37.23$ ppm; MS (ESI) $\mathrm{m} / \mathrm{z}: 464[\mathrm{M}+\mathrm{Na}]^{+}$.

(4-(1-(Allyloxy)allyl)phenoxy)triisopropylsilane (31): a) To a solution of 4-hydroxybenzaldeyde $(200 \mathrm{mg}, 1.64 \mathrm{mmol})$ in dry DMF $(4 \mathrm{~mL})$, imidazole $(267 \mathrm{mg}, 3.93 \mathrm{mmol})$ was added. The mixture was cooled to $0^{\circ} \mathrm{C}$ and TIPS-Cl $(416 \mu \mathrm{L}, 1.96 \mathrm{mmol})$ was slowly added. The mixture was stirred at $60^{\circ} \mathrm{C}$ for $2 \mathrm{~h}$. After that time $\mathrm{H}_{2} \mathrm{O}$ and EtOAc were added. The mixture was extracted with EtOAc, the organic layer was dried over $\mathrm{Na}_{2} \mathrm{SO}_{4}$, filtered off and the solvent removed under reduced pressure. The crude was purified by flash chromatography (Hex/EtOAc 9:1) to give 4-(triisopropylsilyloxy)benzaldehyde as a colorless oil (1.64 mmol, quant). ${ }^{1} \mathrm{H}$ NMR $\left(400 \mathrm{MHz}, \mathrm{CDCl}_{3}\right): \delta=9.72(\mathrm{~s}, 1 \mathrm{H}), 7.64-7.62(\mathrm{~d}, J=8,2 \mathrm{H}), 6.83-$ $6.81(\mathrm{~d}, J=8,2 \mathrm{H}), 1.17-1.09(\mathrm{~m}, 3 \mathrm{H}), 0.96 \mathrm{ppm}(\mathrm{m}, 18 \mathrm{H}) ;{ }^{13} \mathrm{C} \mathrm{NMR}$ $\left(100 \mathrm{MHz}, \mathrm{CDCl}_{3}\right): \delta=190.26,161.62,131.67,130.16,120.10,17.64$, $12.51 \mathrm{ppm} ; \mathrm{MS}(\mathrm{ESI}) \mathrm{m} / \mathrm{z}: 301[\mathrm{M}+\mathrm{Na}]^{+}$.

b) To a solution of 4-(triisopropylsilyloxy)benzaldehyde $(459.2 \mathrm{mg}$, $1.64 \mathrm{mmol})$ in THF dry $(20 \mathrm{~mL})$ cooled to $0^{\circ} \mathrm{C}$ was slowly added a solution $1 \mathrm{M}$ of vinylmagnesium bromide in THF $(1.96 \mathrm{~mL}$, $1.96 \mathrm{mmol})$. The mixture was vigorously stirred for $1.5 \mathrm{~h} ; \mathrm{NH}_{4} \mathrm{Cl}$ was then added and the mixture was extracted with EtOAc $(2 \times 5 \mathrm{~mL})$. The organic layers were dried over $\mathrm{Na}_{2} \mathrm{SO}_{4}$, filtered and the solvent evaporated. The residue was purified by flash chromatography (Hex/EtOAc 4:1) to give 1-(4-(triisopropylsilyloxy)phenyl)prop-2-en1 -ol as a colorless oil $(1.34 \mathrm{mmol}, 82 \%)$. ${ }^{1} \mathrm{H}$ NMR $\left(400 \mathrm{MHz}, \mathrm{CDCl}_{3}\right)$ : $\delta=7.13-7.11(\mathrm{~d}, J=8,2 \mathrm{H}), 6.80-6.78(\mathrm{~d}, J=8,2 \mathrm{H}), 5.97-5.89(\mathrm{~m}$, $1 \mathrm{H}), 5.22-5.17(\mathrm{~m}, 1 \mathrm{H}), 5.07-5.04(\mathrm{~m}, 1 \mathrm{H}), 5.00-4.98(\mathrm{~m}, 1 \mathrm{H}), 1.25-$ $1.15(\mathrm{~m}, 3 \mathrm{H}), 1.05 \mathrm{ppm}(\mathrm{s}, 18 \mathrm{H}) ;{ }^{13} \mathrm{C} \mathrm{NMR}\left(100 \mathrm{MHz}, \mathrm{CDCl}_{3}\right): \delta=$ $155.47,140.49,135.21,127.56,119.67,114.41,74.62,17.85$, $12.62 \mathrm{ppm} ; \mathrm{MS}(\mathrm{ESI}) \mathrm{m} / \mathrm{z}: 305[\mathrm{M}-\mathrm{H}]^{-}$.

c) To a solution of 1-(4-(triisopropylsilyloxy)phenyl)prop-2-en-1-ol $(411 \mathrm{mg}, 1.34 \mathrm{mmol})$ in dry THF $(10 \mathrm{~mL})$ under argon atmosphere previously cooled to $0^{\circ} \mathrm{C}, \mathrm{NaH}(32 \mathrm{mg}, 1.34 \mathrm{mmol})$ was added. The mixture was stirred at room temperature for $15 \mathrm{~min}$ and allyl bro- mide $(2 \mathrm{mmol})$ was added dropwise. The reaction mixture was allowed to stir at room temperature for a further $10 \mathrm{~h}$. After that time $\mathrm{H}_{2} \mathrm{O}$ and EtOAc were added. The mixture was extracted with EtOAc, the organic layer was dried over $\mathrm{Na}_{2} \mathrm{SO}_{4}$, filtered off and the solvent removed under reduced pressure. The crude was purified by flash chromatography (Hex/EtOAc 98:2) to give $\mathbf{3 1}$ as a colorless oil $(0.71 \mathrm{mmol}, 53 \%)$. ' $\mathrm{H}$ NMR $\left(400 \mathrm{MHz}, \mathrm{CDCl}_{3}\right)$ : $\delta=7.15-7.13(\mathrm{~d}$, $J=8,2 \mathrm{H}), 6.77-6.75(\mathrm{~d}, J=8,2 \mathrm{H}), 5.94-5.84(\mathrm{~m}, 2 \mathrm{H}), 5.25-5.21(\mathrm{~m}$, $2 \mathrm{H}), 5.18-5.10(\mathrm{~m}, 2 \mathrm{H}), 4.72-4.69(\mathrm{~m}, 1 \mathrm{H}), 3.92-3.90(\mathrm{~m}, 2 \mathrm{H}), 1.25-$ $1.18(\mathrm{~m}, 3 \mathrm{H}), 1.07 \mathrm{ppm}(\mathrm{s}, 18 \mathrm{H}) ;{ }^{13} \mathrm{C}$ NMR $\left(100 \mathrm{MHz}, \mathrm{CDCl}_{3}\right): \delta=$ $155.52,139.01,134.89,133.25,128.13,127.91,127.66,119.98$, $119.70,119.40,117.46,116.61,115.83,114.60,81.55,68.97,17.85$, $12.86 \mathrm{ppm} ; \mathrm{MS}(\mathrm{ESI}) \mathrm{m} / \mathrm{z}: 369[\mathrm{M}+\mathrm{Na}]^{+}$.

(4-(2,5-Dihydrofuran-2-yl)phenol (32): a) Compound 31 (103 mg, $0.29 \mathrm{mmol})$ was dissolved in $\mathrm{CH}_{2} \mathrm{Cl}_{2}$ dry $(20 \mathrm{~mL})$ under argon atmosphere, then second-generation Grubbs catalyst (2\%) was added. The reaction mixture was allowed to stir at room temperature for $1 \mathrm{~h}$, then the solvent was removed and the crude was purified by flash chromatography $\left(\mathrm{Hex}_{\mathrm{Et}} \mathrm{O} \mathrm{O}\right.$ 96:4) to give the desired compound as a colorless oil $(0.226 \mathrm{mmol}, 78 \%)$. ${ }^{1} \mathrm{H}$ NMR $(400 \mathrm{MHz}$, $\left.\mathrm{CDCl}_{3}\right): \delta=7.10-7.08(\mathrm{~d}, J=8,2 \mathrm{H}), 6.80-6.78(\mathrm{~d}, J=8,2 \mathrm{H}), 5.97-$ $5.95(\mathrm{~m}, 1 \mathrm{H}), 5.81-5.79(\mathrm{~m}, 1 \mathrm{H}), 5.67-5.66(\mathrm{~m}, 1 \mathrm{H}), 4.81-4.76(\mathrm{~m}$, $1 \mathrm{H}), 4.69-4.65(\mathrm{~m}, 1 \mathrm{H}), 1.23-1.14(\mathrm{~m}, 3 \mathrm{H}), 1.05 \mathrm{ppm}(\mathrm{s}, 18 \mathrm{H})$; ${ }^{13} \mathrm{C} \mathrm{NMR} \quad\left(100 \mathrm{MHz}, \quad \mathrm{CDCl}_{3}\right): \delta=155.74,134.26,130.08,127.71$, $126.45,119.67,87.53,75.41,17.85,12.61 \mathrm{ppm}$; MS (ESI) m/z: 341 $[\mathrm{M}+\mathrm{Na}]+$.

b) To a solution of the previous compound $(67 \mathrm{mg}, 0.21 \mathrm{mmol})$, in dry THF ( $3 \mathrm{~mL}$ ) previously cooled to $0{ }^{\circ} \mathrm{C}$ was slowly added a solution $1 \mathrm{M}$ of TBAF in THF $(250 \mu \mathrm{L}, 0.25 \mathrm{mmol})$. The mixture was stirred at room temperature for $1 \mathrm{~h}$ and then $1 \mathrm{~N} \mathrm{HCl}$ and EtOAC were added. The mixture was extracted with EtOAc, the organic layer was dried over $\mathrm{Na}_{2} \mathrm{SO}_{4}$, filtered and the solvent evaporated. The residue was purified by flash chromatography $\mathrm{Hex} / \mathrm{Et}_{2} \mathrm{O} 3: 2$ to give desired compound as a colorless oil $(0.17 \mathrm{mmol}, 82 \%)$. ${ }^{1} \mathrm{H}$ NMR $\left(400 \mathrm{MHz}, \mathrm{CDCl}_{3}\right): \delta=7.06-7.04(\mathrm{~d}, J=8,2 \mathrm{H}), 6.64-6.62(\mathrm{~d}$, $J=8,2 \mathrm{H}), 6.40(\mathrm{brs}, 1 \mathrm{H}), 5.99-5.97(\mathrm{~m}, 1 \mathrm{H}), 5.79-5.78(\mathrm{~m}, 1 \mathrm{H})$, 5.70-5.69 $(\mathrm{m}, 1 \mathrm{H}), 4.81-4.77(\mathrm{~m}, 1 \mathrm{H}), 4.69-4.66 \mathrm{ppm}(\mathrm{m}, 1 \mathrm{H})$; ${ }^{13} \mathrm{C} \mathrm{NMR} \quad\left(100 \mathrm{MHz}, \mathrm{CDCl}_{3}\right): \delta=155.85,133.01,129.70,128.17$, 126.45, 115.41, 87.70, 75.27 ppm; MS (ESI) $\mathrm{m} / \mathrm{z}: 163[\mathrm{M}+\mathrm{H}]^{+}$.

\section{4-(4-(2,5-Dihydrofuran-2-yl)phenoxy)-7-nitrobenzo[c]-}

$[1,2,5]$ oxadiazole (33): Compound 33 was obtained according to general procedure (B) for aromatic nucleophilic substitution. Yellow solid $(0.09 \mathrm{mmol}, 59 \%)$. ${ }^{1} \mathrm{H}$ NMR $\left(400 \mathrm{MHz}, \mathrm{CD}_{3} \mathrm{OD}\right): \delta=8.35-8.33$ $(\mathrm{d}, J=8,1 \mathrm{H}), 7.45-7.43(\mathrm{~d}, J=8,2 \mathrm{H}), 7.18-7.16(\mathrm{~d}, J=8,2 \mathrm{H}), 6.47-$ $6.45(\mathrm{~d}, J=8,1 \mathrm{H}), 6.05-6.04(\mathrm{~m}, 1 \mathrm{H}), 5.87-5.86(\mathrm{~m}, 1 \mathrm{H}), 5.79-5.78$ $(\mathrm{m}, 1 \mathrm{H}), 4.87-4.82(\mathrm{~m}, 1 \mathrm{H}), 4.76-4.73 \mathrm{ppm}(\mathrm{m}, 1 \mathrm{H}) ;{ }^{13} \mathrm{CNMR}$ $\left(100 \mathrm{MHz}, \mathrm{CDCl}_{3}\right): \delta=154.35,152.20,145.09,144.09,141.34,133.22$, $129.34,128.80,127.32,120.91,107.53,87.03,75.03,75.88$, $29.58 \mathrm{ppm} ; \mathrm{MS}(\mathrm{ESI}) \mathrm{m} / \mathrm{z}: 348[\mathrm{M}+\mathrm{Na}]^{+}$.

\section{4-(4-(4-Methylpiperazin-1-yl)phenoxy)-7-nitrobenzo[c]-}

[1,2,5]oxadiazole (38a): A mixture of 1-(4-hydroxyphenyl)piperazine $(100 \mathrm{mg}, 0.56 \mathrm{mmol})$, formic acid (16 equiv) and formaldehyde (1.1 equiv) in $\mathrm{MeOH}(6 \mathrm{~mL}$ ) was held at reflux for $12 \mathrm{~h}$. After evaporation of solvents in vacuo the residue was partitioned between $\mathrm{CH}_{2} \mathrm{Cl}_{2}$ and a saturated aqueous solution of $\mathrm{NaHCO}_{3}$. The extract was dried over anhydrous $\mathrm{Na}_{2} \mathrm{SO}_{4}$, filtered and concentrated to give intermediate 35. This was dissolved in $\mathrm{EtOH}$ and 4-chloro-7-nitrobenzofurazan (1 equiv) and a catalytic amount of KOAc and pyridine were added. The resulting mixture was heated at reflux for $3 \mathrm{~h}$, then was concentrated in vacuo and the crude product was purified by flash chromatography (EtOAc/MeOH 7:3) to give de- 
sired compound (0.44 mmol, $85 \%)$. ' $\mathrm{H}$ NMR $\left(400 \mathrm{MHz}, \mathrm{CDCl}_{3}\right)$ : $\delta=$ $8.32(\mathrm{~d}, J=7.9 \mathrm{~Hz}, 1 \mathrm{H}), 7.05(\mathrm{~d}, J=8.2 \mathrm{~Hz}, 2 \mathrm{H}), 6.93(\mathrm{~d}, J=8.2 \mathrm{~Hz}$, $2 \mathrm{H}), 6.45(\mathrm{~d}, J=7.9 \mathrm{~Hz}, 1 \mathrm{H}), 3.18(4 \mathrm{H}, \mathrm{m}), 2.54(4 \mathrm{H}, \mathrm{m}), 2.30 \mathrm{ppm}$ $(3 \mathrm{H}, \mathrm{s}) ;{ }^{13} \mathrm{CNMR}\left(100 \mathrm{MHz}, \mathrm{CDCl}_{3}\right): \delta=155.18,150.05,146.51$, $145.22,145.09,133.46,130.21,121.36,117.25,107.09,54.86,48.85$, 45.94 ppm; MS (ESI) m/z: $356[M+\mathrm{H}]^{+}, 378[M+\mathrm{Na}]^{+}$.

1-(4-(4-(7-Nitrobenzo[c][1,2,5]oxadiazol-4-yloxy)phenyl)piperazin-1-yl)ethanone (38 b): To a solution of 1-(4-hydroxyphenyl)piperazine $(100 \mathrm{mg}, 0.56 \mathrm{mmol})$ in pyridine $(3 \mathrm{~mL}), \mathrm{Ac}_{2} \mathrm{O}(58 \mu \mathrm{L}$, 0.61 equiv) were added and the mixture was stirred at room temperature for $1 \mathrm{~h}$. The reaction mixture was quenched with saturated aqueous solution of $\mathrm{NaHCO}_{3}(10 \mathrm{~mL})$ and extracted with EtOAc $(3 \times 10 \mathrm{~mL})$. The combined extract was dried over anhydrous $\mathrm{Na}_{2} \mathrm{SO}_{4}$, filtered and concentrated to give intermediate 36. This was dissolved in $\mathrm{EtOH}$ and 4-chloro-7-nitrobenzofurazan (1 equiv) and a catalytic amount of KOAC and pyridine were added. The resulting mixture was heated at reflux for $3 \mathrm{~h}$. This was concentrated in vacuo and the crude product was purified by flash chromatography (EtOAc/Hex 3:1) to give desired compound $(0.45 \mathrm{mmol}, 87 \%)$. ${ }^{1} \mathrm{H}$ NMR $\left(400 \mathrm{MHz}, \mathrm{CD}_{3} \mathrm{CN}\right): \delta=8.41(\mathrm{~d}, J=7.9 \mathrm{~Hz}, 1 \mathrm{H}), 7.14(\mathrm{~d}, J=$ $8.2 \mathrm{~Hz}, 2 \mathrm{H}), 7.03(\mathrm{~d}, J=8.2 \mathrm{~Hz}, 2 \mathrm{H}), 6.51(\mathrm{~d}, J=7.9 \mathrm{~Hz}, 1 \mathrm{H}), 3.61$ $(2 \mathrm{H}, \mathrm{m}), 3.56(2 \mathrm{H}, \mathrm{m}), 3.16(2 \mathrm{H}, \mathrm{m}), 3.10(2 \mathrm{H}, \mathrm{m}), 2.00 \mathrm{ppm}(3 \mathrm{H}, \mathrm{s})$; ${ }^{13} \mathrm{C}$ NMR $\quad\left(100 \mathrm{MHz}, \quad \mathrm{CD}_{3} \mathrm{CN}\right): \delta=170.29,156.22,151.42,147.35$, $147.14,146.34,137.68,131.85,123.36,119.19,110.78,50.56,50.19$, 47.41, 42.64, 23.14 ppm; MS (ESI) m/z: $384[\mathrm{M}+\mathrm{H}]^{+}, 406[\mathrm{M}+\mathrm{Na}]^{+}$.

tert-Butyl-(4-(4-hydroxyphenyl)piperazin-1-yl)methanediylidenedicarbamate (37): Preparation of $N, N^{\prime}$-di-Boc- $N^{\prime \prime}$-trifluoromethanesulfonylguanidine: To a solution of $N, N^{\prime}$-di-Boc-guanidine $(7.5 \mathrm{~g}$, $29 \mathrm{mmol})$ in $\mathrm{CH}_{2} \mathrm{Cl}_{2}(100 \mathrm{~mL}) \mathrm{Et}_{3} \mathrm{~N}(5.0 \mathrm{~mL}, 36 \mathrm{mmol})$ was added and the temperature of the mixture was equilibrated to $-78^{\circ} \mathrm{C}$ using a dry ice/ $\mathrm{PrOH}$ bath. Trifluoromethanesulfanyl anhydride $(5.9 \mathrm{~mL}, 35 \mathrm{mmol})$ was added dropwise through the dropping funnel over a period of $20 \mathrm{~min}$, and the resulting mixture was allowed to warm to $-20^{\circ} \mathrm{C}$ over $4 \mathrm{~h}$. A $2 \mathrm{M}$ aqueous $\mathrm{NaHSO}_{4}$ solution was added to the mixture at $-20^{\circ} \mathrm{C}$, such that the reaction temperature did not rise above $-10^{\circ} \mathrm{C}$, and the resulting layers were stirred vigorously for $5 \mathrm{~min}$. The layers were immediately separated, and the aqueous phase was extracted with $\mathrm{CH}_{2} \mathrm{Cl}_{2}(3 \times 50 \mathrm{~mL})$. The combined organic layers were washed with $2 \mathrm{M}$ aqueous $\mathrm{NaHSO}_{4}(80 \mathrm{~mL})$, brine $(50 \mathrm{~mL})$, dried $\left(\mathrm{Na}_{2} \mathrm{SO}_{4}\right)$, filtered, and concentrated under reduced pressure. The crude material was purified by flash column chromatography $\left(\mathrm{CH}_{2} \mathrm{Cl}_{2} / \mathrm{Hex} 4: 1\right)$ to provide desired compound (24.6 mmol, $85 \%)$. ${ }^{1} \mathrm{H} \mathrm{NMR}\left(400 \mathrm{MHz},\left[\mathrm{D}_{6}\right] \mathrm{DMSO}\right): \delta=$ $1.46(\mathrm{~s}, 18 \mathrm{H}), 11.06 \mathrm{ppm}$ (brs, $2 \mathrm{H}) ;{ }^{13} \mathrm{C}$ NMR (100 MHz, [D 6 ]DMSO): $\delta=27.5,83.4,119.1,150.0,152.3 \mathrm{ppm}$.

Preparation of 37: A mixture of $N, N^{\prime}$-di-Boc- $\mathrm{N}^{\prime \prime}$-trifluoromethanesulfonylguanidine ( $218 \mathrm{mg}, 0.56$ equiv), 1-(4-hydroxyphenyl)piperazine ( $100 \mathrm{mg}, 0.56 \mathrm{mmol})$, EDC ( 1.2 equiv) and DIPEA ( 1.2 equiv) in DMF $(10 \mathrm{~mL})$ was stirred for $16 \mathrm{~h}$ at room temperature. The mixture was partitioned between $\mathrm{NH}_{4} \mathrm{Cl}_{(\mathrm{aq})}(5 \mathrm{~mL}, 1 \mathrm{~N})$ and EtOAc $(25 \mathrm{~mL})$. The organic layer was separated, dried $\left(\mathrm{Na}_{2} \mathrm{SO}_{4}\right)$, filtered, and concentrated in vacuo. The residue was purified by column chromatography (EtOAc/Hex 3:2) to give desired compound $(0.42 \mathrm{mmol}$, $76 \%$ ). ${ }^{1} \mathrm{H}$ NMR $\left(400 \mathrm{MHz}, \mathrm{CD}_{3} \mathrm{OD}\right): \delta=6.80(\mathrm{~d}, J=8.3 \mathrm{~Hz}, 2 \mathrm{H}), 6.64$ (d, $J=8.3 \mathrm{~Hz}, 2 \mathrm{H}), 3.65-3.63(4 \mathrm{H}, \mathrm{m}), 3.23-3.20(4 \mathrm{H}, \mathrm{m}), 1.42 \mathrm{ppm}$ $(18 \mathrm{H}, \mathrm{s}) ; \mathrm{MS}(\mathrm{ESI}) \mathrm{m} / \mathrm{z}: 419[\mathrm{M}-\mathrm{H}]^{-}$.

\section{di-tert-Butyl(4-(4-(7-nitrobenzo[c][1,2,5]oxadiazol-4-yloxy)phe-} nyl)piperazin-1-yl)methanediylidenedicarbamate (38 c): To a solution of 4-chloro-7-nitrobenzofurazan (1 equiv) in $\mathrm{EtOH}$ compound 20, a catalytic amount of KOAc and pyridine were added. The resulting mixture was heated at reflux for $3 \mathrm{~h}$, then concentrated in vacuo and the crude product was purified by flash chromatography (EtOAc/Hex 3:2) (0.23 mmol, 94\%). ${ }^{1} \mathrm{H}$ NMR ( $\left.400 \mathrm{MHz}, \mathrm{CD}_{3} \mathrm{OD}\right)$ : $\delta=8.47(\mathrm{~d}, J=7.8 \mathrm{~Hz}, 1 \mathrm{H}), 7.16(\mathrm{~d}, J=8.2 \mathrm{~Hz}, 2 \mathrm{H}), 7.07(\mathrm{~d}, J=$ $8.2 \mathrm{~Hz}, 2 \mathrm{H}), 6.55(\mathrm{~d}, J=7.8 \mathrm{~Hz}, 1 \mathrm{H}), 3.65-3.63(4 \mathrm{H}, \mathrm{m}), 3.23-3.20$ $(4 \mathrm{H}, \mathrm{m}), 1.42 \mathrm{ppm}(18 \mathrm{H}, \mathrm{s}) ;{ }^{13} \mathrm{C}$ NMR $\left(100 \mathrm{MHz}, \mathrm{CD}_{3} \mathrm{OD}\right): \delta=159.72$, $154.14,151.11,149.15,145.24,144.24,135.58,129.74,121.29$, 118.24, 116.99, 115.43, 108.70, 80.09, 77.15, 47.82, 45.09, 27.87, 27.70 ppm; MS (ESI) $\mathrm{m} / \mathrm{z}: 582[\mathrm{M}-\mathrm{H}]^{-}$.

1-Acetyl-4-(4-(7-nitrobenzo[c][1,2,5]oxadiazol-4-yloxy)phenyl)piperazin-1-ium chloride (38a) and 1-methyl-4-(4-(7-nitrobenzo[c][1,2,5] oxadiazol-4-yloxy)phenyl)piperazin-1-ium chloride (38 b): To a solution of compounds $\mathbf{3 8} \mathbf{a}$ or $\mathbf{3 8} \mathbf{b}$ ( 1 equiv) in $\mathrm{CH}_{2} \mathrm{Cl}_{2}$ a solution of $1 \mathrm{M} \mathrm{HCl}$ in $\mathrm{MeOH}$ (2 equiv) was added dropwise. The mixture was stirred at room temperature for $2 \mathrm{~min}$ then the solvent was removed in vacuo to give the desired product pure. $38 \mathrm{a}$ : (0.44 mmol, quant). ' $\mathrm{H}$ NMR (400 MHz, $\mathrm{CD}_{3} \mathrm{OD}$ ): $\delta=8.50$ (d, $J=$ $7.8 \mathrm{~Hz}, 1 \mathrm{H}), 7.69(\mathrm{~d}, J=8.3 \mathrm{~Hz}, 2 \mathrm{H}), 7.45(\mathrm{~d}, J=8.3 \mathrm{~Hz}, 2 \mathrm{H}), 6.74(\mathrm{~d}$ $J=7.8 \mathrm{~Hz}, 1 \mathrm{H}), 3.95(4 \mathrm{H}, \mathrm{m}), 3.63(2 \mathrm{H}, \mathrm{m}), 3.57(2 \mathrm{H}, \mathrm{m}), 2.15 \mathrm{ppm}$ $(3 \mathrm{H}, \mathrm{s}) ;{ }^{13} \mathrm{C}$ NMR $\left(100 \mathrm{MHz}, \mathrm{CD}_{3} \mathrm{OD}\right): \delta=170.63,153.59,149.62$, $145.59,145.35,144.33,133.76,130.81,121.65,120.15,108.77$, 51.65, 51.35, 44.88, 40.13, 19.55 ppm; MS (ESI) m/z: $418[\mathrm{M}-\mathrm{H}]^{-}$. $38 \mathrm{~b}$ :(0.45 mmol, quant). ' $\mathrm{H}$ NMR ( $\left.400 \mathrm{MHz}, \mathrm{CD}_{3} \mathrm{OD}\right): \delta=8.47$ (d, $J=$ $7.8 \mathrm{~Hz}, 1 \mathrm{H}), 7.21(\mathrm{~d}, J=8.1 \mathrm{~Hz}, 2 \mathrm{H}), 7.14(\mathrm{~d}, J=8.1 \mathrm{~Hz}, 2 \mathrm{H}), 6.56(\mathrm{~d}$, $J=7.8 \mathrm{~Hz}, 1 \mathrm{H}), 3.85-3.82(2 \mathrm{H}, \mathrm{m}), 3.60-3.57(2 \mathrm{H}, \mathrm{m}), 3.28-3.24(2 \mathrm{H}$, $\mathrm{m}), \quad 3.12-3.09(2 \mathrm{H}, \mathrm{m}), 2.92 \mathrm{ppm}(3 \mathrm{H}, \mathrm{s}) ;{ }^{13} \mathrm{C} \mathrm{NMR}(100 \mathrm{MHz}$, $\left.\mathrm{CD}_{3} \mathrm{OD}\right): \delta=155.99,150.09,148.50,146.94,145.88,135.61,131.94$, 122.97, 119.86, 109.39, 54.79, 48.30, 43.76 ppm; MS (ESI) m/z: 390 $[\mathrm{M}-\mathrm{H}]^{-}$.

\section{4-(4-(7-Nitrobenzo[c][1,2,5]oxadiazol-4-yloxy)phenyl)piperazine-} 1-carboximidamide $(40 \mathrm{c})$ : Compound $38 \mathrm{c}(0.23 \mathrm{mmol})$ were dissolved in $5 \mathrm{~mL}$ dry $\mathrm{CH}_{2} \mathrm{Cl}_{2}$ and added with $0.5 \mathrm{~mL}$ of freshly distilled TFA. The mixtures were stirred at room temperature for $24 \mathrm{~h}$. The solvent was removed under reduced pressure and the crude compound was washed several times with toluene to yield the desired product ( $0.23 \mathrm{mmol}$, quant). ${ }^{1} \mathrm{H} \mathrm{NMR}\left(400 \mathrm{MHz}, \mathrm{CD}_{3} \mathrm{OD}\right): \delta=8.47$ (d, $J=7.8 \mathrm{~Hz}, 1 \mathrm{H}), 7.19(\mathrm{~d}, J=8.2 \mathrm{~Hz}, 2 \mathrm{H}), 7.09(\mathrm{~d}, J=8.2 \mathrm{~Hz}, 2 \mathrm{H}), 6.55$ $(\mathrm{d}, J=7.8 \mathrm{~Hz}, 1 \mathrm{H}), 3.81-3.79(1 \mathrm{H}, \mathrm{dd}), 3.63-3.60(4 \mathrm{H}, \mathrm{m}), 3.29-3.26$ $(4 \mathrm{H}, \mathrm{m}), 3.16-3.14 \mathrm{ppm}(1 \mathrm{H}, \mathrm{dd}) ;{ }^{13} \mathrm{C}$ NMR $\left(100 \mathrm{MHz}, \mathrm{CD}_{3} \mathrm{OD}\right): \delta=$ $159.72,149.15,145.24,144.24,135.58,129.74,121.29,118.24$, 116.99, 115.43, 108.70, 47.82, 45.09 ppm; MS (ESI) m/z: 479 $[\mathrm{M}-\mathrm{H}]^{-}$.

4-Azidophenol (42a): To a stirred ice cooled solution of 4-hydroxylaniline $(1.0 \mathrm{~g}, 18.3 \mathrm{mmol})$ dissolved in a (1:1) mixture of $\mathrm{AcOH} / \mathrm{H}_{2} \mathrm{O}$ $(50 \mathrm{~mL})$ was added $\mathrm{NaNO}_{2}(2.1 \mathrm{~g}, 30.4 \mathrm{mmol})$ slowly. After $5 \mathrm{~min}$ were added $\mathrm{NaN}_{3}(2 \mathrm{~g}, 30.76 \mathrm{mmol})$ and $\mathrm{Et}_{2} \mathrm{O}(50 \mathrm{~mL})$ and the reaction was stirred for further $10 \mathrm{~min}$. The $\mathrm{Et}_{2} \mathrm{O}$ layer was then separated, washed with $\mathrm{H}_{2} \mathrm{O}$, dried on $\mathrm{Na}_{2} \mathrm{SO}_{4}$, evaporated and the resultant black oil triturated with hexane $(12.26 \mathrm{mmol}, 67 \%)$. ${ }^{1} \mathrm{H}$ NMR $\left(400 \mathrm{MHz}, \mathrm{CDCl}_{3}\right): \delta=6.8 \mathrm{ppm}(\mathrm{s}, 4 \mathrm{H}) ;{ }^{13} \mathrm{C} \mathrm{NMR}\left(100 \mathrm{MHz}, \mathrm{CDCl}_{3}\right)$ : $\delta=116,120,132,152.5 \mathrm{ppm}$.

3-azidophenol (42 b): 3-Azidophenol was obtained with the same procedure as for $42 \mathrm{a}$ but starting from 3-hydroxylaniline. After being stirred for $20 \mathrm{~min}$, the reaction mixture was filtered to remove black insoluble polymeric residues, extracted with $\mathrm{CH}_{2} \mathrm{Cl}_{2}$, dried on $\mathrm{Na}_{2} \mathrm{SO}_{4}$, and the solvent was removed in vacuo to give a yellow/brown oil $(6.4 \mathrm{mmol}, 35 \%)$. ${ }^{1} \mathrm{H} \mathrm{NMR}\left(400 \mathrm{MHz}, \mathrm{CDCl}_{3}\right): \delta=$ $7.15(\mathrm{t}, J=8.0 \mathrm{~Hz}, 1 \mathrm{H}), 6.6(\mathrm{~d}, J=11.7 \mathrm{~Hz}, 2 \mathrm{H}), 6.5 \mathrm{ppm}(\mathrm{s}, 1 \mathrm{H})$; ${ }^{13} \mathrm{C}$ NMR $\left(100 \mathrm{MHz}, \mathrm{CDCl}_{3}\right): \delta=106,111,112,113,130,157$ ppm.

(4-Ethynylphenyl)(methyl)sulfane (43c): To a solution of triisopropyl((4-(methylthio)phenyl)ethynyl)silane $(0.46 \mathrm{mmol})$ in THF dry $(4 \mathrm{~mL})$ TBAF was added $(0.56 \mathrm{mmol})$ and the mixture was stirred at 
room temperature for $2 \mathrm{~h}$. Then a $\mathrm{NH}_{4} \mathrm{Cl}$ saturated solution $(4 \mathrm{~mL})$ was added and the aqueous phase was extracted with $\mathrm{Et}_{2} \mathrm{O}(2 \times$ $10 \mathrm{~mL}$ ). The organic layers were then collected, washed with saturated $\mathrm{NaCl}$ solution, dried with $\mathrm{Na}_{2} \mathrm{CO}_{3}$, and concentrated in vacuo to provide desired compound $(0.45 \mathrm{mmol}, 97 \%)$. ${ }^{1} \mathrm{H}$ NMR $\left(400 \mathrm{MHz}, \mathrm{CDCl}_{3}\right): \delta=7.32(\mathrm{~d}, 2 \mathrm{H}, J=7.8 \mathrm{~Hz}), 7.10(\mathrm{~d}, 2 \mathrm{H}, J=$ $7.8 \mathrm{~Hz}), 3.0(\mathrm{~s}, 1 \mathrm{H}), 2.40 \mathrm{ppm}(\mathrm{s}, 3 \mathrm{H}) ;{ }^{13} \mathrm{C} \mathrm{NMR}\left(100 \mathrm{MHz}, \mathrm{CDCl}_{3}\right)$ : $\delta=139.98,132.29,125.68,118.26,83.37,77.31,14.04$ ppm; MS (ESI): $m / z: 282[M-H]^{-}$.

$\mathrm{N}$-tert-Butyloxycarbonyl-O-propargyl-L-serine methyl ester (43 f): To a stirred solution of $N$-tertbutyloxycarbonyl-L-serine $(5.13 \mathrm{~g}$, $25 \mathrm{mmol})$ in DMF $(150 \mathrm{~mL})$ at $0{ }^{\circ} \mathrm{C}$ was carefully added $\mathrm{NaH}(60 \%$ in mineral oil, $4.0 \mathrm{~g}, 100 \mathrm{mmol})$. The reaction mixture was stirred for $30 \mathrm{~min}$ until hydrogen evolution stopped. Propargyl bromide $(4.46 \mathrm{~mL}, 50 \mathrm{mmol})$ was added, and the mixture was stirred at $0{ }^{\circ} \mathrm{C}$ for $30 \mathrm{~min}$ and then room temperature for $12 \mathrm{~h}$; Mel $(2.40 \mathrm{~mL})$ was added. Four hours later the reaction mixture was poured into brine, and extracted with $\mathrm{Et}_{2} \mathrm{O}(3 \times 150 \mathrm{~mL})$. The combined organic layers were washed with brine, dried $\left(\mathrm{Na}_{2} \mathrm{SO}_{4}\right)$, and concentrated. The residue was purified by flash chromatography $\left(\mathrm{Hex} / \mathrm{Et}_{2} \mathrm{O}\right.$ 4:1) to provide desired compound $(9.75 \mathrm{mmol}, 39 \%)$. $[\alpha]_{D}:+17.8(c=$ 2.7, $\left.\mathrm{CHCl}_{3}\right)$; ${ }^{1} \mathrm{H}$ NMR $\left(400 \mathrm{MHz}, \mathrm{CDCl}_{3}\right): \delta=5.38(\mathrm{~d}, J=8.4 \mathrm{~Hz}, 1 \mathrm{H})$, $4.46(\mathrm{dt}, J=8.4,3.3 \mathrm{~Hz}, 1 \mathrm{H}), 4.15(\mathrm{~d}, J=2.4 \mathrm{~Hz}, 2 \mathrm{H}), 3.96(\mathrm{dd}, J=$ 9.3, $3.3 \mathrm{~Hz}, 1 \mathrm{H}), 3.77(\mathrm{~s}, 3 \mathrm{H}), 3.76(\mathrm{dd}, J=9.3,3.3 \mathrm{~Hz}, 1 \mathrm{H}), 2.46(\mathrm{t}$, $J=2.4 \mathrm{~Hz}, 1 \mathrm{H}), 1.46 \mathrm{ppm}(\mathrm{s}, 9 \mathrm{H}) ;{ }^{13} \mathrm{C} \mathrm{NMR}\left(100 \mathrm{MHz}, \mathrm{CDCl}_{3}\right): \delta=$ 170.86, 155.40, 79.98, 78.77, 75.03, 69.61, 58.49, 53.72, 52.49, $28.24 \mathrm{ppm}$

1-Propynyl-2,3,4-tri-O-benzoyl- $\beta$-D-ribofuranose (43 g): To a solution of $\beta$-D-ribofuranose 1-acetate $2,3,5$ tribenzoate $(200 \mathrm{mg}$, $0.4 \mathrm{mmol})$ in $\mathrm{CH}_{2} \mathrm{Cl}_{2}(5 \mathrm{~mL})$ was added propargyl alcohol $(28 \mu \mathrm{L}$, $0.47 \mathrm{mmol})$ and $\mathrm{BF}_{3} \cdot \mathrm{Et}_{2} \mathrm{O}(73 \mu \mathrm{L}, 0.6 \mathrm{mmol})$ at $0{ }^{\circ} \mathrm{C}$ and the reaction mixture was stirred at room temperature for $1 \mathrm{~h}$. After completion of the reaction anhydrous $\mathrm{K}_{2} \mathrm{CO}_{3}(100 \mathrm{mg})$ was added and stirring was continued for further $15 \mathrm{~min}$. Then the reaction mixture was filtered and washed with $\mathrm{CH}_{2} \mathrm{Cl}_{2}$. The filtrate was washed with $\mathrm{H}_{2} \mathrm{O}$, the aqueous phase was separated and extracted with $\mathrm{CH}_{2} \mathrm{Cl}_{2}(2 \times$ $10 \mathrm{~mL})$ and the combined organic phases were dried $\left(\mathrm{Na}_{2} \mathrm{SO}_{4}\right)$ and concentrated to yield the desired compound as a crystalline solid (0.356 mmol, $89 \%) .[\alpha]_{\mathrm{D}}:+12.4^{\circ}\left(c=10, \mathrm{CHCl}_{3}\right) ;{ }^{1} \mathrm{H} \mathrm{NMR}(400 \mathrm{MHz}$, $\left.\mathrm{CDCl}_{3}\right): \delta=8.02-7.96(\mathrm{~m}, 4 \mathrm{H}), 7.81(\mathrm{~d}, J=8.1 \mathrm{~Hz}, 2 \mathrm{H}), 7.51-7.41(\mathrm{~m}$, $3 \mathrm{H}), 7.38-7.32(\mathrm{~m}, 4 \mathrm{H}), 7.26-7.22(\mathrm{~m}, 2 \mathrm{H}), 5.87-5.84(\mathrm{~m}, 1 \mathrm{H}, \mathrm{H}-2)$, $5.69(\mathrm{~d}, J=4.2 \mathrm{~Hz}, 1 \mathrm{H}, \mathrm{H}-1), 5.44(\mathrm{~s}, 1 \mathrm{H}, \mathrm{H}-4), 4.70-4.65(\mathrm{~m}, 2 \mathrm{H})$, 4.50-4.46 (m, $1 \mathrm{H}, \mathrm{H}-3), 4.20(\mathrm{~s}, 2 \mathrm{H}), 2.39 \mathrm{ppm}(\mathrm{s}, 1 \mathrm{H}) ;{ }^{13} \mathrm{C} \mathrm{NMR}$ $\left(100 \mathrm{MHz}, \mathrm{CDCl}_{3}\right): \delta=166.10,165.26,165.07,133.44,133.33,133.10$, $129.75,129.67,129.11,128.84,128.43,128.34,128.29,103.30,79.30$, $78.25,75.48,75.24,72.07,64.42,54.49 \mathrm{ppm} ; \mathrm{MS}$ (ESI) $\mathrm{m} / \mathrm{z}: 523[\mathrm{M}+$ $\mathrm{Na}]^{+}$.

\section{General procedure for the synthesis of triazoles 44-45a-e}

The appropriate alkyne ( 1 equiv) and the freshly synthesized phenylazide (1 equiv) were suspended in a 1:1 mixture of $\mathrm{H}_{2} \mathrm{O}$ and tert$\mathrm{BuOH}$ ( $1 \mathrm{~mL}$ each). To this, was added sodium ascorbate ( 0.1 equiv) and $\mathrm{CuSO}_{4} \cdot 5 \mathrm{H}_{2} \mathrm{O}$ (0.01 equiv). The mixture was then irradiated for $10 \mathrm{~min}$ at $125^{\circ} \mathrm{C}$. The mixture was then partitioned between a saturated aqueous solution of $\mathrm{NH}_{4} \mathrm{Cl}\left(10 \mathrm{~mL}+2 \mathrm{gtt} \mathrm{NH}_{4} \mathrm{OH}\right)$ and EtOAC $(15 \mathrm{~mL})$ and stirred for $15 \mathrm{~min}$. The organic layer was separated, dried $\left(\mathrm{Na}_{2} \mathrm{SO}_{4}\right)$, and solvent removed in vacuo to furnish the desired triazoles as pure compounds.

4-(4-Phenyl-1H-1,2,3-triazol-1-yl)phenol (44a): (7.75 mmol, 79\%). ${ }^{1} \mathrm{H}$ NMR $\left(400 \mathrm{MHz}, \mathrm{CD}_{3} \mathrm{OD}\right): \delta=8.65(\mathrm{~s}, 1 \mathrm{H}), 7.82(\mathrm{~d}, J=8.1 \mathrm{~Hz}, 2 \mathrm{H})$, $7.61(\mathrm{~d}, J=8.1 \mathrm{~Hz}, 2 \mathrm{H}), 7.40-7.36(\mathrm{~m}, 2 \mathrm{H}), 7.31-7.29(\mathrm{~m}, 1 \mathrm{H})$,
$6.89 \mathrm{ppm} \quad(\mathrm{d} ， J=8.1 \mathrm{~Hz}, 2 \mathrm{H}) ;{ }^{13} \mathrm{C}$ NMR $\quad\left(100 \mathrm{MHz}, \quad \mathrm{CD}_{3} \mathrm{OD}\right): \delta=$ $158.13,147.82,130.05,129.23,128.50,127.99,125.28,121.86$, 118.90, $115.67 \mathrm{ppm}$; MS (ESI) m/z: $236[\mathrm{M}-\mathrm{H}]^{-}$.

4-(4-(4-Methoxyphenyl)-1 H-1,2,3-triazol-1-yl)phenol

(44b): (2.72 mmol, $85 \%$ ). ${ }^{1} \mathrm{H}$ NMR ( $\left.400 \mathrm{MHz}, \mathrm{CD}_{3} \mathrm{OD}\right): \delta=8.44(\mathrm{~s}, 1 \mathrm{H}), 7.68$ $(\mathrm{d}, J=7.9 \mathrm{~Hz}, 2 \mathrm{H}), 7.55(\mathrm{~d}, J=7.9 \mathrm{~Hz}, 2 \mathrm{H}), 6.89-6.85(\mathrm{~m}, 4 \mathrm{H})$, $3.72 \mathrm{ppm}(\mathrm{s}, 3 \mathrm{H}) ;{ }^{13} \mathrm{C}$ NMR $\left(100 \mathrm{MHz}, \mathrm{CD}_{3} \mathrm{OD}\right): \delta=159.90,158.02$, $147.74,129.26,126.62,122.51,121.78,117.97,115.65,113.88$, 54.28 ppm; MS (ESI) m/z: $268[\mathrm{M}+\mathrm{H}]^{+}, 290[\mathrm{M}+\mathrm{Na}]^{+}$.

4-(4-Cyclohexenyl-1 H-1,2,3-triazol-1-yl)phenol (44 d): (1.46 mmol, $73 \%)$. ${ }^{1} \mathrm{H}$ NMR $\left(400 \mathrm{MHz}, \mathrm{CD}_{3} \mathrm{OD}\right): \delta=8.19(\mathrm{~s}, 1 \mathrm{H}), 7.53(\mathrm{~d}, J=$ $8.1 \mathrm{~Hz}, 2 \mathrm{H}), 6.86(\mathrm{~d}, J=8.1 \mathrm{~Hz}, 2 \mathrm{H}), 6.45(\mathrm{~s}, 1 \mathrm{H}), 2.37(\mathrm{brs}, 2 \mathrm{H}), 2.15$ (brs, 2H), 1.73 (brs, 2H), 1.64 ppm (brs, 2H); ${ }^{13} \mathrm{C}$ NMR (100 MHz, $\mathrm{CD}_{3} \mathrm{OD}$ ): $\delta=157.95,149.41,129.30,126.83,124.94,121.71,117.53$, 115.61, 25.82, 24.80, 22.09, 21.79 ppm; MS (ESI) m/z: $240[\mathrm{M}-\mathrm{H}]^{-}$.

4-(4-(Hydroxymethyl)-1H-1,2,3-triazol-1-yl)phenol

(44 e): (1.14 mmol, 57\%). ' $\mathrm{H}$ NMR (400 MHz, CD $\mathrm{OD}): \delta=8.21(\mathrm{~s}, 1 \mathrm{H}), 7.53$ $(\mathrm{d}, J=8.2 \mathrm{~Hz}, 2 \mathrm{H}), 6.87(\mathrm{~d}, J=8 \mathrm{~Hz}, 2 \mathrm{H}), 4.67 \mathrm{ppm}(\mathrm{s}, 2 \mathrm{H}) ;{ }^{13} \mathrm{C}$ NMR $\left(100 \mathrm{MHz}, \mathrm{CD}_{3} \mathrm{OD}\right): \delta=158.09,148.11,129.25,121.92,120.91$, 115.64, 55 ppm; MS (ESI) m/z: $190[M-H]^{-}$.

(S)-Methyl-2-(tert-butoxycarbonylamino)-3-((1-(4-hydroxyphenyl)-1H-1,2,3-triazol-4-yl)methoxy)propanoate (44 f): $(6.5 \mathrm{mmol}$, $67 \%) .[\alpha]_{D}:-1.47^{\circ}\left(c=10, \mathrm{CHCl}_{3}\right) ;{ }^{1} \mathrm{H}$ NMR $\left(400 \mathrm{MHz}, \mathrm{CDCl}_{3}\right): \delta=$ $7.91(\mathrm{~s}, 1 \mathrm{H}), 7.85(\mathrm{brs}, 1 \mathrm{H}), 7.40(\mathrm{~d}, J=7.8 \mathrm{~Hz}, 1 \mathrm{H}), 6.89(\mathrm{~d}, J=8 \mathrm{~Hz}$, $1 \mathrm{H}), 5.87$ (brs, 1 H), 5.65 (brs, 1 H), 4.78 (brs, 2H), 3.70 (brs, 3H), 2.10 (brs, $2 \mathrm{H}), 1.36 \mathrm{ppm}(\mathrm{s}, 9 \mathrm{H}) ;{ }^{13} \mathrm{C}$ NMR $\left(100 \mathrm{MHz}, \mathrm{CDCl}_{3}\right): \delta=$ $165.30,157.16,153.82,144.74,139.61,129.75,122.16,121.38$, $121.34,118.48,116.31,82.02,77.26,76.94,52.34,45.16,28.03$ ppm; MS (ESI) $m / z: 393[M+H]^{+}$.

1-(1-(4-Hydroxyphenyl)-1 H-1,2,3-triazol-4-yl)-2,3,4-tri-O-benzoyl$\beta$-D-ribofuranose $(\mathbf{4 4} \mathrm{g}):(0.256 \mathrm{mmol}, 72 \%) .[\alpha]_{D}:-4.25^{\circ} \quad(c=10$, $\left.\mathrm{CHCl}_{3}\right) ;{ }^{1} \mathrm{H}$ NMR $\left(400 \mathrm{MHz}, \mathrm{CHCl}_{3}\right): \delta=8.77(\mathrm{brs}, 1 \mathrm{H}), 7.97-7.91(\mathrm{~m}$, $4 \mathrm{H}), 7.80(\mathrm{~d}, J=8.2 \mathrm{~Hz}, 2 \mathrm{H}), 7.76(\mathrm{~s}, 1 \mathrm{H}), 7.48-7.44(\mathrm{~m}, 1 \mathrm{H}), 7.42-$ $7.33(\mathrm{~m}, 6 \mathrm{H}), 7.31-7.21(\mathrm{~m}, 4 \mathrm{H}), 6.98(\mathrm{~d}, J=8.2 \mathrm{~Hz}, 2 \mathrm{H}), 5.88-5.85$ $(\mathrm{m}, 1 \mathrm{H}, \mathrm{H}-2), 5.69(\mathrm{~d}, J=4.2 \mathrm{~Hz}, 1 \mathrm{H}, \mathrm{H}-1), 5.39(\mathrm{~s}, 1 \mathrm{H}, \mathrm{H}-4), 4.93-$ $4.90(\mathrm{~m}, 1 \mathrm{H}), 4.76-4.72(\mathrm{~m}, 3 \mathrm{H}), 4.55-4.51 \mathrm{ppm}(\mathrm{m}, 1 \mathrm{H}, \mathrm{H}-3)$; ${ }^{13} \mathrm{C} \mathrm{NMR} \quad\left(100 \mathrm{MHz}, \mathrm{CHCl}_{3}\right): \delta=166.34,165.48,165.31,157.66$, $144.04,133.57,133.45,133.22,129.72,129.67,129.43,129.36$, $128.93,128.72,128.47,128.34,122.30,121.52,116.48,104.78,79.41$ 75.59, 72.21, 64.56, $61.00 \mathrm{ppm}$; MS (ESI) $\mathrm{m} / \mathrm{z}: 634[\mathrm{M}-\mathrm{H}]^{-}$.

3-(4-Phenyl-1H-1,2,3-triazol-1-yl)phenol (45 a): (4.72 mmol, 77\%). ${ }^{1} \mathrm{H}$ NMR $\left(400 \mathrm{MHz}, \mathrm{CD}_{3} \mathrm{OD}\right): \delta=8.72(\mathrm{~s}, 1 \mathrm{H}), 7.83(\mathrm{~d}, J=8.1 \mathrm{~Hz}, 2 \mathrm{H})$, 7.40-7.37 (m, 2H), 7.31-7.24 (m, 3H), $6.59 \mathrm{ppm}(\mathrm{d}, J=8.1 \mathrm{~Hz}, 2 \mathrm{H})$; ${ }^{13} \mathrm{C}$ NMR $\left(100 \mathrm{MHz}, \mathrm{CD}_{3} \mathrm{OD}\right): \delta=158.11,151.77,130.31,129.30$, $128.55,128.10,125.33,118.95,115.54,112.37 \mathrm{ppm}$; MS (ESI) m/z: $236[M-H]^{-}$

3-(4-(4-Methoxyphenyl)-1H-1,2,3-triazol-1-yl)phenol

(45 b): (2.24 mmol, 70\%). ${ }^{1} \mathrm{H}$ NMR (400 MHz, $\left.\mathrm{CD}_{3} \mathrm{OD}\right): \delta=8.63(\mathrm{~s}, 1 \mathrm{H}), 7.75$ $(\mathrm{d}, J=7.9 \mathrm{~Hz}, 1 \mathrm{H}), 7.31-7.23(\mathrm{~m}, 3 \mathrm{H}), 6.95(\mathrm{~d}, J=7.9 \mathrm{~Hz}, 1 \mathrm{H})$, $6.84 \mathrm{ppm}(\mathrm{d}, J=8 \mathrm{~Hz}, 1 \mathrm{H}) ;{ }^{13} \mathrm{C}$ NMR $\left(100 \mathrm{MHz}, \mathrm{CD}_{3} \mathrm{OD}\right): \delta=160.04$, $158.56,137.94,130.27,126.68,122.45,117.89,115.43,113.92$, 110.63, 107.05, 54.30 ppm; MS (ESI) m/z: $266[M-H]^{-}$.

3-(4-(4-(Methylthio)phenyl)-1 H-1,2,3-triazol-1-yl)phenol (45 c): (0.26 mmol, $58 \%)$. ${ }^{~} \mathrm{H}$ NMR ( $\left.400 \mathrm{MHz}, \mathrm{CD}_{3} \mathrm{OD}\right): \delta=8.72(\mathrm{~s}, 1 \mathrm{H}), 7.78$ $(\mathrm{s}, 1 \mathrm{H}), 7.75(\mathrm{~s}, 1 \mathrm{H}), 7.34-7.24(\mathrm{~m}, 5 \mathrm{H}), 6.84 \mathrm{ppm}(\mathrm{d}, 1 \mathrm{H}, J=8.2 \mathrm{~Hz})$; ${ }^{13} \mathrm{C}$ NMR $\left(100 \mathrm{MHz}, \mathrm{CD}_{3} \mathrm{OD}\right): \delta=157.66,138.43,129.82,126.42$, 125.85, 121.90, 118.18, 116, 14.42 ppm; MS (ESI) m/z: $282[\mathrm{M}-\mathrm{H}]^{-}$.

1-(1-(4-Hydroxyphenyl)-1H-1,2,3-triazol-4-yl)-2,3,4-trihydroxy- $\beta$ D-ribofuranose (46): Compound $44 \mathrm{~g}(61 \mathrm{mg}, 0.07 \mathrm{mmol})$ was dis- 
solved in 4:1 MeOH/conc $\mathrm{NH}_{4} \mathrm{OH}(5 \mathrm{~mL})$ and stirred at room temperature for $18 \mathrm{~h}$. The reaction mixture was concentrated in vacuo and azeotroped 3 times with $\mathrm{EtOH}$. The crude product was dissolved in $\mathrm{H}_{2} \mathrm{O}(5 \mathrm{~mL})$, extracted with $\mathrm{CH}_{2} \mathrm{Cl}_{2}(3 \times 50 \mathrm{~mL})$ and the aqueous layer concentrated in vacuo to provide desired compound (0.069 mmol, 99\%). $[\alpha]_{\mathrm{D}}:-1.28^{\circ}\left(c=10, \mathrm{CHCl}_{3}\right) ;{ }^{1} \mathrm{H} \mathrm{NMR}(400 \mathrm{MHz}$, $\left.\mathrm{CD}_{3} \mathrm{OD}\right): \delta=8.27(\mathrm{~s}, 1 \mathrm{H}), 7.52(\mathrm{~d}, J=8.2 \mathrm{~Hz}, 2 \mathrm{H}), 6.86(\mathrm{~d}, J=8.2 \mathrm{~Hz}$, $2 \mathrm{H}), 4.95(\mathrm{~s}, 1 \mathrm{H}, \mathrm{H}-4), 4.81(\mathrm{~d}, J=11.9 \mathrm{~Hz}, 1 \mathrm{H}), 4.62(\mathrm{~d}, J=11.9 \mathrm{~Hz}$, $1 \mathrm{H}), 4.08-4.05(\mathrm{~m}, 1 \mathrm{H}, \mathrm{H}-2), 3.95-3.88(\mathrm{~m}, 2 \mathrm{H}), 3.72-3.69(\mathrm{~m}, 1 \mathrm{H}$, $\mathrm{H}-1), 3.56-3.51 \mathrm{ppm}(\mathrm{m}, 1 \mathrm{H}, \mathrm{H}-3)$; MS (ESI) $\mathrm{m} / \mathrm{z}: 322[\mathrm{M}-\mathrm{H}]^{-}$.

\section{General procedure for the synthesis of compounds $47-48 a-h$}

To a solution of 4-chloro-7-nitrobenzofurazan $(0.25 \mathrm{mmol}, 1$ equiv) in $\mathrm{EtOH}$ the appropriate triazole (1.1 equiv) and a catalytic amount of KOAC and pyridine were added. The resulting mixture was heated at reflux for $3 \mathrm{~h}$. This was concentrated in vacuo and the crude product was purified by flash chromatography with the appropriate eluent.

4-Nitro-7-(4-(4-phenyl-1H-1,2,3-triazol-1-yl)phenoxy)benzo[c][1,2,5]oxadiazole (47 a): $(0.23 \mathrm{mmol}, 91 \%)$. ${ }^{1} \mathrm{H} \mathrm{NMR} \quad(400 \mathrm{MHz}$, [D $\mathrm{D}_{6}$ ]acetone): $\delta=9.00(\mathrm{~s}, 1 \mathrm{H}), 8.64(\mathrm{~d}, 1 \mathrm{H}, J=7.8 \mathrm{~Hz}), 8.13(\mathrm{~d}, J=$ $8.2 \mathrm{~Hz}, 2 \mathrm{H}) 7.94(\mathrm{~d}, J=8.1 \mathrm{~Hz}, 2 \mathrm{H}), 7.64(\mathrm{~d}, J=8.1 \mathrm{~Hz}, 2 \mathrm{H}), 7.45-$ $7.41(\mathrm{~m}, 2 \mathrm{H}), 7.32(\mathrm{t}, 1 \mathrm{H}, J=8.2 \mathrm{~Hz}), 6.94 \mathrm{ppm}(\mathrm{d}, 1 \mathrm{H}, J=7.8 \mathrm{~Hz})$; ${ }^{13} \mathrm{C} \mathrm{NMR}(100 \mathrm{MHz}$, [D 6 ]acetone): $\delta=153.23,153.13,148.03,135.58$, $134.27,128.77,128.14,125.46,122.39,122.31,118.73,109.82$ ppm; MS (ESI) $m / z: 435[M+C l]^{-}$.

4-(4-(4-(4-Methoxyphenyl)-1 H-1,2,3-triazol-1-yl)phenoxy)-7nitrobenzo[c][1,2,5]oxadiazole (47 b): $(0.22 \mathrm{mmol}, 88 \%) .{ }^{1} \mathrm{H}$ NMR (400 MHz, [D $\mathrm{D}_{6}$ ]acetone): $\delta=8.87(\mathrm{~s}, 1 \mathrm{H}), 8.61(\mathrm{~d}, J=7.8 \mathrm{~Hz}, 1 \mathrm{H})$, $8.11(\mathrm{~d}, 2 \mathrm{H}, J=8.2 \mathrm{~Hz}) 7.86(\mathrm{~d}, 2 \mathrm{H}, J=8.1 \mathrm{~Hz}), 7.63(\mathrm{~d}, J=8.1 \mathrm{~Hz}$, $2 \mathrm{H}), 6.99(\mathrm{~d}, J=8.2 \mathrm{~Hz}, 2 \mathrm{H}), 6.93(\mathrm{~d}, J=7.8 \mathrm{~Hz}, 1 \mathrm{H}), 3.79 \mathrm{ppm}(\mathrm{s}$, $3 \mathrm{H}) ;{ }^{13} \mathrm{C}$ NMR $(100 \mathrm{MHz}$, [D ] acetone): $\delta=161.40,154.76,154.62$, $149.44,147.42,146.41,137.29,136.94,132.75,128.76,124.28$, 123.79, 120.78, 118.12, 116.47, 112.59, 57.23 ppm; MS (ESI) m/z: 429 $[\mathrm{M}-\mathrm{H}]^{-}$.

4-(4-(4-Cyclohexenyl-1H-1,2,3-triazol-1-yl)phenoxy)-7nitrobenzo[c][1,2,5]oxadiazole $(47 \mathrm{~d}):(0.217 \mathrm{mmol}, 87 \%) .{ }^{1} \mathrm{H}$ NMR (400 MHz, [D $\mathrm{D}_{6}$ ]acetone): $\delta=8.60(\mathrm{~d}, J=7.9 \mathrm{~Hz}, 1 \mathrm{H}), 8.48(\mathrm{~s}, 1 \mathrm{H})$, $8.06(\mathrm{~d}, J=8.0 \mathrm{~Hz}, 1 \mathrm{H}) 7.60(\mathrm{~d}, J=8.0 \mathrm{~Hz}, 1 \mathrm{H}), 6.91(\mathrm{~d}, J=7.9 \mathrm{~Hz}$, $1 \mathrm{H}), 6.57-6.55(\mathrm{~m}, 1 \mathrm{H}), 2.40-2.38(\mathrm{~m}, 2 \mathrm{H}), 2.17-2.14(\mathrm{~m}, 2 \mathrm{H}), 1.74-$ $1.71 \quad(m, 2 H), \quad 1.65-1.61 \mathrm{ppm} \quad(\mathrm{m}, 2 \mathrm{H}) ;{ }^{13} \mathrm{C} \mathrm{NMR} \quad(100 \mathrm{MHz}$, $\left[\mathrm{D}_{6}\right.$ ]acetone): $\delta=152.8,145.5,143.2,135.6,134.1,127.3,124.6$, $122.25,122.13,117.11,111.47,109.73,25.94,24.85,22.23,22.0$ ppm; MS (ESI) m/z: $403[\mathrm{M}-\mathrm{H}]^{-}, 439[\mathrm{M}+\mathrm{Cl}]^{-}$.

(1-(4-(7-Nitrobenzo[c][1,2,5]oxadiazol-4-yloxy)phenyl)-1H-1,2,3triazol-4-yl)methanol (47e): $0.21 \mathrm{mmol}, 85 \%$. ${ }^{1} \mathrm{H}$ NMR $(400 \mathrm{MHz}$, [D $\mathrm{D}_{6}$ ]acetone): $\delta=8.61(\mathrm{~d}, J=7.8 \mathrm{~Hz}, 1 \mathrm{H}), 8.43(\mathrm{~s}, 1 \mathrm{H}), 8.06(\mathrm{~d}, J=$ $8.2 \mathrm{~Hz}, 2 \mathrm{H}), 7.60(\mathrm{~d}, J=8.2 \mathrm{~Hz}, 2 \mathrm{H}), 6.91(\mathrm{~d}, J=7.8 \mathrm{~Hz}, 1 \mathrm{H})$, $4.72 \mathrm{ppm} \quad(\mathrm{s}, 2 \mathrm{H}) ;{ }^{13} \mathrm{C}$ NMR $\left(100 \mathrm{MHz}, \quad\left[\mathrm{D}_{6}\right.\right.$ ]acetone $): \delta=154.90$, $154.55,151.20,147.19,146.17,137.27,135.92,132.81,123.94$, $123.88,121.93,111.36,57.36$ ppm; MS (ESI) m/z: $377\left[\mathrm{M}+\mathrm{Cl}^{-}, 389\right.$ $[\mathrm{M}+\mathrm{Na}]^{+}$.

(R)-Methyl-2-(tert-butoxycarbonylamino)-3-((1-(4--(7nitrobenzo[c][1,2,5] oxadiazol-4-yloxy)phenyl)-1 H-1,2,3-triazol-4yl)methoxy)propanoate $(47 \mathrm{f}):(0.157 \mathrm{mmol}, 63 \%) .[\alpha]_{\mathrm{D}}:+2.65^{\circ}$ $(c=10, \mathrm{MeOH}) ;{ }^{1} \mathrm{H} \mathrm{NMR}\left(400 \mathrm{MHz}, \mathrm{CDCl}_{3}\right): \delta=8.37(\mathrm{~d}, J=7.8 \mathrm{~Hz}$, $1 \mathrm{H}), 8.10(\mathrm{~s}, 1 \mathrm{H}), 7.83(\mathrm{~d}, J=8.2 \mathrm{~Hz}, 1 \mathrm{H}), 7.37(\mathrm{~d}, J=8.2 \mathrm{~Hz}, 1 \mathrm{H})$, $6.59(\mathrm{~d}, J=7.8 \mathrm{~Hz}, 1 \mathrm{H}), 5.82(\mathrm{brs}, 1 \mathrm{H}), 5.61(\mathrm{brs}, 1 \mathrm{H}), 4.78$ (brs, $2 \mathrm{H}), 3.70$ (brs, 4H), $1.34 \mathrm{ppm}(\mathrm{s}, 9 \mathrm{H}) ;{ }^{13} \mathrm{C} \mathrm{NMR}\left(100 \mathrm{MHz}, \mathrm{CDCl}_{3}\right)$ : $\delta=165.24,153.39,152.58,145.82,144.98,144.07,139.82,135.58$,
133.06, 131.13，122.64，122.25，117.61，108.37,81.76，52.26，45.19， $27.99 \mathrm{ppm} ; \mathrm{MS}(\mathrm{ESI}) \mathrm{m} / \mathrm{z}: 556[\mathrm{M}+\mathrm{H}]^{+}$.

1-(1-(4-(7-Nitrobenzo[c][1,2,5]oxadiazol-4-yloxy)phenyl)-1H-1,2,3-

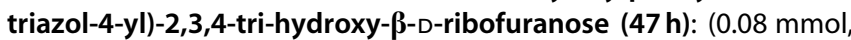
$32 \%) .[\alpha]_{D}:-1.09^{\circ}(c=10, \mathrm{MeOH}) ;{ }^{1} \mathrm{H}$ NMR $\left(400 \mathrm{MHz},\left[\mathrm{D}_{6}\right]\right.$ acetone): $\delta=8.60(\mathrm{~d}, J=8.0 \mathrm{~Hz}, 1 \mathrm{H}), 8.55(\mathrm{~s}, 1 \mathrm{H}), 8.06(\mathrm{~d}, J=8.2 \mathrm{~Hz}, 1 \mathrm{H}), 7.60$ $(\mathrm{d}, J=8.2 \mathrm{~Hz}, 1 \mathrm{H}), 6.91(\mathrm{~d}, J=8.0 \mathrm{~Hz}, 1 \mathrm{H}), 4.98(\mathrm{~s}, 1 \mathrm{H}, \mathrm{H}-4), 4.81(\mathrm{~d}$, $J=11.8 \mathrm{~Hz}, 1 \mathrm{H}), 4.67(\mathrm{~d}, J=11.8 \mathrm{~Hz}, 1 \mathrm{H}), 4.18-4.16(\mathrm{~m}, 1 \mathrm{H}, \mathrm{H}-2)$, 3.91-3.89 (m, 2H), $5.68(\mathrm{~d}, J=11.9 \mathrm{~Hz}, 1 \mathrm{H}, \mathrm{H}-1), 3.56-3.52(\mathrm{~m}, 1 \mathrm{H}$,

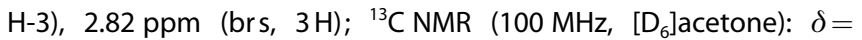
$153.24,153.08,145.73,145.57,144.56,135.50,134.32,131.23$, $122.48,122.27,121.71,109.83,106.83,84.56,75.26,70.85,62.92$, $60.07 \mathrm{ppm}$; MS (ESI) m/z: $485[\mathrm{M}-\mathrm{H}]^{-}$.

4-Nitro-7-(3-(4-phenyl-1H-1,2,3-triazol-1-yl)phenoxy)benzo[c][1,2,5]oxadiazole (48a): $(0.225 \mathrm{mmol}, 90 \%)$. ${ }^{1} \mathrm{H} \mathrm{NMR}(400 \mathrm{MHz}$, [D $\mathrm{D}_{6}$ ]acetone): $\delta=8.99(\mathrm{~s}, 1 \mathrm{H}), 8.60(\mathrm{~d}, J=7.8 \mathrm{~Hz}, 1 \mathrm{H}), 8.02(\mathrm{~s}, 1 \mathrm{H})$, $8.00(\mathrm{~d}, J=8.2 \mathrm{~Hz}, 1 \mathrm{H}), 7.94(\mathrm{~d}, J=8.2 \mathrm{~Hz}, 1 \mathrm{H}), 7.79(\mathrm{t}, J=8.2 \mathrm{~Hz}$, $1 \mathrm{H}), 7.51(\mathrm{~d}, J=8.1 \mathrm{~Hz}, 1 \mathrm{H}), 7.42-7.40(\mathrm{~m}, 2 \mathrm{H}), 7.32-7.29(\mathrm{~m}, 1 \mathrm{H})$, $6.99 \mathrm{ppm}(\mathrm{d}, J=7.8 \mathrm{~Hz}, 1 \mathrm{H}) ;{ }^{13} \mathrm{C}$ NMR $\left(100 \mathrm{MHz},\left[\mathrm{D}_{6}\right.\right.$ ]acetone): $\delta=$ $155.94,154.34,149.50,141.41,146.40,140.23,137.26,134.26$, $132.88,132.03,131.01,130.35,127.36,122.70,121.77,119.98$, 114.61, 112.93 ppm; MS (ESI) m/z: $435\left[\mathrm{M}+\mathrm{Cl}^{-}\right.$.

4-(3-(4-(4-Methoxyphenyl)-1 H-1,2,3-triazol-1-yl)phenoxy)-7nitrobenzo[c][1,2,5]oxadiazole (48 b): $(0.217 \mathrm{mmol}, 87 \%) .{ }^{1} \mathrm{H}$ NMR (400 MHz, [D ]acetone): $\delta=8.85(\mathrm{~s}, 1 \mathrm{H}), 8.57(\mathrm{~d}, J=7.8 \mathrm{~Hz}, 1 \mathrm{H})$, $7.98(\mathrm{~s}, 1 \mathrm{H}), 7.96(\mathrm{~d}, J=8.2 \mathrm{~Hz}, 1 \mathrm{H}), 7.80-7.74(\mathrm{~m}, 3 \mathrm{H}), 7.48(\mathrm{~d}, J=$ $8.2 \mathrm{~Hz}, 1 \mathrm{H}), \quad 6.97-6.92(\mathrm{~m}, 3 \mathrm{H}), 3.76 \mathrm{ppm} \quad(\mathrm{s}, 1 \mathrm{H}) ;{ }^{13} \mathrm{C} \mathrm{NMR}$ (100 MHz, [D $]$ acetone): $\delta=161.43,155.91,154.36,149.46,147.38$, $146.37,140.29,137.23,134.21,132.84,128.73,124.55,122.56$, $120.67,119.86,116.45,114.48,112.84,57.20$ ppm; MS (ESI) m/z: 429 $[\mathrm{M}-\mathrm{H}]^{-}$.

4-(3-(4-(4-(Methylthio)phenyl)-1H-1,2,3-triazol-1-yl)phenoxy)-7nitrobenzo[c][1,2,5]oxadiazole $(48 \mathrm{c})$ : $(0.14 \mathrm{mmol}, 57 \%)$. ' $\mathrm{H}$ NMR (400 MHz, [D $\mathrm{D}_{6}$ ]acetone): $\delta=8.97(\mathrm{~s}, 1 \mathrm{H}), 8.60(\mathrm{~d}, J=7.8 \mathrm{~Hz}, 1 \mathrm{H})$, $8.02(\mathrm{~s}, 1 \mathrm{H}), 8.00(\mathrm{~d}, J=8.2 \mathrm{~Hz}, 1 \mathrm{H}), 7.84(\mathrm{~d}, J=8.1 \mathrm{~Hz}, 2 \mathrm{H}), 7.79(\mathrm{t}$, $J=8.2 \mathrm{~Hz}, 1 \mathrm{H}), 7.51(\mathrm{~d}, J=8.2 \mathrm{~Hz}, 1 \mathrm{H}), 7.31(\mathrm{~d}, J=8.1 \mathrm{~Hz}, 2 \mathrm{H}), 6.99$ $(\mathrm{d}, J=8 \mathrm{~Hz}, 1 \mathrm{H}), 2.46 \mathrm{ppm}(\mathrm{s}, 1 \mathrm{H}) ;{ }^{13} \mathrm{C}$ NMR $\left(100 \mathrm{MHz},\left[\mathrm{D}_{6}\right.\right.$ ] lacetone): $\delta=154.38,153.02,147.75,145.59,139.13,138.90,134.28,131.37$, $127.08,126.37,126.00,125.75,120.71,120.48,118.33,112.97$, $112.81,110.12,14.50 \mathrm{ppm}$; MS (ESI) $\mathrm{m} / \mathrm{z}: 469[\mathrm{M}+\mathrm{Na}]^{+}, 481[\mathrm{M}+$ $\mathrm{Cl}]^{-}$.

\section{General procedure for reduction of nitro to 7-amino deriva- tives $(50 a-c)$}

The appropriate nitro compound $(5.6 \mathrm{mmol})$ was dissolved in a mixture of $\mathrm{CH}_{2} \mathrm{Cl}_{2}(200 \mathrm{~mL})$, conc $\mathrm{HCl}(12 \mathrm{~mL})$ and $\mathrm{MeOH}(90 \mathrm{~mL})$. After the addition of $\mathrm{Fe}^{0}(2.13 \mathrm{~g})$, the mixture was stirred for $25 \mathrm{~min}$ at room temperature. The reaction mixture was poured into $\mathrm{H}_{2} \mathrm{O}$ $(100 \mathrm{~mL})$ and extracted with $\mathrm{CH}_{2} \mathrm{Cl}_{2}(3 \times 150 \mathrm{~mL})$. The organic layer was dried over anhydrous $\mathrm{Na}_{2} \mathrm{SO}_{4}$ and concentrated in vacuo. The crude product was then purified by flash chromatography (Hex/ EtOAc 3:2).

7-(4-Bromobenzylthio)benzo[c][1,2,5]oxadiazol-4-amine (50a): (4.87 mmol, $87 \%)$. ${ }^{1} \mathrm{H} \mathrm{NMR}\left(400 \mathrm{MHz}, \mathrm{CDCl}_{3}\right): \delta=7.25$ (d, $J=4.5 \mathrm{~Hz}$, $2 \mathrm{H}), 7.01(\mathrm{~d}, J=7.8 \mathrm{~Hz}, 1 \mathrm{H}), 6.94(\mathrm{~d}, J=4 \mathrm{~Hz}, 2 \mathrm{H}), 6.13(\mathrm{~d}, J=$ $7.8 \mathrm{~Hz}, 1 \mathrm{H}), 4.57$ (brs, $2 \mathrm{H}), 4.07$ ppm (s, 2H); MS (ESI) m/z: 334-336 $[\mathrm{M}-\mathrm{H}]^{-}$.

7-(4-Bromophenylthio)benzo[c][1,2,5]oxadiazol-4-amine (50 b): (2.91 mmol, $52 \%)$. ' $\mathrm{H}$ NMR (400 MHz, $\left.\mathrm{CDCl}_{3}\right): \delta=7.36-7.34$ (d, $J=$ 
7.8, $1 \mathrm{H}), 7.29-7.27(\mathrm{~d}, J=8,2 \mathrm{H}), 7.09-7.07(\mathrm{~d}, J=8,2 \mathrm{H}), 6.29-6.27$ $(\mathrm{d}, J=7.8,1 \mathrm{H}), 4.73 \mathrm{ppm}(\mathrm{brs}, 2 \mathrm{H}) ;{ }^{13} \mathrm{C}$ NMR $\left(100 \mathrm{MHz}, \mathrm{CDCl}_{3}\right): \delta=$ 147.99, 141.43, 136.89, 134.02, 131.96, 130.65, 129.72, 126.44, 125.05, $121.62 \mathrm{ppm}$; MS (ESI) m/z: $323[M+\mathrm{H}]^{+}$.

3-(7-Aminobenzo[c][1,2,5]oxadiazol-4-ylthio)-1-morpholinopropan-1-one (50 c): $(5.15 \mathrm{mmol}, 92 \%)$. ${ }^{1} \mathrm{H} \mathrm{NMR}\left(400 \mathrm{MHz}, \mathrm{CDCl}_{3}\right): \delta=$ $29(\mathrm{~d}, J=7.8 \mathrm{~Hz}, 1 \mathrm{H}), 6.34(\mathrm{~d}, J=7.8 \mathrm{~Hz}, 1 \mathrm{H}), 5.99(\mathrm{brs}, 2 \mathrm{H}), 3.49$ $3.44(\mathrm{~m}, 4 \mathrm{H}), 3.38-3.35(\mathrm{~m}, 4 \mathrm{H}), 3.13(\mathrm{t}, J=8 \mathrm{~Hz}, 2 \mathrm{H}), 2.59 \mathrm{ppm}(\mathrm{t}$, $J=8 \mathrm{~Hz}, 2 \mathrm{H}) ;{ }^{13} \mathrm{C} \mathrm{NMR}\left(100 \mathrm{MHz}, \mathrm{CDCl}_{3}\right): \delta=169.40,151.13,145.56$, $139.05,136.89,106.84,105.60,66.58,45.83,41.81,33.13$ ppm; MS (ESI) $m / z: 309[\mathrm{M}+\mathrm{Na}]^{+}$.

\section{General procedure for 7-chloro derivatives $51 a, b$}

To a solution of $\mathrm{CuCl}_{2}(0.15 \mathrm{mmol})$ and tert-butyl nitrite $(0.19 \mathrm{mmol})$ in dry $\mathrm{CH}_{3} \mathrm{CN}$ at $65^{\circ} \mathrm{C}$ was slowly added the appropriate amine previously solubilized in $\mathrm{CH}_{3} \mathrm{CN}$. During the addition the reaction solution turned black from the initial green color. The mixture was stirred at $65^{\circ} \mathrm{C}$ for further $3 \mathrm{~h}$, then was quenched with $3 \mathrm{~N} \mathrm{HCl}$ and extracted with $\mathrm{Et}_{2} \mathrm{O}$. The organic layer was dried over $\mathrm{Na}_{2} \mathrm{SO}_{4}$ filtered off and concentrated and the residue was purified by flash chromatography (Hex/EtOAc 4:1).

\section{4-Chloro-7-(4-methoxybenzylthio)benzo[c][1,2,5]oxadiazole}

(51 a): Yellow solid (1.86 mmol, $65 \%)$. ${ }^{1} \mathrm{H} N M R\left(400 \mathrm{MHz}, \mathrm{CDCl}_{3}\right)$ : $\delta=8.29-8.27(\mathrm{~d}, J=8,1 \mathrm{H}), 7.29-7.27(\mathrm{~d}, J=8,2 \mathrm{H}), 7.13-7.11(\mathrm{~d}$, $J=8,1 \mathrm{H}), 6.82-6.80(\mathrm{~d}, J=8,2 \mathrm{H}), 4.41(\mathrm{~s}, 2 \mathrm{H}), 3.73 \mathrm{ppm}(\mathrm{s}, 2 \mathrm{H})$; ${ }^{13} \mathrm{C} \mathrm{NMR} \quad\left(100 \mathrm{MHz}, \quad \mathrm{CDCl}_{3}\right): \delta=159.76,146.32,144.87,130.48$, $128.36,127.51,126.83,117.53,115.62,113.56,57.02,36.45$ ppm; MS (ESI) $m / z: 329[\mathrm{M}+\mathrm{Na}]^{+}$.

4-(4-Bromophenylthio)-7-chlorobenzo[c][1,2,5]oxadiazole (51 b): Yellow solid (1.51 mmol, 52\%). 'H NMR $\left(400 \mathrm{MHz}^{1} \mathrm{CDCl}_{3}\right): \delta=7.51-$ 7.49 (d, $J=8.3,2 \mathrm{H}), 7.38-7.36(\mathrm{~d}, J=8.3,2 \mathrm{H}), 7.19-7.17$ (d, $J=7.8$, $1 \mathrm{H}), 6.78-6.76 \mathrm{ppm}(\mathrm{d}, J=7.8,1 \mathrm{H}) ;{ }^{13} \mathrm{C}$ NMR $\left(100 \mathrm{MHz}, \mathrm{CDCl}_{3}\right): \delta=$ $136.65,135.69,133.20,130.41,128.79,128.28,126.92,124.27$, 122.41, 119.73 ppm; MS (ESI) $\mathrm{m} / \mathrm{z}: 342[\mathrm{M}+\mathrm{H}]^{+}$

3-(7-lodobenzo[c][1,2,5]oxadiazol-4-ylthio)-1-morpholinopropan1-one (52 c): To a cooled solution $\left(0^{\circ} \mathrm{C}\right)$ of compound $50 \mathrm{c}$ $(2.25 \mathrm{mmol})$ in concentrated $\mathrm{HCl}(0.56 \mathrm{~mL})$ and $98 \% \mathrm{H}_{2} \mathrm{SO}_{4}(2 \mathrm{~mL})$ was added dropwise a solution of $\mathrm{NaNO}_{2}(2.23 \mathrm{mmol})$ in $1 \mathrm{~mL} \mathrm{H}_{2} \mathrm{O}$. The mixture was stirred vigorously at $0^{\circ} \mathrm{C}$ for $40 \mathrm{~min}$. Then, a solution of $\mathrm{KI}(4.5 \mathrm{mmol})$ in $0.9 \mathrm{~mL}$ of $\mathrm{H}_{2} \mathrm{O}$ was added dropwise, and the mixture was stirred at room temperature for $2 \mathrm{~h}$. The product was extracted with EtOAc, washed with a saturated $\mathrm{Na}_{2} \mathrm{CO}_{3}$ solution, $\mathrm{H}_{2} \mathrm{O}$ and brine. After drying on anhydrous $\mathrm{Na}_{2} \mathrm{SO}_{4}$, the solution was concentrated in vacuo. The crude product was then purified by flash chromatography (Hex/EtOAc 3:1) to provide desired compound (2.07 mmol, 92\%). ${ }^{1} \mathrm{H}$ NMR $\left(400 \mathrm{MHz}, \mathrm{CDCl}_{3}\right): \delta=7.66$ $(\mathrm{d}, J=8 \mathrm{~Hz}, 1 \mathrm{H}), 6.91(\mathrm{~d}, J=8 \mathrm{~Hz}, 1 \mathrm{H}), 3.59-3.54(\mathrm{~m}, 6 \mathrm{H}), 3.40(\mathrm{t}$, $J=8 \mathrm{~Hz}, 2 \mathrm{H}), 3.37-3.35(\mathrm{~m}, 2 \mathrm{H}), 2.69 \mathrm{ppm}(\mathrm{t}, J=8 \mathrm{~Hz}, 2 \mathrm{H}) ;{ }^{13} \mathrm{C} \mathrm{NMR}$ $\left(100 \mathrm{MHz}, \mathrm{CDCl}_{3}\right): \delta=168.84,151.25,147.77,140.85,128.12,127.80$, $66.69,66.39,45.69,42.07,32.42,27.36 \mathrm{ppm}$.

7-(4-Methoxybenzylthio)benzo[c][1,2,5]oxadiazol-4-amine hydrochloride (53 a): Compound 53 a was obtained using the same procedure as for $39 \mathbf{a}, \mathbf{b}(1.5 \mathrm{mmol}, 75 \%)$. ${ }^{1} \mathrm{H} \mathrm{NMR}\left(400 \mathrm{MHz}, \mathrm{CDCl}_{3}\right)$ : $\delta=7.02-7.01(\mathrm{~d}, 3 \mathrm{H}), 6.68(\mathrm{~d}, J=8 \mathrm{~Hz}, 2 \mathrm{H}), 6.12(\mathrm{~d}, J=8 \mathrm{~Hz}, 1 \mathrm{H})$, 4.55 (brs, 2H), $4.08(\mathrm{~s}, 2 \mathrm{H}), 3.68 \mathrm{ppm}(\mathrm{s}, 3 \mathrm{H}) ; \mathrm{MS}(\mathrm{ESI}) \mathrm{m} / \mathrm{z}: 286$ $[\mathrm{M}-\mathrm{H}]^{-}$.

$\mathrm{N}$-(7-(3-Morpholino-3-oxopropylthio)benzo[c][1,2,5]oxadiazol-4yl)acetamide $(54 \mathrm{c})$ : To a solution of compound $50 \mathrm{c}(0.56 \mathrm{mmol})$ in pyridine $(3 \mathrm{~mL}), \mathrm{Ac}_{2} \mathrm{O}(0.61 \mathrm{mmol})$ was added and the mixture was stirred at room temperature for $1 \mathrm{~h}$. The reaction mixture was quenched with saturated aqueous solution of $\mathrm{NaHCO}_{3}(10 \mathrm{~mL})$ and extracted with EtOAc $(3 \times 10 \mathrm{~mL})$. The combined extract was dried over anhydrous $\mathrm{Na}_{2} \mathrm{SO}_{4}$, filtered and concentrated in vacuo and the crude product was purified by flash chromatography (EtOAc/Hex $3: 1)$ to provide desired compound $(0.509 \mathrm{mmol}, 91 \%)$. ${ }^{1} \mathrm{H}$ NMR $\left(400 \mathrm{MHz}, \mathrm{CDCl}_{3}\right): \delta=8.12(\mathrm{~d}, J=8 \mathrm{~Hz}, 1 \mathrm{H}), 8.00$ (brs, $\left.1 \mathrm{H}\right), 7.25(\mathrm{~d}$, $J=8 \mathrm{~Hz}, 1 \mathrm{H}), 3.59-3.54(\mathrm{~m}, 6 \mathrm{H}), 3.39-3.34(\mathrm{~m}, 4 \mathrm{H}), 2.65(\mathrm{t}, J=8 \mathrm{~Hz}$, $2 \mathrm{H}), 2.24 \mathrm{ppm}(\mathrm{s}, 3 \mathrm{H}) ;{ }^{13} \mathrm{C} \mathrm{NMR}\left(100 \mathrm{MHz}, \mathrm{CDCl}_{3}\right): \delta=169.13$, $168.69,139.88,132.31,124.42,116.89,111.18,90.26,66.73,66.41$, $45.69,41.99,32.99,28.34,24.55$ ppm.

7-Chloro- $N, N$-dimethylbenzo[C][1,2,5]oxadiazole-4-sulfonamide (56): 4-Chlorosulfonyl-7-chloro-2,1,3-benzoxadiazole 55 (200 mg, $0.92 \mathrm{mmol})$ was dissolved in $\mathrm{CH}_{3} \mathrm{CN}(6 \mathrm{~mL})$. After the addition of $\mathrm{Me}_{2} \mathrm{NH}$ (0.9 equiv) and $\mathrm{Et}_{3} \mathrm{~N}$ (cat.), the mixture was stirred at room temperature for $3 \mathrm{~h}$. The reaction mixture was evaporated to dryness under reduced pressure, and the residue was separated by chromatography on silica gel using $\mathrm{CH}_{2} \mathrm{Cl}_{2}$. To give desired compound $(0.84 \mathrm{mmol}, 92 \%)$. ${ }^{1} \mathrm{H}$ NMR $\left(400 \mathrm{MHz}, \mathrm{CDCl}_{3}\right): \delta=7.89$ (d, $J=$ $7.8 \mathrm{~Hz}, 1 \mathrm{H}), 7.49(\mathrm{~d}, J=7.8 \mathrm{~Hz}, 1 \mathrm{H}), 2.88 \mathrm{ppm}(\mathrm{s}, 6 \mathrm{H}) ;{ }^{13} \mathrm{C} \mathrm{NMR}$ $\left(100 \mathrm{MHz}, \mathrm{CDCl}_{3}\right): \delta=150.40,147.20,135.99,130.68,129.21,127.58$, 39.18 ppm; MS (ESI) m/z: 284-286 [M+Na] ${ }^{+}$.

\section{General procedure for the synthesis of compounds 58 a-d}

To a solution of compound $56(65 \mathrm{mg}, 0.25 \mathrm{mmol})$ in $5 \mathrm{~mL}$ of EtOH was added the appropriate nucleophile $(0.27 \mathrm{mmol})$ and a catalytic amount of pyridine $(0.05 \mathrm{~mL})$ or of $\mathrm{KOAC}(0.01 \mathrm{mmol})$. The reaction mixture was heated at reflux for $2 \mathrm{~h}$. The mixture was then concentrated in vacuo and the crude product was purified by flash chromatography (Hex/EtOAc 3:2).

7-(4-Methoxybenzylthio)- $\mathrm{N}, \mathrm{N}$-dimethylbenzo[c][1,2,5]oxadiazole4-sulfonamide (58a): $(0.23 \mathrm{mmol}, 92 \%)$. ${ }^{1} \mathrm{H}$ NMR $\left(400 \mathrm{MHz}, \mathrm{CDCl}_{3}\right)$ : $\delta=7.77(\mathrm{~d}, J=7.8 \mathrm{~Hz}, 1 \mathrm{H}), 7.26(\mathrm{~d}, J=8.1 \mathrm{~Hz}, 2 \mathrm{H}), 7.09(\mathrm{~d}, J=$ $7.8 \mathrm{~Hz}, 1 \mathrm{H}), 6.80(\mathrm{~d}, J=8.1 \mathrm{~Hz}, 2 \mathrm{H}), 4.35(\mathrm{~s}, 2 \mathrm{H}), 3.75(\mathrm{~s}, 3 \mathrm{H})$, $2.85 \mathrm{ppm}(\mathrm{s}, 6 \mathrm{H}) ;{ }^{13} \mathrm{C} \mathrm{NMR}\left(100 \mathrm{MHz}, \mathrm{CDCl}_{3}\right): \delta=160.96,150.32$, $146.64,137.24,136.22,131.56,127.71,124.61,123.43,115.90,56.84$, 39.22, $37.61 \mathrm{ppm}$; MS (ESI) m/z: $402[\mathrm{M}+\mathrm{Na}]^{+}$.

7-(4-Bromobenzylthio)- $N, N$-dimethylbenzo[C][1,2,5]oxadiazole-4sulfonamide (58 b): $(0.227 \mathrm{mmol}, 91 \%)$. ${ }^{1} \mathrm{H}$ NMR $\left(400 \mathrm{MHz}, \mathrm{CDCl}_{3}\right)$ : $\delta=7.76(\mathrm{~d}, J=7.9 \mathrm{~Hz}, 1 \mathrm{H}), 7.39(\mathrm{~d}, J=7.7 \mathrm{~Hz}, 2 \mathrm{H}), 7.22(\mathrm{~d}, J=$ $7.7 \mathrm{~Hz}, 2 \mathrm{H}), 7.08(\mathrm{~d}, J=7.9 \mathrm{~Hz}, 1 \mathrm{H}), 4.35(\mathrm{~s}, 2 \mathrm{H}), 2.85 \mathrm{ppm}(\mathrm{s}, 6 \mathrm{H})$; ${ }^{13} \mathrm{C} \mathrm{NMR} \quad\left(100 \mathrm{MHz}, \quad \mathrm{CDCl}_{3}\right): \quad \delta=150.32,146.65,136.19,136.08$, $135.25,133.65,131.96,125.30,124.07,123.64,39.22,37.43$ ppm; MS (ESI) $m / z:$ :450-452 [M+Na] ${ }^{+}$.

$N, N$-Dimethyl-7-(3-nitrobenzylthio)benzo[c][1,2,5]oxadiazole-4sulfonamide (58c): $(0.23 \mathrm{mmol}, 93 \%)$. ${ }^{1} \mathrm{H}$ NMR $\left(400 \mathrm{MHz}, \mathrm{CDCl}_{3}\right)$ : $\delta=8.21(\mathrm{~s}, 1 \mathrm{H}), 8.08(\mathrm{~d}, J=8.2 \mathrm{~Hz}, 2 \mathrm{H}), 7.77(\mathrm{~d}, J=7.8 \mathrm{~Hz}, 1 \mathrm{H}), 7.69$ $(\mathrm{d}, J=8.2 \mathrm{~Hz}, 2 \mathrm{H}), 7.49-7.45(\mathrm{~m}, 1 \mathrm{H}), 7.13(\mathrm{~d}, J=7.8 \mathrm{~Hz}, 1 \mathrm{H}), 4.52$ $(\mathrm{s}, 2 \mathrm{H}), 2.85 \mathrm{ppm}(\mathrm{s}, 6 \mathrm{H}) ;{ }^{13} \mathrm{C}$ NMR $\left(100 \mathrm{MHz}, \mathrm{CDCl}_{3}\right): \delta=148.47$, $137.19,134.70,134.33,133.47,129.96,125.27,124.71,123.63$, 123.26, 123.07, 117.43, 37.59, 35.73 ppm; MS (ESI) m/z: 393 $[\mathrm{M}-\mathrm{H}]^{-}, 429[\mathrm{M}+\mathrm{Cl}]^{-}$.

7-(4-Fluorobenzylthio)- $N, N$-dimethylbenzo[C][1,2,5]oxadiazole-4sulfonamide (58d): $(0.23 \mathrm{mmol}, 92 \%)$. ${ }^{1} \mathrm{H}$ NMR $\left(400 \mathrm{MHz}, \mathrm{CDCl}_{3}\right)$ : $\delta=7.77(\mathrm{~d}, J=7.8 \mathrm{~Hz}, 1 \mathrm{H}), 7.34-7.30(\mathrm{~m}, 2 \mathrm{H}), 7.09(\mathrm{~d}, J=7.8 \mathrm{~Hz}$, $1 \mathrm{H}), 6.99-6.94(\mathrm{~m}, 2 \mathrm{H}), 4.38(\mathrm{~s}, 2 \mathrm{H}), 2.85 \mathrm{ppm}(\mathrm{s}, 6 \mathrm{H}) ;{ }^{13} \mathrm{C} \mathrm{NMR}$ $\left(100 \mathrm{MHz}, \mathrm{CDCl}_{3}\right): \delta=163.58-161.11$ (C-F), 148.71, 145.04, 134.94, $134.52,130.40,123.48,122.30,115.85,37.61,35.73$ ppm; MS (ESI) $\mathrm{m} / \mathrm{z}: 366[\mathrm{M}-\mathrm{H}]^{-}, 402[\mathrm{M}+\mathrm{Cl}]^{-}$. 


\section{General procedure for Diels-Alder with Danishefsky diene}

In a sealed tube the appropriate starting material (49a-f) $(0.28 \mathrm{mmol})$ was dissolved in freshly distilled $\mathrm{CH}_{2} \mathrm{Cl}_{2}(2 \mathrm{~mL})$ then trans-1-methoxy-3-trimethylsilyloxy-buta-1,3-diene was added. The reaction mixture was heated at $50^{\circ} \mathrm{C}$ for $6-12 \mathrm{~h}$. After that time $2 \mathrm{~N}$ $\mathrm{HCl}$ was added and the mixture was stirred for further $1 \mathrm{~h}$ then the mixture was extracted with $\mathrm{CH}_{2} \mathrm{Cl}_{2}$. The organic layer was dried over $\mathrm{Na}_{2} \mathrm{SO}_{4}$, filtered off and the solvent was removed under reduced pressure. The crude was then purified by flash chromatography to give two diastereomers $59 a-f$ and $60 a-f$.

\section{(9R,9aR)-4-Chloro-9-methoxy-9a-nitro-5a,6,9,9a-}

tetrahydronaphtho[2,1-c][1,2,5]oxadiazol-7(8H)-one (59a): White solid $(0.07 \mathrm{mmol}, 25 \%)$. ${ }^{1} \mathrm{H}$ NMR $\left(400 \mathrm{MHz}, \mathrm{CDCl}_{3}\right): \delta=6.72-6.70(\mathrm{~m}$, $1 \mathrm{H}), 5.11-5.10(\mathrm{~m}, 1 \mathrm{H}), 4.45-4.39(\mathrm{~m}, 1 \mathrm{H}), 3.42(\mathrm{~s}, 3 \mathrm{H}), 2.98-2.94$ $(\mathrm{m}, 1 \mathrm{H}), 2.83-2.77(\mathrm{~m}, 1 \mathrm{H}), 2.71-2.67(\mathrm{~m}, 1 \mathrm{H}), 1.91-1.84 \mathrm{ppm}(\mathrm{m}$, $1 \mathrm{H}) ;{ }^{13} \mathrm{C}$ NMR $\left(100 \mathrm{MHz}, \mathrm{CDCl}_{3}\right): \delta=200.09,149.28,145.75,132.19$, $121.02,88.98,79.70,78.92,58.73,42.49,42.17,41.04$ ppm.

(9R,9aR)-4,9-Dimethoxy-9a-nitro-5a,6,9,9a-tetrahydronaphtho$[2,1-c][1,2,5]$ oxadiazol-7(8H)-one $(59 \mathrm{~b})$ : White solid $(0.067 \mathrm{mmol}$, $24 \%) .{ }^{1} \mathrm{H}$ NMR $\left(400 \mathrm{MHz}, \mathrm{CDCl}_{3}\right): \delta=5.48-5.46(\mathrm{~m}, 1 \mathrm{H}), 5.01-5.00$ $(\mathrm{m}, 1 \mathrm{H}), 4.31-4.24(\mathrm{~m}, 1 \mathrm{H}), 3.74(\mathrm{~s}, 3 \mathrm{H}), 3.35(\mathrm{~s}, 3 \mathrm{H}), 2.89-2.83(\mathrm{~m}$, $1 \mathrm{H}), 2.73-2.67(\mathrm{~m}, 1 \mathrm{H}), 2.64-2.59(\mathrm{~m}, 1 \mathrm{H}), 1.80-1.73 \mathrm{ppm}(\mathrm{m}, 1 \mathrm{H})$.

(9R,9aR)-9-Methoxy-4-(4-methoxyphenoxy)-9a-nitro-5a,6,9,9atetrahydronaphtho[2,1-c][1,2,5]oxadiazol-7(8H)-one (59c): White solid $(0.07 \mathrm{mmol}, 25 \%)$. ${ }^{1} \mathrm{H}$ NMR $\left(400 \mathrm{MHz}, \mathrm{CDCl}_{3}\right): \delta=7.19-7.17(\mathrm{~d}$, $J=8,2 \mathrm{H}), 6.92-6.90(\mathrm{~d}, J=8,2 \mathrm{H}), 5.58-5.56(\mathrm{~m}, 1 \mathrm{H}), 5.11-5.09(\mathrm{~m}$, $1 \mathrm{H}), 4.28-4.22(\mathrm{~m}, 1 \mathrm{H}), 3.87(\mathrm{~s}, 3 \mathrm{H}), 3.41(\mathrm{~s}, 3 \mathrm{H}), 2.96-2.91(\mathrm{~m}, 1 \mathrm{H})$, 2.73-2.68 $(\mathrm{m}, 2 \mathrm{H}), 1.90-1.83 \mathrm{ppm}(\mathrm{m}, 1 \mathrm{H})$.

(9R,9aR)-9-Methoxy-4-(4-methoxybenzylthio)-9a-nitro-5a,6,9,9atetrahydronaphtho[2,1-c][1,2,5]oxadiazol-7(8H)-one (59d): White solid $(0.064 \mathrm{mmol}, 23 \%)$. ${ }^{1} \mathrm{H}$ NMR $\left(400 \mathrm{MHz}, \mathrm{CDCl}_{3}\right): \delta=6.98-6.96$ $(\mathrm{d}, J=8,2 \mathrm{H}), 6.72-6.69(\mathrm{~d}, J=8,2 \mathrm{H}), 6.37-6.36(\mathrm{~m}, 1 \mathrm{H}), 4.98-4.97$ $(\mathrm{m}, 1 \mathrm{H}), 4.18-4.12(\mathrm{~m}, 1 \mathrm{H}), 4.06-3.96(\mathrm{~m}, 2 \mathrm{H}), 3.71(\mathrm{~s}, 3 \mathrm{H}), 3.35(\mathrm{~s}$, $3 \mathrm{H}), 2.85-2.80(\mathrm{~m}, 1 \mathrm{H}), 2.59-2.55(\mathrm{~m}, 1 \mathrm{H}), 2.53-2.47(\mathrm{~m}, 1 \mathrm{H}), 1.60-$ $1.49 \mathrm{ppm}(\mathrm{m}, 1 \mathrm{H}) ;{ }^{13} \mathrm{C}$ NMR $\left(100 \mathrm{MHz}, \mathrm{CDCl}_{3}\right): \delta=201.11,159.01$, $148.65,146.00,138.40,129.73,129.20,127.53,122.11,114.08,87.05$ $79.94,57.77,55.22,42.35,40.20,37.72,35.92$ ppm.

(9R,9aR)-4-(4-Bromophenylthio)-9-methoxy-9a-nitro-5a,6,9,9atetrahydronaphtho[2,1-c][1,2,5]oxadiazol-7(8H)-one (59e): White solid $(0.064 \mathrm{mmol}, 23 \%)$. ${ }^{1} \mathrm{H}$ NMR $\left(400 \mathrm{MHz}, \mathrm{CDCl}_{3}\right): \delta=7.44-7.42$ $(\mathrm{d}, J=8,2 \mathrm{H}), 7.23-7.21(\mathrm{~d}, J=8,2 \mathrm{H}), 6.36-6.34(\mathrm{~m}, 1 \mathrm{H}), 5.04-5.03$ $(\mathrm{m}, 1 \mathrm{H}), 4.28-4.22(\mathrm{~m}, 1 \mathrm{H}), 3.34(\mathrm{~s}, 3 \mathrm{H}), 2.89-2.83(\mathrm{~m}, 1 \mathrm{H}), 2.64-$ $2.58(\mathrm{~m}, 2 \mathrm{H}), 1.77-1.70 \mathrm{ppm}(\mathrm{m}, 1 \mathrm{H}) ;{ }^{13} \mathrm{C}$ NMR $\left(100 \mathrm{MHz}, \mathrm{CDCl}_{3}\right)$ : $\delta=200.81,146.15,137.20,134.43,132.92,128.65,125.98,123.66$, $123.29,113.73,87.29,79.75,57.79,42.22,40.16,37.96$ ppm.

(9R,9aR)-9-Methoxy-4-(3-morpholino-3-oxopropylthio)-9a-nitro5a,6,9,9a-tetrahydronaphtho[2,1-c][1,2,5]oxadiazol-7(8H)-one (59 f): White solid $(0.07 \mathrm{mmol}, 25 \%)$. ${ }^{1} \mathrm{H}$ NMR $\left(400 \mathrm{MHz}, \mathrm{CDCl}_{3}\right): \delta=$ 6.47-6.45 $(\mathrm{m}, 1 \mathrm{H}), 5.02-5.01(\mathrm{~m}, 1 \mathrm{H}), 4.28-4.22(\mathrm{~m}, 1 \mathrm{H}), 3.57-3.49$ $(\mathrm{m}, 8 \mathrm{H}), 3.32(\mathrm{~s}, 3 \mathrm{H}), 3.23-3.16(\mathrm{~m}, 1 \mathrm{H}), 3.09-3.02(\mathrm{~m}, 1 \mathrm{H}), 2.86-$ $2.82(\mathrm{~m}, 1 \mathrm{H}), 2.63-2.59(\mathrm{~m}, 2 \mathrm{H}), 2.53-2.48(\mathrm{~m}, 2 \mathrm{H}), 1.79-1.72 \mathrm{ppm}$ $(\mathrm{m}, 1 \mathrm{H}) ;{ }^{13} \mathrm{C} \mathrm{NMR}\left(100 \mathrm{MHz}, \mathrm{CDCl}_{3}\right): \delta=201.16,168.61,148.50$, $146.11,135.56,122.65,87.35,79.83,66.69,66.38,60.26,57.76$, $45.58,42.36,41.99,40.18,37.83,32.38,26.58,20.92,14.09$ ppm.

\section{(9S,9aR)-4-Chloro-9-methoxy-9a-nitro-5a,6,9,9a-}

tetrahydronaphtho[2,1-c][1,2,5]oxadiazol-7(8H)-one (60a): White solid $(0.117 \mathrm{mmol}, 42 \%)$. ${ }^{1} \mathrm{H}$ NMR $\left(400 \mathrm{MHz}, \mathrm{CDCl}_{3}\right): \delta=6.37-6.36$ $(\mathrm{m}, 1 \mathrm{H}), 4.55-4.51(\mathrm{~m}, 1 \mathrm{H}), 3.81-3.75(\mathrm{~m}, 1 \mathrm{H}), 3.39(\mathrm{~s}, 3 \mathrm{H}), 3.02-$ $2.97(\mathrm{~m}, 1 \mathrm{H}), 2.70-2.64(\mathrm{~m}, 2 \mathrm{H}), 1.94-1.87 \mathrm{ppm}(\mathrm{m}, 1 \mathrm{H})$.
(9S,9aR)-4,9-Dimethoxy-9a-nitro-5a,6,9,9a-tetrahydronaphtho[2,1-c][1,2,5]oxadiazol-7(8H)-one $(60 \mathrm{~b})$ : White solid $(0.142 \mathrm{mmol}$, $51 \%)$. ${ }^{1} \mathrm{H}$ NMR $\left(400 \mathrm{MHz}, \mathrm{CDCl}_{3}\right): \delta=5.22-5.21(\mathrm{~m}, 1 \mathrm{H}), 4.52-4.47$ $(\mathrm{m}, 1 \mathrm{H}), 3.73(\mathrm{~s}, 3 \mathrm{H}), 3.69-3.62(\mathrm{~m}, 1 \mathrm{H}), 3.40(\mathrm{~s}, 3 \mathrm{H}), 3.02-2.97(\mathrm{~m}$, $1 \mathrm{H}), 2.66-2.61(\mathrm{~m}, 2 \mathrm{H}), 1.81-1.74 \mathrm{ppm}(\mathrm{m}, 1 \mathrm{H})$.

(9S,9aR)-9-Methoxy-4-(4-methoxyphenoxy)-9a-nitro-5a,6,9,9atetrahydronaphtho[2,1-c][1,2,5]oxadiazol-7(8H)-one $(60 \mathrm{c})$ : White solid (0.134 mmol, $48 \%)$. ${ }^{1} \mathrm{H} \mathrm{NMR}\left(400 \mathrm{MHz}, \mathrm{CDCl}_{3}\right): \delta=7.18-7.16$ $(\mathrm{d}, J=8,2 \mathrm{H}), 6.92-6.90(\mathrm{~d}, J=8,2 \mathrm{H}), 6.52-6.50(\mathrm{~m}, 1 \mathrm{H}), 5.30-5.28$ $(\mathrm{m}, 1 \mathrm{H}), 4.60-4.56(\mathrm{~m}, 1 \mathrm{H}), 3.87(\mathrm{~s}, 3 \mathrm{H}), 3.66-3.59129(\mathrm{~m}, 1 \mathrm{H}), 3.49$ $(\mathrm{s}, 3 \mathrm{H}), 3.10-3.05(\mathrm{~m}, 1 \mathrm{H}), 2.75-2.66(\mathrm{~m}, 2 \mathrm{H}), 2.64-2.62(\mathrm{~m}, 1 \mathrm{H})$, $1.91-1.87 \mathrm{ppm}(\mathrm{m}, 1 \mathrm{H})$.

(9S,9aR)-9-Methoxy-4-(4-methoxybenzylthio)-9a-nitro-5a,6,9,9atetrahydronaphtho[2,1-c][1,2,5]oxadiazol-7(8H)-one $(60 \mathrm{~d})$ : White solid $(0.137 \mathrm{mmol}, 49 \%)$. ${ }^{1} \mathrm{H}$ NMR $\left(400 \mathrm{MHz}, \mathrm{CDCl}_{3}\right): \delta=7.07-7.05$ $(\mathrm{d}, J=8,2 \mathrm{H}), 6.74-6.72(\mathrm{~d}, J=8,2 \mathrm{H}), 6.05-6.03(\mathrm{~m}, 1 \mathrm{H}), 4.47-4.43$ $(\mathrm{m}, 1 \mathrm{H}), 4.03(\mathrm{~s}, 2 \mathrm{H}), 3.69(\mathrm{~s}, 3 \mathrm{H}), 3.61-3.57(\mathrm{~m}, 1 \mathrm{H}), 3.37(\mathrm{~s}, 3 \mathrm{H})$, 2.96-2.91 $(\mathrm{m}, 1 \mathrm{H}), 2.64-2.57(\mathrm{~m}, 1 \mathrm{H}), 2.46-2.41(\mathrm{~m}, 1 \mathrm{H}), 1.69-$ $1.61 \mathrm{ppm}(\mathrm{m}, 1 \mathrm{H})$.

(9S,9aR)-4-(4-Bromophenylthio)-9-methoxy-9a-nitro-5a,6,9,9atetrahydronaphtho[2,1-c][1,2,5]oxadiazol-7(8H)-one (60 e): White solid $(0.154 \mathrm{mmol}, 55 \%)$. ${ }^{1} \mathrm{H}$ NMR $\left(400 \mathrm{MHz}, \mathrm{CDCl}_{3}\right): \delta=7.45-7.43$ $(\mathrm{d}, J=8,2 \mathrm{H}), 7.22-7.20(\mathrm{~d}, J=8,2 \mathrm{H}), 6.02-6.00(\mathrm{~m}, 1 \mathrm{H}), 4.53-4.49$ $(\mathrm{m}, 1 \mathrm{H}), 3.67-3.61(\mathrm{~m}, 1 \mathrm{H}), 3.40(\mathrm{~s}, 3 \mathrm{H}), 3.02-2.97(\mathrm{~m}, 1 \mathrm{H}), 2.67-$ $2.61(\mathrm{~m}, 1 \mathrm{H}), 2.58-2.53(\mathrm{~m}, 1 \mathrm{H}), 1.81-1.74 \mathrm{ppm}(\mathrm{m}, 1 \mathrm{H}) ;{ }^{13} \mathrm{C}$ NMR $\left(100 \mathrm{MHz}, \mathrm{CDCl}_{3}\right): \delta=200.25,149.27,145.51,134.46,132.90,131.43$, $128.39,126.23,123.71,89.39,79.88,58.71,42.95,42.47,41.02$ ppm.

(9S,9aR)-9-Methoxy-4-(3-morpholino-3-oxopropylthio)-9a-nitro$5 a, 6,9,9 a-t e t r a h y d r o n a p h t h o[2,1-c][1,2,5]$ oxadiazol-7(8H)-one (60 f): White solid $(0.131 \mathrm{mmol}, 47 \%)$. ${ }^{1} \mathrm{H}$ NMR $\left(400 \mathrm{MHz}, \mathrm{CDCl}_{3}\right)$ : $\delta=6.25-6.23(\mathrm{~m}, 1 \mathrm{H}), 4.51-4.48(\mathrm{~m}, 1 \mathrm{H}), 4.07-4.02(\mathrm{~m}, 2 \mathrm{H}), 3.56-$ $3.48(\mathrm{~m}, 8 \mathrm{H}), 3.08-2.97(\mathrm{~m}, 2 \mathrm{H}), 2.79-2.75(\mathrm{~m}, 2 \mathrm{H}), 2.69-2.57(\mathrm{~m}$, $1 \mathrm{H}), 2.51-2.48(\mathrm{~m}, 1 \mathrm{H}), 1.81-1.75 \mathrm{ppm}(\mathrm{m}, 1 \mathrm{H})$.

4-Bromo-7-nitrobenzo[c][1,2,5]thiadiazole (62): A mixture of 4,7dibromobenzo[c][1,2,5]thiadiazole $(100 \mathrm{mg}, 0.34 \mathrm{mmol})$ in conc $\mathrm{HNO}_{3}(5 \mathrm{~mL})$ was heated at reflux with stirring for $1 \mathrm{~h}$. The resulting clear solution was poured into $10 \mathrm{~mL}$ of ice- $\mathrm{H}_{2} \mathrm{O}$ and then extracted with EtOAc $(2 \times 10 \mathrm{~mL})$. The combined organic phases were washed with brine, dried over $\mathrm{Na}_{2} \mathrm{SO}_{4}$, filtered and concentrated under reduced pressure. The crude product was separated by chromatography on silica gel (Hex/EtOAc 3:1) to afford the desired product $(0.227 \mathrm{mmol}, 67 \%) .{ }^{1} \mathrm{H}$ NMR $\left(400 \mathrm{MHz}, \mathrm{CDCl}_{3}\right): \delta=8.41(\mathrm{~d}$, $J=7.89 \mathrm{~Hz}, 1 \mathrm{H}), 7.98 \mathrm{ppm}(\mathrm{d}, J=7.89 \mathrm{~Hz}, 1 \mathrm{H})$.

\section{General procedure for the synthesis of compounds $63 a, b$}

To a solution of compound 62 (1 equiv) in EtOH the appropriate nucleophile and a catalytic amount of KOAC and pyridine were added. The resulting mixture was heated at reflux for $3 \mathrm{~h}$. This was concentrated in vacuo and the crude product was purified by flash chromatography with the appropriate eluent.

4-(4-Methoxybenzylthio)-7-nitrobenzo[c][1,2,5]thiadiazole (63a): (0.082 mmol, $72 \%)$. ' $\mathrm{H}$ NMR $\left(400 \mathrm{MHz}, \mathrm{CDCl}_{3}\right): \delta=8.42$ (d, $J=$ $8.1 \mathrm{~Hz}, 1 \mathrm{H}), 7.31-7.29(\mathrm{~m}, 3 \mathrm{H}), 6.81(\mathrm{~d}, J=7.8 \mathrm{~Hz}, 2 \mathrm{H}), 4.35(\mathrm{~s}, 2 \mathrm{H})$, $3.73 \mathrm{ppm}(\mathrm{s}, 3 \mathrm{H}) ;{ }^{13} \mathrm{C}$ NMR $\left(100 \mathrm{MHz}, \mathrm{CDCl}_{3}\right): \delta=159.39,153.24$, $146.09,143.64,135.99,129.94,128.06,125.90,120.04,114.34,55.24$, 35.84 ppm.

1-Morpholino-3-(7-nitrobenzo[c][1,2,5]thiadiazol-4-ylthio)propan-1-one (58b): (0.078 mmol, 69\%). ${ }^{1} \mathrm{H} \mathrm{NMR}\left(400 \mathrm{MHz}, \mathrm{CDCl}_{3}\right)$ : 
$\delta=8.46(\mathrm{~d}, J=8 \mathrm{~Hz}, 1 \mathrm{H}), 7.34(\mathrm{~d}, J=8 \mathrm{~Hz}, 1 \mathrm{H}), 3.61-3.59(\mathrm{~m}, 6 \mathrm{H})$, $3.50(\mathrm{t}, J=8.2 \mathrm{~Hz}, 2 \mathrm{H}), 3.40-3.38(\mathrm{~m}, 2 \mathrm{H}), 2.77 \mathrm{ppm}(\mathrm{t}, J=8 \mathrm{~Hz}$, $2 \mathrm{H}) ;{ }^{13} \mathrm{C}$ NMR $\left(100 \mathrm{MHz}, \mathrm{CDCl}_{3}\right): \delta=168.46,153.25,143.18,135.96$, $128.09,119.52,66.68,66.36,45.66,42.14,31.57,26.46$ ppm.

8-Chloro-5-nitroquinoline (66): To a solution of 2-chloro-5-nitroaniline $(100 \mathrm{mg}, 0.579 \mathrm{mmol})$ in $6 \mathrm{~N} \mathrm{HCl}(15 \mathrm{~mL})$, toluene $(3 \mathrm{~mL})$ and acrolein $(76 \mu \mathrm{L}, 1.158 \mathrm{mmol})$ were added and the mixture was heated at $100^{\circ} \mathrm{C}$ for $2 \mathrm{~h}$. The aqueous layer was separated and neutralized with aqueous $\mathrm{NaOH}$ to afford crude 66 as a crystalline solid. The crude product was purified by flash chromatography (Hex/EtOAc 3:1) to give desired compound (0.55 mmol, $95 \%$ ). ${ }^{1} \mathrm{H}$ NMR (400 MHz, [D $]$ ]acetone): $\delta=9.09(\mathrm{~d}, J=4.2 \mathrm{~Hz}, 1 \mathrm{H}), 8.92(\mathrm{~d}$, $J=11.9 \mathrm{~Hz}, 1 \mathrm{H}), 8.36(\mathrm{~d}, J=7.8 \mathrm{~Hz}, 1 \mathrm{H}), 8.07(\mathrm{~d}, J=7.8 \mathrm{~Hz}, 1 \mathrm{H})$, $7.83 \mathrm{ppm}(\mathrm{dd}, J=4.2 \mathrm{~Hz}$ and $J=11.9 \mathrm{~Hz}, 1 \mathrm{H}) ;{ }^{13} \mathrm{C} \mathrm{NMR}(100 \mathrm{MHz}$, $\left[\mathrm{D}_{6}\right.$ ]acetone): $\delta=152.12,140.42,132.12,128.31,127.99,124.80$, $124.71,124.50,121.97 \mathrm{ppm}$.

\section{General procedure for aromatic nucleophilic substitution on quinoline 66}

8-Chloro-5-nitroquinoline $(0.25 \mathrm{mmol}, 1$ equiv) and the appropriate nucleophile (1.1 equiv) were suspended in the minimal amount of dry DMF $(2 \mathrm{~mL})$ in sealed vessels in the presence of $\mathrm{K}_{2} \mathrm{CO}_{3}$ ( 1 equiv), and the mixtures were irradiated at $130^{\circ} \mathrm{C}$ for $10 \mathrm{~min}$ The reaction mixtures were then diluted with $\mathrm{H}_{2} \mathrm{O}(2 \mathrm{~mL})$ and extracted with EtOAc $(3 \times 10 \mathrm{~mL})$. Finally, the organic phases were dried over anhydrous $\mathrm{Na}_{2} \mathrm{SO}_{4}$ and evaporated to dryness. The crude product was purified by flash chromatography with the appropriate eluent.

8-(4-Methoxybenzylthio)-5-nitroquinoline (67 a): $\quad(0.22 \mathrm{mmol}$, $88 \%$ ). ${ }^{1} \mathrm{H}$ NMR $\left(400 \mathrm{MHz},\left[\mathrm{D}_{6}\right.\right.$ ]acetone): $\delta=9.02(\mathrm{~d}, J=4.2 \mathrm{~Hz}, 1 \mathrm{H})$, $8.92(\mathrm{~d}, J=11.9 \mathrm{~Hz}, 1 \mathrm{H}), 8.35(\mathrm{~d}, J=7.8 \mathrm{~Hz}, 1 \mathrm{H}), 7.77(\mathrm{dd}, J=4.2 \mathrm{~Hz}$ and $J=11.9 \mathrm{~Hz}, 1 \mathrm{H}), 7.71(\mathrm{~d}, J=7.8 \mathrm{~Hz}, 1 \mathrm{H}), 7.41(\mathrm{~d}, J=8.2 \mathrm{~Hz}, 1 \mathrm{H})$, $6.86(\mathrm{~d}, J=8.2 \mathrm{~Hz}, 1 \mathrm{H}), 4.33(\mathrm{~s}, 2 \mathrm{H}), 3.72 \mathrm{ppm}(\mathrm{s}, 3 \mathrm{H})$.

1-Morpholino-3-(5-nitroquinolin-8-ylthio)propan-1-one

(67b): (0.22 mmol, $88 \%)$. ${ }^{1} \mathrm{H}$ NMR $\left(400 \mathrm{MHz}, \mathrm{CDCl}_{3}\right): \delta=9.04(\mathrm{~d}, J=4 \mathrm{~Hz}$, $1 \mathrm{H}), 8.88(\mathrm{~d}, J=11.9 \mathrm{~Hz}, 1 \mathrm{H}), 8.31(\mathrm{~d}, J=7.8 \mathrm{~Hz}, 1 \mathrm{H}), 7.60(\mathrm{dd}, J=$ $4.2 \mathrm{~Hz}$ and $J=11.9 \mathrm{~Hz}, 1 \mathrm{H}), 7.43(\mathrm{~d}, J=7.8 \mathrm{~Hz}, 1 \mathrm{H}), 3.58(\mathrm{brs}, 6 \mathrm{H})$, 3.37 (brs, $2 \mathrm{H}), 3.36-3.34(\mathrm{~m}, 2 \mathrm{H}), 2.77-2.73 \mathrm{ppm}(\mathrm{m}, 2 \mathrm{H}) ;{ }^{13} \mathrm{C}$ NMR $\left(100 \mathrm{MHz}, \mathrm{CDCl}_{3}\right): \delta=168.87,149.94,149.65,144.39,141.11,132.82$, 125.32, 124.61, 120.98, 120.14, 66.70, 66.38, 45.67, 42.09, 31.45, 25.83 ppm; MS (ESI) m/z: $348[M+\mathrm{H}]^{+}, 370[M+\mathrm{Na}]^{+}$.

8-(4-(4-Methylpiperazin-1-yl)phenoxy)-5-nitroquinoline (67 c): (0.205 mmol, $82 \%)$. ${ }^{1} \mathrm{H}$ NMR ( $400 \mathrm{MHz},\left[\mathrm{D}_{6}\right.$ ] acetone): $\delta=9.03$ (d, $J=$ $4.2 \mathrm{~Hz}, 1 \mathrm{H}), 8.98(\mathrm{~d}, J=11.9 \mathrm{~Hz}, 1 \mathrm{H}), 8.36(\mathrm{~d}, J=7.8 \mathrm{~Hz}, 1 \mathrm{H}), 7.78$ $(\mathrm{dd}, J=4.2 \mathrm{~Hz}$ and $J=11.9 \mathrm{~Hz}, 1 \mathrm{H}), 7.08-6.90(\mathrm{~m}, 4 \mathrm{H}), 6.73(\mathrm{~d}, J=$ $8.2 \mathrm{~Hz}, 2 \mathrm{H}), 3.15-3.14(4 \mathrm{H}, \mathrm{m}), 2.47-2.46(4 \mathrm{H}, \mathrm{m}), 2.21 \mathrm{ppm}(3 \mathrm{H}, \mathrm{s})$; ${ }^{13} \mathrm{C}$ NMR (100 MHz, [D $\mathrm{D}_{6}$ ]acetone): $\delta=160.81,150.43,149.41,147.26$, $139.42,131.68,126.78,124.74,122.78,118.03,115.43,110.10,54.86$, 48.81, $45.31 \mathrm{ppm} ; \mathrm{MS}(\mathrm{ESI}) \mathrm{m} / \mathrm{z}: 365[\mathrm{M}+\mathrm{H}]^{+}, 387[\mathrm{M}+\mathrm{Na}]^{+}$.

1-(4-(4-(5-Nitroquinolin-8-yloxy)phenyl)piperazin-1-yl)ethanone (67 d): (0.207 mmol, 83\%). ${ }^{1} \mathrm{H}$ NMR (400 MHz, [ $\mathrm{D}_{6}$ ] acetone): $\delta=9.05$ $(\mathrm{d}, J=4.2 \mathrm{~Hz}, 1 \mathrm{H}), 9.00(\mathrm{~d}, J=11.9 \mathrm{~Hz}, 1 \mathrm{H}), 8.38(\mathrm{~d}, J=7.8 \mathrm{~Hz}, 1 \mathrm{H})$, $7.81(\mathrm{dd}, J=4.2 \mathrm{~Hz}$ and $J=11.9 \mathrm{~Hz}, 1 \mathrm{H}), 7.09-7.06(\mathrm{~m}, 4 \mathrm{H}), 6.95(\mathrm{~d}$, $J=8.2 \mathrm{~Hz}, 2 \mathrm{H}), 3.64-3.61(4 \mathrm{H}, \mathrm{m}), 3.20-3.18(2 \mathrm{H}, \mathrm{m}), 3.12-3.10(2 \mathrm{H}$, $\mathrm{m}), 2.01 \mathrm{ppm}(3 \mathrm{H}, \mathrm{s}) ;{ }^{13} \mathrm{C}$ NMR $\left(100 \mathrm{MHz},\left[\mathrm{D}_{6}\right]\right.$ acetone): $\delta=150.48$, 149.19 , 141.49, 139.13, 132.71, 131.88, 131.69, 126.72, 124.74, 121.28, 118.60, 117.88, 110.33， 49.57，49.20，45.76，40.85， 20.35 ppm; MS (ESI) m/z: $393[M+\mathrm{H}]^{+}, 416[M+\mathrm{Na}]^{+}$.

5-Bromo-8-nitroisoquinoline (69): Concentrated $\mathrm{H}_{2} \mathrm{SO}_{4} \quad(96 \%$, $20 \mathrm{~mL}$ ) was cooled to $0{ }^{\circ} \mathrm{C}$ under nitrogen atmosphere and isoqui- noline $(500 \mu \mathrm{L}, 4.21 \mathrm{mmol}$ ) was slowly added to the well-stirred acid at a rate such that the internal temperature was maintained $<30^{\circ} \mathrm{C}$. The solution was cooled to $-25^{\circ} \mathrm{C}$ in a dry ice-acetone bath and $\mathrm{N}$-bromosuccinimide $(976 \mathrm{mg}, 5.48 \mathrm{mmol}$ ) was added to the vigorously stirred solution in portions such that the internal temperature was maintained between -22 and $-26^{\circ} \mathrm{C}$. The suspension was stirred for $2 \mathrm{~h}$ at $-22^{\circ} \mathrm{C}$ and then for $3 \mathrm{~h}$ at $-18^{\circ} \mathrm{C}$. $\mathrm{KNO}_{3}$ (446 mg, $4.41 \mathrm{mmol}$ ) was then added at a rate such as to maintain the internal temperature below $-10^{\circ} \mathrm{C}$ and the mixture was then stirred at $-10^{\circ} \mathrm{C}$ for $1 \mathrm{~h}$. The cooling bath was removed and the solution was stirred overnight. The resulting homogeneous reaction mixture was poured onto crushed ice in a $500 \mathrm{~mL}$ flask and the reaction flask was quickly washed with ice-cold $\mathrm{H}_{2} \mathrm{O}$, which was added to the $500 \mathrm{~mL}$ flask. The resulting mixture was stirred while the solution was adjusted to $\mathrm{pH} 8.0$ using $25 \%$ aqueous $\mathrm{NH}_{3}$ with the internal temperature maintained $<30^{\circ} \mathrm{C}$. The resulting suspension was stirred in an ice $\mathrm{H}_{2} \mathrm{O}$ bath for $2 \mathrm{~h}$ and the precipitated solids were isolated by filtration. The solids were thoroughly washed three times with ice-cold $\mathrm{H}_{2} \mathrm{O}$ and then air dried to constant weight. This material was suspended in $12 \mathrm{~mL}$ heptane and $3 \mathrm{~mL}$ toluene and heated at reflux for $1.5 \mathrm{~h}$ with stirring. The hot solution was then filtered through Celite using vacuum suction. The volume of the filtrate was decreased by distillation and the resulting orange solution was allowed to slowly cool with stirring overnight. The solids were isolated by filtration, washed with $100 \mathrm{~mL}$ ice-cold heptane, and dried to provide desired product (2.06 mmol, $49 \%$ ). ' ${ }^{\mathrm{H}} \mathrm{NMR}\left(400 \mathrm{MHz},\left[\mathrm{D}_{6}\right]\right.$ acetone): $\delta=9.77(\mathrm{~s}, 1 \mathrm{H})$, $8.77(\mathrm{~d}, J=6.2 \mathrm{~Hz}, 1 \mathrm{H}), 8.26(\mathrm{~s}, 2 \mathrm{H}), 8.10 \mathrm{ppm}(\mathrm{d}, J=8.1 \mathrm{~Hz}, 1 \mathrm{H})$; ${ }^{13} \mathrm{C} \mathrm{NMR} \quad\left(100 \mathrm{MHz}, \quad \mathrm{CDCl}_{3}\right): \delta=148.20,145.81,145.54,135.12$, $133.16,127.80,125.29,120.49,118.89$ ppm; MS (ESI) m/z: 253-255 $[\mathrm{M}+\mathrm{H}]^{+}$

\section{General procedure for aromatic nucleophilic substitution on isoquinoline 69}

Compounds $\mathbf{7 0} \mathbf{a}, \mathbf{b}$ were obtained by using the same procedure as for compounds $67 \mathrm{a}-\mathbf{d}$ but with 5-bromo-8-nitroisoquinoline as the starting material.

5-(4-Methoxybenzylthio)-8-nitroisoquinoline (70 a): $(0.207 \mathrm{mmol}$, $83 \%$ ). ${ }^{1} \mathrm{H}$ NMR (400 MHz, [ $\mathrm{D}_{6}$ ]acetone): $\delta=9.87(\mathrm{~s}, 1 \mathrm{H}), 8.65(\mathrm{~d}, J=$ $6.2 \mathrm{~Hz}, 1 \mathrm{H}), 8.29(\mathrm{~d}, J=8.1 \mathrm{~Hz}, 1 \mathrm{H}), 8.05(\mathrm{~d}, J=6.2 \mathrm{~Hz}, 1 \mathrm{H}), 7.82(\mathrm{~d}$, $J=8.1 \mathrm{~Hz}, 1 \mathrm{H}), 7.36(\mathrm{~d}, J=7.8 \mathrm{~Hz}, 1 \mathrm{H}), 6.84(\mathrm{~d}, J=7.8 \mathrm{~Hz}, 1 \mathrm{H}), 4.44$ $(\mathrm{s}, 2 \mathrm{H}), 3.71 \mathrm{ppm}(\mathrm{s}, 2 \mathrm{H}) ;{ }^{13} \mathrm{C} \mathrm{NMR}\left(100 \mathrm{MHz},\left[\mathrm{D}_{6}\right.\right.$ ]acetone): $\delta=$ $159.39,148.52,148.39,144.44,142.98,133.83,130.27,127.00$, $125.11,124.87,119.72,116.12,114.01,54.60,35.83$ ppm; MS (ESI) $\mathrm{m} / \mathrm{z}: 327[\mathrm{M}+\mathrm{H}]^{+}$.

1-Morpholino-3-(8-nitroisoquinolin-5-ylthio)propan-1-one (70 b): (0.217 mmol, 87\%). ${ }^{1} \mathrm{H}$ NMR $\left(400 \mathrm{MHz}, \mathrm{CDCl}_{3}\right): \delta=9.96(\mathrm{~s}, 1 \mathrm{H}), 8.58$ $(\mathrm{d}, J=6.2 \mathrm{~Hz}, 1 \mathrm{H}), 8.18(\mathrm{~d}, J=8.1 \mathrm{~Hz}, 1 \mathrm{H}), 7.94(\mathrm{~d}, J=6.2 \mathrm{~Hz}, 1 \mathrm{H})$, $7.48(\mathrm{~d}, J=8.1 \mathrm{~Hz}, 1 \mathrm{H}), 3.58$ (brs, 4H), 3.57 (brs, 2H), 3.42-3.49 (m, $2 \mathrm{H}), 3.36-3.34(\mathrm{~m}, 2 \mathrm{H}), 2.73-2.69 \mathrm{ppm}(\mathrm{m}, 2 \mathrm{H}) ;{ }^{13} \mathrm{C} \mathrm{NMR}(100 \mathrm{MHz}$, $\left.\mathrm{CDCl}_{3}\right): \delta=168.52,148.81,144.44,142.77,134.16,125.04,123.33$, $119.98,116.26,66.67,66.33,45.61,42.09,31.65,27.17$ ppm; MS (ESI) $m / z: 348[\mathrm{M}+\mathrm{H}]^{+}, 370[\mathrm{M}+\mathrm{Na}]^{+}$.

$\mathrm{N}$-(3-Chloro-2-fluorophenyl)acetamide (72): 3-Chloro-2-fluoroaniline $(200 \mu \mathrm{L}, 2.4 \mathrm{mmol})$ was mixed with acetic anhydride $(10 \mathrm{~mL})$ and heated at reflux for $2 \mathrm{~h}$. The reaction was quenched with $\mathrm{H}_{2} \mathrm{O}$ $(3 \mathrm{~mL})$, neutralized with a saturated solution of $\mathrm{Na}_{2} \mathrm{CO}_{3}$ and extracted with EtOAc $(3 \times 10 \mathrm{~mL})$. The combined extract was dried over anhydrous $\mathrm{Na}_{2} \mathrm{SO}_{4}$ and evaporated to dryness to provide desired compound (2.4 mmol, quant). ' $\mathrm{H}$ NMR (400 MHz, $\left.\mathrm{CDCl}_{3}\right): \delta=8.18-$ 
$8.16(\mathrm{~m}, 1 \mathrm{H}), 7.31$ (brs, 1 H), 7.04-6.99 (m, 2H), $2.17 \mathrm{ppm}(\mathrm{s}, 3 \mathrm{H})$; ${ }^{13} \mathrm{C} \mathrm{NMR} \quad\left(100 \mathrm{MHz}, \mathrm{CDCl}_{3}\right): \delta=170.75,154.36,124.82,124.65$, 120.15, 119.90, $29.61 \mathrm{ppm} ; \mathrm{MS}(\mathrm{ESI}) \mathrm{m} / \mathrm{z}: 188[\mathrm{M}+\mathrm{H}]^{+}$.

7-Chloro-2-methylbenzo[d]thiazole (73): In a $50 \mathrm{~mL}$ flask were placed compound 72 (74 mg, $0.39 \mathrm{mmol})$, Lawesson's reagent (96 mg, 0.6 equiv), xylene $(2 \mathrm{~mL})$ and a magnetic stir bar. The mixture was stirred under argon at $105-115^{\circ} \mathrm{C}$ for $2.5 \mathrm{~h}$. Then $\mathrm{Cs}_{2} \mathrm{CO}_{3}$ (302.5 mg, 2 equiv) was added and the reaction mixture was stirred at reflux for $16 \mathrm{~h}$. The solvent was evaporated to dryness and the crude product was separated by chromatography on silica gel (Hex/EtOAc $3: 1)$ to afford the desired product $(0.3 \mathrm{mmol}, 77 \%)$. ${ }^{1} \mathrm{H}$ NMR $\left(400 \mathrm{MHz}, \mathrm{CDCl}_{3}\right): \delta=7.76(\mathrm{~d}, J=8 \mathrm{~Hz}, 1 \mathrm{H}), 7.33-7.24(\mathrm{~m}$, $2 \mathrm{H}), 2.76 \mathrm{ppm} \quad(\mathrm{s}, 3 \mathrm{H}) ;{ }^{13} \mathrm{C} \mathrm{NMR}\left(100 \mathrm{MHz}, \mathrm{CDCl}_{3}\right): \delta=167.66$, 153.97, 135.77, 126.77, 126.54, 124.33, 120.63, 20.09 ppm; MS (ESI) $\mathrm{m} / \mathrm{z}: 185[\mathrm{M}+\mathrm{H}]^{+}$.

7-Chloro-2-methyl-4-nitrobenzo[d]thiazole (74): Concentrated $\mathrm{H}_{2} \mathrm{SO}_{4}(96 \%, 20 \mathrm{~mL})$ was cooled to $-10^{\circ} \mathrm{C}$ under nitrogen atmosphere and compound 73 ( $370 \mathrm{mg}, 2.02 \mathrm{mmol}$ ) was slowly added to the well-stirred acid at a rate such that the internal temperature was maintained $<30^{\circ} \mathrm{C} . \mathrm{KNO}_{3}(213 \mathrm{mg}, 2.1 \mathrm{mmol})$ was then added at a rate such as to maintain the internal temperature below $-10^{\circ} \mathrm{C}$ and the mixture was then stirred at $-10^{\circ} \mathrm{C}$ for $1 \mathrm{~h}$. The cooling bath was removed and the solution was stirred at room temperature for $2 \mathrm{~h}$. The resulting homogeneous reaction mixture was poured onto crushed ice and stirred while adjusting the solution to $\mathrm{pH} 8.0$ using $25 \%$ aqueous $\mathrm{NH}_{3}$ with the internal temperature maintained $<30^{\circ} \mathrm{C}$. This was extracted with EtOAc $(3 \times 25 \mathrm{~mL})$ dried over anhydrous $\mathrm{Na}_{2} \mathrm{SO}_{4}$ and solvent removed in vacuo. The crude product was separated by chromatography on silica gel (Hex/EtOAc $3: 1)$ to afford the desired product $(1.35 \mathrm{mmol}, 67 \%)$. ${ }^{1} \mathrm{H}$ NMR $\left(400 \mathrm{MHz}, \mathrm{CDCl}_{3}\right): \delta=8.09(\mathrm{~d}, J=8 \mathrm{~Hz}, 1 \mathrm{H}), 7.40(\mathrm{~d}, J=$ $8 \mathrm{~Hz}, 1 \mathrm{H}), 2.90 \mathrm{ppm}(\mathrm{s}, 3 \mathrm{H}) ;{ }^{13} \mathrm{C}$ NMR $\left(100 \mathrm{MHz}, \mathrm{CDCl}_{3}\right): \delta=172.63$, $145.67,140.38,138.96,132.35,123.81,123.64,20.75$ ppm; MS (ESI) $\mathrm{m} / \mathrm{z}: 230[\mathrm{M}+\mathrm{H}]^{+}$.

\section{General procedure for the synthesis of compounds 75 a-d}

Compound 74 ( $0.25 \mathrm{mmol}, 1$ equiv) and the appropriate nucleophile (1 equiv) were suspended in anhydrous DMF $(3 \mathrm{~mL})$ in a $10 \mathrm{~mL}$ glass vial equipped with a small magnetic stir bar. $\mathrm{K}_{2} \mathrm{CO}_{3}$ ( 1 equiv) was then added to this solution and the mixture was irradiated under microwave for $10 \mathrm{~min}$ at $130^{\circ} \mathrm{C}$, using an irradiation power of $300 \mathrm{~W}$. The mixture was then poured into $\mathrm{H}_{2} \mathrm{O}(10 \mathrm{~mL})$ and then extracted with EtOAc $(2 \times 10 \mathrm{~mL})$. The combined organic phases were washed with brine, dried over $\mathrm{Na}_{2} \mathrm{SO}_{4}$, filtered and concentrated under reduced pressure. The crude products were purified by flash column chromatography using the appropriate eluent.

7-(4-Methoxybenzylthio)-2-methyl-4-nitrobenzo[d]thiazole (75 a): (0.187 mmol, $75 \%)$. ${ }^{1} \mathrm{H}$ NMR $\left(400 \mathrm{MHz}, \mathrm{CDCl}_{3}\right): \delta=8.00$ (d, $J=$ $8.2 \mathrm{~Hz}, 1 \mathrm{H}), 7.16(\mathrm{~m}, 3 \mathrm{H}), 6.74(\mathrm{~d}, J=7.8 \mathrm{~Hz}, 2 \mathrm{H}), 4.21(\mathrm{~s}, 2 \mathrm{H}), 3.69$ $(\mathrm{s}, 3 \mathrm{H}), 2.83 \mathrm{ppm}(\mathrm{s}, 3 \mathrm{H}) ;{ }^{13} \mathrm{C}$ NMR $\left(100 \mathrm{MHz}, \mathrm{CDCl}_{3}\right): \delta=171.79$, $159.23,144.86,141.43,139.40,138.51,129.92,126.91,123.22$, $121.78,114.16,55.21,37.52,20.73 \mathrm{ppm}$; MS (ESI) $\mathrm{m} / \mathrm{z}: 347[\mathrm{M}+\mathrm{H}]^{+}$, $369[\mathrm{M}+\mathrm{Na}]^{+}$.

3-(2-Methyl-4-nitrobenzo[d]thiazol-7-ylthio)-1-morpholinopropan-1-one (75 b): $(0.155 \mathrm{mmol}, 62 \%)$. ${ }^{1} \mathrm{H}$ NMR $\left(400 \mathrm{MHz}, \mathrm{CDCl}_{3}\right)$ : $\delta=8.03(\mathrm{~d}, J=8.2 \mathrm{~Hz}, 1 \mathrm{H}), 7.21(\mathrm{~d}, J=8 \mathrm{~Hz}, 1 \mathrm{H}), 3.54-3.52(\mathrm{~m}, 6 \mathrm{H})$, $3.38(\mathrm{t}, J=8 \mathrm{~Hz}, 2 \mathrm{H}), 3.32-3.30(\mathrm{~m}, 2 \mathrm{H}), 2.83(\mathrm{~s}, 3 \mathrm{H}), 2.65 \mathrm{ppm}(\mathrm{t}$, $J=8 \mathrm{~Hz}, 2 \mathrm{H}) ;{ }^{13} \mathrm{C} \mathrm{NMR}\left(100 \mathrm{MHz}, \mathrm{CDCl}_{3}\right): \delta=171.80,168.61,144.95$,
139.19, 138.45, 137.95, 123.37, 120.47, 66.65, 66.34, 45.59, 42.04, 32.32, 28.16, 20.75 ppm; MS (ESI) $\mathrm{m} / \mathrm{z}: 368[\mathrm{M}+\mathrm{H}]^{+}$.

2-Methyl-7-(4-(4-methylpiperazin-1-yl)phenoxy)-4-nitrobenzo[d]thiazole (75 c): $(0.14 \mathrm{mmol}, 56 \%)$. ${ }^{1} \mathrm{H}$ NMR $\left(400 \mathrm{MHz}, \mathrm{CDCl}_{3}\right): \delta=$ $8.07(\mathrm{~d}, J=8.2 \mathrm{~Hz}, 1 \mathrm{H}), 6.97(\mathrm{~d}, J=7.9 \mathrm{~Hz}, 2 \mathrm{H}), 6.89(\mathrm{~d}, J=7.9 \mathrm{~Hz}$, $2 \mathrm{H}), 6.59(\mathrm{~d}, J=8.2 \mathrm{~Hz}, 1 \mathrm{H}), 3.16-3.13(4 \mathrm{H}, \mathrm{m}), 2.88(\mathrm{~s}, 3 \mathrm{H}), 2.53-$ $2.51(4 \mathrm{H}, \mathrm{m}), 2.28 \mathrm{ppm}(3 \mathrm{H}, \mathrm{s}) ;{ }^{13} \mathrm{C}$ NMR $\left(100 \mathrm{MHz}, \mathrm{CDCl}_{3}\right): \delta=$ $172.35,157.59,149.43,148.09,146.42,136.36,125.33,121.48$, $117.22,108.20,55.04,54.95,49.18,46.04,20.70$ ppm; MS (ESI) $\mathrm{m} / \mathrm{z}$ : $385[\mathrm{M}+\mathrm{H}]^{+}$.

1-(4-(4-(2-Methyl-4-nitrobenzo[d]thiazol-7-yloxy)phenyl)piperazin-1-yl)ethanone (75 d): $(0.135 \mathrm{mmol}, 54 \%)$. ${ }^{1} \mathrm{H} \mathrm{NMR}(400 \mathrm{MHz}$, $\left.\mathrm{CDCl}_{3}\right): \delta=8.09(\mathrm{~d}, \mathrm{~J}=8.1 \mathrm{~Hz}, 1 \mathrm{H}), 7.01(\mathrm{~d}, \mathrm{~J}=7.8 \mathrm{~Hz}, 2 \mathrm{H}), 6.91(\mathrm{~d}$, $\mathrm{J}=7.8 \mathrm{~Hz}, 2 \mathrm{H}), 6.61(\mathrm{~d}, \mathrm{~J}=8.1 \mathrm{~Hz}, 1 \mathrm{H}), 3.74-3.73(\mathrm{~m}, 2 \mathrm{H}), 3.59-3.58$ $(\mathrm{m}, 2 \mathrm{H}), 3.15-3.10(\mathrm{~m}, 4 \mathrm{H}), 2.90(\mathrm{~s}, 3 \mathrm{H}), 2.08 \mathrm{ppm}(\mathrm{s}, 3 \mathrm{H}) ;{ }^{13} \mathrm{C}$ NMR $\left(100 \mathrm{MHz}, \mathrm{CDCl}_{3}\right): \delta=172.43,157.38,149.06,147.47,147.18,136.52$, $125.30,121.62,117.99,108.29,49.80,49.50,46.08,41.21,21.23$, $20.70 \mathrm{ppm} ; \mathrm{MS}(\mathrm{ESI}) \mathrm{m} / \mathrm{z}: 413[\mathrm{M}+\mathrm{H}]^{+}, 435[\mathrm{M}+\mathrm{Na}]^{+}$.

5-(4-Methoxybenzylthio)-2-nitroaniline (77): To a solution of 5chloro-2-nitroaniline $(100 \mathrm{mg}, 0.58 \mathrm{mmol})$ in $10 \mathrm{~mL}$ of EtOH, 4-methoxytoluenethiol $\left(80 \mu \mathrm{L}, 0.58 \mathrm{mmol}\right.$ ) and $\mathrm{K}_{2} \mathrm{CO}_{3}$ (1 equiv) were added. The reaction mixture was heated at reflux for $2 \mathrm{~h}$. The mixture was then cooled to room temperature, the solvent was removed in vacuo. This was extracted with EtOAc $(3 \times 10 \mathrm{~mL})$, washed with brine, dried over anhydrous $\mathrm{Na}_{2} \mathrm{SO}_{4}$ and the solvent was removed in vacuo. The crude product was separated by chromatography on silica gel (Hex/EtOAc 3:1) to afford the desired product $(0.388 \mathrm{mmol}, 67 \%) .{ }^{1} \mathrm{H}$ NMR $\left(400 \mathrm{MHz}, \mathrm{CDCl}_{3}\right): \delta=8.06(\mathrm{~d}$, $J=8 \mathrm{~Hz}, 1 \mathrm{H}), 7.47(\mathrm{~s}, 1 \mathrm{H}), 7.25(\mathrm{~d}, J=8 \mathrm{~Hz}, 1 \mathrm{H}), 6.82(\mathrm{~m}, 4 \mathrm{H}), 4.30$ $(\mathrm{s}, 2 \mathrm{H}), 3.70 \mathrm{ppm}(\mathrm{s}, 3 \mathrm{H}) ; \mathrm{MS}(\mathrm{ESI}) \mathrm{m} / \mathrm{z}: 291[\mathrm{M}+\mathrm{H}]^{+}$.

$\mathbf{N}$-(5-(4-Methoxybenzylthio)-2-nitrophenyl)acetamide (78): To a solution of compound $77(50 \mathrm{mg}, 0.17 \mathrm{mmol})$ in $\mathrm{CH}_{2} \mathrm{Cl}_{2}, \mathrm{Et}_{3} \mathrm{~N}$ ( $45 \mu \mathrm{L}, 0.34 \mathrm{mmol})$ and $\mathrm{Ac}_{2} \mathrm{O}(24 \mu \mathrm{L}, 0.26 \mathrm{mmol})$ were added, and the mixture was stirred at room temperature for $1 \mathrm{~h}$. The reaction mixture was quenched with saturated aqueous $\mathrm{NaHCO}_{3}(10 \mathrm{~mL})$ and extracted with EtOAc $(3 \times 10 \mathrm{~mL})$. The combined extracts were washed with brine, dried over anhydrous $\mathrm{Na}_{2} \mathrm{SO}_{4}$ and the solvent removed in vacuo. The crude product was separated by chromatography on silica gel (Hex/EtOAc 4:1) to afford the desired product $(0.147 \mathrm{mmol}, 87 \%)$. ${ }^{1} \mathrm{H}$ NMR $\left(400 \mathrm{MHz}, \mathrm{CDCl}_{3}\right): \delta=8.47(\mathrm{~s}, 1 \mathrm{H})$, $8.22(\mathrm{~d}, J=8 \mathrm{~Hz}, 1 \mathrm{H}), 7.32(\mathrm{~d}, J=8 \mathrm{~Hz}, 1 \mathrm{H}), 6.82(\mathrm{~m}, 4 \mathrm{H}), 4.30(\mathrm{~s}$, $2 \mathrm{H}), 3.70(\mathrm{~s}, 3 \mathrm{H}), 2.07 \mathrm{ppm}(\mathrm{s}, 3 \mathrm{H}) ;{ }^{13} \mathrm{C}$ NMR $\left(100 \mathrm{MHz}, \mathrm{CDCl}_{3}\right): \delta=$ $160.2,143.1,138.8,133.7,129.4,127.5,120.1,114.3,55.4,23.7$ ppm; MS (ESI) $\mathrm{m} / \mathrm{z}: 333[\mathrm{M}+\mathrm{H}]^{+}$.

\section{Biology}

Virus strains: Infection experiments were carried out using influenza A/WSN/33 (H1N1). ${ }^{[35]}$

Plasmid constructs: Plasmids pCA-Flag-GFP and pCA-PB ${ }_{11-25} \mathrm{~A}-\mathrm{GFP}$, pCAPB1-HA, the FluA minireplicon plasmids and the expression plasmids for the FluB minireplicon are described elsewhere. ${ }^{[36]}$ The FluB minigenome expression plasmid, pPoll-lucRT_B, was obtained by cloning the firefly luciferase ORF (inverse orientation) flanked by the non-coding region of segment 8 of the B/Yamagata/73 into the Sapl-digested plasmid pPoll-SaplRib according to Pleschka et al. ${ }^{[28]}$ For the construction of pCA-PB ${ }_{11-25} \mathrm{~B}-\mathrm{GFP}$, a linker containing the first 25 codons of $\mathrm{PB} 1$ (B/Yamagata/73) was cloned into the EcoRI/Notl sites of pCA-Flag-GFP plasmid, replacing the Flagcoding sequence with $\mathrm{PB}_{11-25} \mathrm{~B}$. Site-directed mutagenesis was carried out with $\mathrm{PCA}-\mathrm{PB}_{11-25} \mathrm{~A}-\mathrm{GFP}$ to create the plasmid $\mathrm{PCAPB}_{11-}$ 
${ }_{25} \mathrm{~A}_{\text {T6 }}$ GFP. The ORFs of PB1 (B/Yamagata/73) and PA (A/SC35M, A/ Thailand/1(KAN-1)/04, A/Vietnam/1203/04, B/Yamagata/73, B/Lee/ 40) were $P C R$ amplified with sense primers containing a Notl site (FluA strains) or a EcoRI site (FluB strains) upstream of the initiation codon and antisense primers with a deleted stop codon followed by an Xmal site, a coding sequence for an HA tag and a Xhol site. The PCR products were cloned into a modified pCAGGs-vector digested either with EcoRI/Xhol or Notl/Xhol, resulting in PCA-PB1$\mathrm{HA}$ or PCA-PA-HA plasmids, coding for C-terminal-tagged versions of the polymerase subunits. To obtain the $\mathrm{PCA}-\mathrm{PA}_{A / S C 35 M}$-His plas-

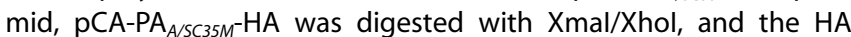
coding sequence was replaced by a $\mathrm{His}_{6}$ linker. The A/B-chimeric expression plasmids were obtained by assembly PCR using the pCA-PB1-HA plasmids of SC $35 \mathrm{M}$ and B/Yamagata/73 and by cloning the resulting $\mathrm{PCR}$ product in $\mathrm{PCA}-\mathrm{PB} 1_{B \text { /ramagata/73 }}-\mathrm{HA}$ digested with EcoRI/EcoRV.

Reconstitution of viral polymerase activity: HEK293T cells were transiently transfected with a plasmid mixture containing either FluAor FluB-derived PB1-, PB2-, PA- and NP-expression plasmids, polymerase I (Pol I)-driven plasmid transcribing an influenza $A$ or influenza $B$ virus-like RNA coding for the reporter protein firefly luciferase to monitor viral polymerase activity and with expression plasmids coding for the indicated GFP fusion proteins. Both minigenome RNAs were flanked by noncoding sequences of segment 8 of FluA and FluB, respectively. The transfection mixture also contained a plasmid constitutively expressing Renilla luciferase, which served to normalize variation in transfection efficiency. The reporter activity was determined $24 \mathrm{~h}$ post-transfection and normalized using the Dual-Glu Luciferase Assay System (Promega). The activity observed with transfection reactions containing Flag-GFP were set to $100 \%$

Immunoprecipitation experiments: HEK293T cells were transfected with the indicated plasmids in six-well plates using Metafectene (Biontex, Martinsried, Germany). Cells were incubated $24 \mathrm{~h}$ posttransfection with lysis buffer $(20 \mathrm{~mm}$ Tris $\mathrm{pH} 7.5,100 \mathrm{mM} \mathrm{NaCl}$, $0.5 \mathrm{~mm}$ EDTA, $0.5 \%$ NP-40, $1 \%$ protease inhibitor Mix G, (Serva, Heidelberg, Germany), $1 \mathrm{~mm}$ DTT) for $15 \mathrm{~min}$ on ice. After centrifugation at $13000 \mathrm{rpm}$ at $4^{\circ} \mathrm{C}$, the supernatant was incubated with anti-HA-specific antibodies coupled to agarose beads (Sigma) for $1 \mathrm{~h}$ at $4^{\circ} \mathrm{C}$. After three washes with $1 \mathrm{~mL}$ washing buffer (lysis buffer without protease inhibitor mix), bound material was eluted under denaturing conditions and separated by SDS-PAGE and transferred into PVDF membranes. Viral polymerase subunits and GFP fusion proteins were detected with antibodies directed against the HA tag (Covance, Berkeley, CA, USA) or His tag (Qiagen) or GFP tag (Santa Cruz Biotechnology).

Enzyme-linked immunosorbent assay (ELISA): Microwell plates (Pierce) were incubated at room temperature with saturating concentrations of small-molecule competitor compounds, washed, and subsequently incubated at room temperature with HA-tagged PA. To obtain PA-HA, HEK293T cells were seeded into 94-mm dishes, transfected with the respective plasmid, and treated with lysis buffer $24 \mathrm{~h}$ post-transfection as previously described. ${ }^{[36,37]}$ After washing the microwell plates, the wells were incubated with an HA-specific primary antibody (Covance), followed by three washes and an incubation with a peroxidase-coupled secondary antibody (Jackson Immuno Research, Newmarket, UK) for a further $30 \mathrm{~min}$. After the final wash step, ABTS substrate (Sigma, ready-to-use solution) was added, and the optical density was determined at $\lambda 405 \mathrm{~nm}$.

Plaque reduction assay: The experiments were carried out as previously described ${ }^{[37]}$ with modifications. Confluent MDCK cells were infected with $100 \mathrm{PFU}$ A/WSN/33, B/Yamagata/73, A/KAN-1, or VSV/ Indiana in PBS containing BSA at room temperature. After removal of the inoculums, cells were overlaid with medium (DMEM with $20 \mathrm{~mm}$ HEPES, $0.01 \%$ DEAE Dextran, $0.001 \% \mathrm{NaHCO}_{3}$ ) containing $1 \%$ Oxoidagar and the benzofurazan compounds at the indicated concentrations. After incubation for $24 \mathrm{~h}$ (VSV), $48 \mathrm{~h}$ (A/WSN/33, A/ $\mathrm{KAN}-1)$ at $37^{\circ} \mathrm{C}$ with $5 \% \mathrm{CO}_{2}$, or $72 \mathrm{~h}$ at $33^{\circ} \mathrm{C}$ with $5 \% \mathrm{CO}_{2}$ (B/Yamagata/73), cells were fixed with formaldehyde and stained with crystal violet. Plaques were counted, and mean plaque number of the water control was set at $100 \%$.

\section{Molecular modeling}

Library preparation: All ligands were built with the Schrödinger Maestro 9.1 graphical interface. ${ }^{[38]}$ Compounds were then processed with the Schrödinger LigPrep tool to generate separate files for all possible enantiomers and protonation states at physiological pH. OPLS_2005 was used as force field.

Protein preparation: The three-dimensional coordinates of $\mathrm{H} 5 \mathrm{~N} 1$ influenza $A$ virus PA (C-terminal region, $\mathrm{PAC}$ ) in complex with the $\mathrm{PA}$ binding region of $\mathrm{PB} 1$ (N-terminal region, $\mathrm{PB} 1 \mathrm{~N}$, residues $1-25$ ) were retrieved from the Protein Data Bank (PDB IDs $3 \mathrm{CM}^{[39]}$ and $2 \mathrm{ZNL}{ }^{[40]}$ with resolutions of 2.90 and $2.30 \AA$, respectively). Because both structures contain gaps, a more complete assembly for PAC was obtained by applying a homology modeling procedure (Prime, Schrödinger). In detail, the FASTA sequence of the protein (influenza A virus, strain A/Wilson-Smith/1933 H1N1) was uploaded into the software, and the model was built using PDB IDs 2ZNL as the first template and $3 \mathrm{CM} 8$ as the second. Indeed, the gaps in the 2ZNL structure were partially filled with the corresponding residues solved in the $3 \mathrm{CM} 8$ structure, while the missing residues in both $\mathrm{X}$ ray structures were completed by the program according to the FASTA sequence. The protein was then energy minimized to remove unfavorable contacts through the all-atom OPLS force field and Polak-Ribiere conjugate gradient method. A continuum solvation method, with water as the solvent, was also applied. Extended cutoffs were used, and convergence was set to $0.3 \mathrm{~kJ} \mathrm{~mol}^{-1}$.

Docking studies: A consensus docking approach that takes advantage of two widely used docking programs (Glide ${ }^{[41]}$ and

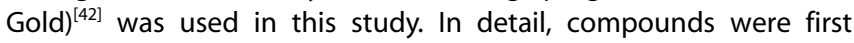
docked using the Glide standard precision (SP) mode. A grid box of default size was centered on PB1-derived peptide of the X-ray crystal structure. No constraints were included during grid generation, while rotation of hydroxy groups was allowed. Default parameters were used for the docking runs. The top-five poses based on the Glide docking score were saved for each ligand. With regard to the docking with Gold, GoldScore and ChemScore were used as fitness functions. The GA parameter settings of Gold were used, with search efficiency set at $200 \%$. Finally, results differing by $<1.5 \AA$ in ligand all-atom RMSD were clustered together. For each inhibitor, the first-ranked solution as well as the lowest-energy conformation of the most populated cluster were analyzed by comparing them with the best poses previously obtained with the Glide software. Poses were then selected by taking into account the overall match between the binding modes proposed by the two programs.

Ligand efficiency: Ligand efficiency (LE) was calculated by dividing the free energy of binding by the number of heavy (i.e., non-hydrogen) atoms. The activity value of each compound was converted into the free energy of binding at $300 \mathrm{~K}$ using the Gibbs equation $\left(\Delta G=-R T \ln K_{d}\right)$, in which $K_{d}$ is substituted by $I C_{50}$ for the purpose of relative comparison, as previously reported. ${ }^{[33]}$ 


\section{Acknowledgements}

We gratefully acknowledge financial support provided by the FP7 FLUCURE (Ref. 259972) project.

Keywords: antiviral agents $\cdot$ benzofurazans $\cdot$ H1N1 $\cdot$ influenza A - RNA polymerase

1] M. R. Hilleman, Vaccine 2002, 20, 3068-3087.

[2] Y. Suzuki, Biol. Pharm. Bull. 2005, 28, 399-408.

[3] K. Y. Yuen, S. S. Wong, Hong Kong Med. J. 2005, 11, 189- 199.

[4] P. Buchy, S. Mardy, S. Vong, T. Toyoda, J. T. Aubin, M. Miller, S. Touch, L. Sovann, J. B. Dufourcq, B. Richner, P. V. Tu, N. T. Tien, W. Lim, J. S. Peiris, S. Van der Werf, J. Clin. Virol. 2007, 39, 164-168.

[5] M. Michaelis, H. W. Doerr, J. Cinatl, Jr., Curr. Mol. Med. 2009, 9, 131-151.

[6] C. Fraser, C. A. Donnelly, S. Cauchemez, W. P. Hanage, M. D. Van Kerkhove, T. D. Hollingsworth, J. Griffin, R. F. Baggaley, H. E. Jenkins, E. J. Lyons, T. Jombart, W. R. Hinsley, N. C. Grassly, F. Balloux, A. C. Ghani, N. M. Ferguson, A. Rambaut, O. G. Pybus, H. Lopez-Gatell, C. M. Apluche-Aranda, I. B. Chapela, E. P. Zavala, D. M. E. Guevara, F. Checchi, E. Garcia, S. Hugonnet, C. Roth, Science 2009, 324, 1557-1561.

[7] F. Carrat, A. Flahault, Vaccine 2007, 25, 6852-6862.

[8] J. N. Treanor, N. Engl. J. Med. 2004, 350, 218-220.

[9] R. J. Webby, R. G. Webster, Science 2003, 302, 1519-1522.

[10] M. Von Itzstein, Nat. Rev. Drug Discovery 2007, 6, 967-974.

[11] P. M. Colman, J. Antimicrob. Chemother. 1999, 44, 17-22.

[12] P. Ward, I. Small, J. Smith, P. Suter, R. Dutkowski, J. Antimicrob. Chemother. 2005, 55, i5-i21.

[13] M. Von Itzstein, W. Y. Wu, G. B. Kok, M. S. Pegg, J. C. Dyason, B. Jin, T. Van Phan, M. L. Smythe, H. F. White, S. W. Oliver, P. M. Colman, J. N. Varghese, D. M. Ryan, J. M. Woods, R. C. Bethell, V. J. Hotham, J. M. Cameron, C. R. Penn, Nature 1993, 363, 418-423.

[14] A. J. Hay, A. J. Wolstenholme, J. J. Skehel, M. H. Smith, EMBO J. 1985, 4, $3021-3024$.

[15] R. G. Douglas, Jr., N. Engl. J. Med. 1990, 322, 443-450.

[16] S. M. Wintermeyer, M. C. Nahata, Ann. Pharmacother. 1995, 29, 299 310.

[17] P. J. Collins, L. F. Haire, Y. P. Lin, J. Liu, R. J. Russell, P. A. Walker, J. J. Skehel, S. R. Martin, A. J. Hay, S. J. Gamblin, Nature 2008, 453, 1258 1261.

[18] M. D. de Jong, T. T. Tran, H. K. Truong, M. H. Vo, G. J. Smith, V. C Nguyen, V. C. Bach, T. Q. Phan, Q. H. Do, Y. Guan, J. S. Peiris, T. H. Tran, J. Farrar, N. Engl. J. Med. 2005, 353, 2667-2672.

[19] A. Moscona, N. Engl. J. Med. 2009, 360, 953-956.

[20] R. Salomon, J. Franks, E. A. Govorkova, N. A. Ilyushina, H. L. Yen, D. J. Hulse-Post, J. Humberd, M. Trichet, J. E. Rehg, R. J. Webby, R. G. Webster E. H. Mann, J. Exp. Med. 2006, 203, 689-697.

[21] J. V. Tuttle, M. Tisdale, T. A. Krenitsky, J. Med. Chem. 1993, 36, 119-125.
[22] M. Tisdale, M. Ellis, K. Klumpp, S. Court, M. Ford, Antimicrob. Agents Chemother. 1995, 39, 2454-2458.

[23] Y. Furuta, K. Takahashi, Y. Fukuda, M. Kuno, T. Kamiyama, K. Kozaki, N. Nomura, H. Egawa, S. Minami, Y. Watanabe, H. Narita, K. Shiraki, Antimicrob. Agents Chemother. 2002, 46, 977-981.

[24] K. Takahashi, Y. Furuta, Y. Fukuda, M. Kuno, T. Kamiyama, K. Kozaki, N. Nomura, H. Egawa, S. Minami, K. Shiraki, Antiviral Chem. Chemother. 2003, 14, 235-241.

[25] Y. Furuta, K. Takahashi, M. Kuno-Maekawa, H. Sangawa, S. Uehara, K. Kozaki, N. Nomura, H. Egawa, K. Shiraki, Antimicrob. Agents Chemother. 2005, 49, $981-986$

[26] J. E. Tomassini, M. E. Davies, J. C. Hastings, R. Lingham, M. Mojena, S. L. Raghoobar, S. B. Singh, J. S. Tkacz, M. A. Goetz, Antimicrob. Agents Che mother. 1996, 40, 1189-1193.

[27] U. Kessler, D. Castagnolo, M. Pagano, D. Deodato, M. Bernardini, B. Pilger, C. Ranadheera, M. Botta, Bioorg. Med. Chem. Lett. 2013, 23 , 5575- 5577.

[28] S. Pleschka, R. Jaskunas, O. G. Engelhardt, T. Zurcher, P. Palese, A. GarciaSastre, J. Virol. 1996, 70, 4188-4192.

[29] D. Castagnolo, M. Pagano, M. Bernardini, M. Botta, Tetrahedron Lett 2012, 53, 5008-5011.

[30] D. Castagnolo, M. Radi, F. Dessì, F. Manetti, M. Saddi, R. Meleddu, A. De Logu, M. Botta, Bioorg. Med. Chem. Lett. 2009, 19, 2203-2205.

[31] G. Muratore, L. Goracci, B. Mercorelli, Á. Foeglein, P. Digard, G. Cruciani, G. Palù, A. Loregian, Proc. Natl. Acad. Sci. USA 2012, 109, 6247-6252.

[32] G. Muratore, B. Mercorelli, L. Goracci, G. Cruciani, P. Digard, G. Palù, A. Loregian, Antimicrob. Agents Chemother. 2012, 56, 6009-6013.

[33] A. L. Hopkins, C. R. Groom, A. Alex, Drug Discovery Today 2004, 9, 430 431.

[34] J. A. Wells, C. L. McClendon, Nature 2007, 450, 1001-1009.

[35] M. Schmidtke, U. Schnittler, B. Jahn, H. Dahse, A. Stelzner, J. Virol. Methods 2001, 95, 133-143.

[36] A. Ghanem, D. Mayer, G. Chase, W. Tegge, R. Frank, G. Kochs, A. GarcíaSastre, M. Schwemmle, J. Virol. 2007, 81, 7801-7804.

[37] K. Wunderlich, D. Mayer, C. Ranadheera, A. S. Holler, B. Mänz, A. Martin, G. Chase, W. Tegge, R. Frank, U. Kessler, M. Schwemmle, PLoS One 2009 4, e7517.

[38] Maestro version 9.2, Schrödinger LLC, New York, NY (USA), 2011.

[39] X. He, J. Zhou, M. Bartlam, R. Zhang, J. Ma, Z. Lou, X. Li, J. Li, A. Joachimiak, Z. Zeng, R. Ge, Z. Rao, Y. Liu, Nature 2008, 454, 1123-1126.

[40] E. Obayashi, H. Yoshida, F. Kawai, N. Shibayama, A. Kawaguchi, K. Nagata, J. R. Tame, S. Y. Park, Nature 2008, 454, 1127-1131.

[41] Glide version 5.5, Schrödinger Inc., New York, NY, 2009.

[42] M. L. Verdonk, J. C. Cole, M. J. Hartshorn, C. W. Murray, R. D. Taylor, Proteins 2003, 52, 609-623.

Received: September 19, 2013

Revised: November 6, 2013

Published online on November 27, 2013 